PRECIPITATION REGIME CHANGES IN THE MARITIME CONTINENT 



\title{
PRECIPITATION REGIME CHANGES IN THE MARITIME CONTINENT
}

\author{
DISSERTATION
}

\section{to obtain}

the degree of doctor at the University of Twente, on the authority of the rector magnificus, Prof. dr. ir. A. Veldkamp on account of the decision of the Doctorate Board, to be publicly defended

on Wednesday 2 February 2022 at 12.45 hrs

by

Vasily Alekseevitsj Kokorev

born on 31st of July 1989.

in St. Petersburg, Russia 
This thesis has been approved by

Prof. dr. G. van der Steenhoven, supervisor

Dr. ir. J. Ettema, co-supervisor

Dr. P. Siegmund, co-supervisor

ITC dissertation number 411

ITC, P.O. Box 217, 7500 AE Enschede, The Netherlands

ISBN 978-90-365-5329-2

DOI $10.3990 / 1.97890365$

Cover designed by Vasily Kokorev and Job Duim

Printed by CTRL-P Hengelo

Copyright (C) 2021 by

\section{UNIVERSITY OF TWENTE.}

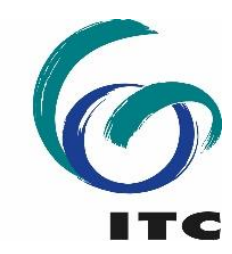


Graduation committee:

\section{Chairman/Secretary}

Prof. Dr. F.D. van der Meer

\section{Supervisor(s)}

Prof. dr. G. van der Steenhoven

\section{Co-supervisor(s)}

Dr. ir. J. Ettema

Dr. P. Siegmund

\section{Members}

Prof. dr. V.G. Jetten

Prof. Dr. M.K. van Aalst

Prof. Dr. D. Coumou

Prof. Dr. A.M.G. Klein Tank

Dr. G. van der Schrier 



\section{Acknowledgments}

This work would not be possible without the guidance and supervision of Dr. Ir. Janneke Ettema and Dr. Peter Siegmund who provided guidance and were supportive in a bad times as much as a good onces, for which I am grateful.

The immense gratitude goes to my parents Lidia Kokoreva and Alexey Kokorev, who encouraged me to get an education despite all the troubles I had on the way.

My scientific career would never even start without help and mentoring from prof. Oleg Anisimov. For his role in my life, I am forever grateful. During the work on this thesis, I got inspiration and ideas from several of my friend and colleagues - Arsenii Mustafin, Dr. Gerard van der Schrier, Dr. Haakon Bakka, Dr. Erik van Sebille, Alexei Andreev I am grateful to Prof. Nikolay Shiklomanov, prof. Terry Prowse, Dr. Arne Instanes provide advice, compassion, and a role model when it was most needed.

My friend helped to keep me at least half sane over the years - Dr. Pavel Lajus, Anastasia Vasenina, Marina Lajus, Mitya Lajus, Arina Miksuk, Michael Andreev. This work would not be finalized without encouragement, love, and support from Imke van Barneveld. 


\section{Table of Contents}

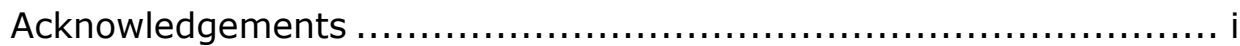

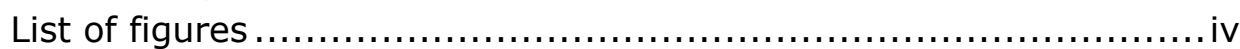

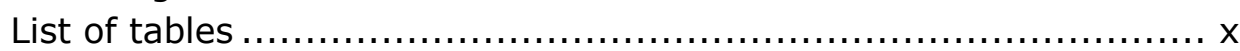

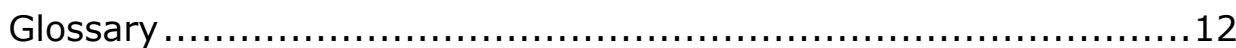

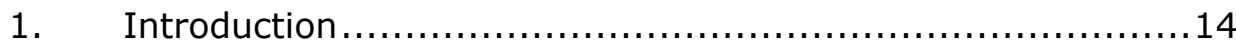

1.1. Geography of the Maritime continent ........................ 14

1.2. Role of precipitation in the Maritime Continent ...............15

1.3. Climate change in the Maritime Continent ...................16

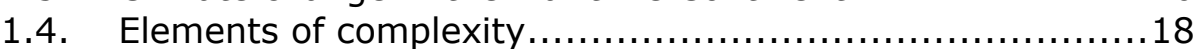

1.4.1. Influence of global circulations........................... 18

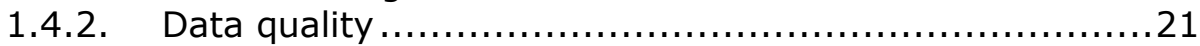

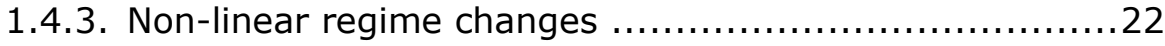

1.5. Research questions ........................................ 23

2. Analysis of PDO-ENSO modulation effect on precipitation anomalies in the Maritime Continent................................... 25

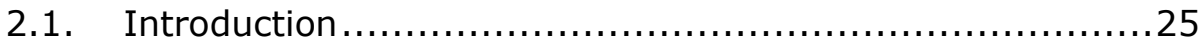

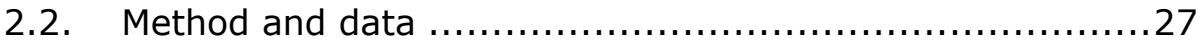

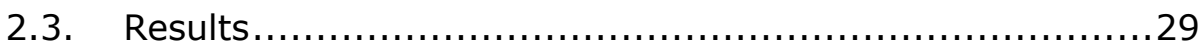

2.3.1. Long-Period Data......................................... 29

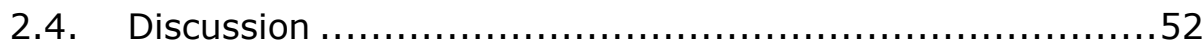

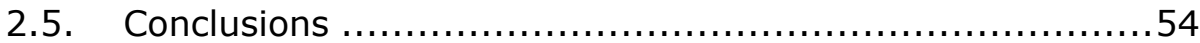

3. PDO Associated Precipitation Regime Shift in the Maritime

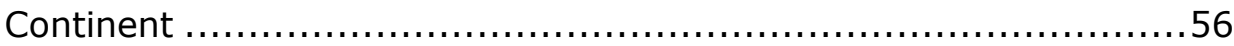

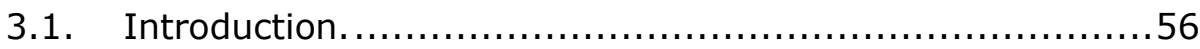

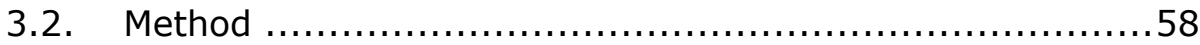

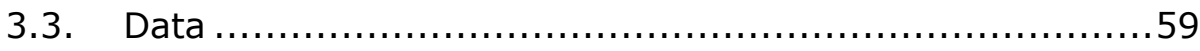

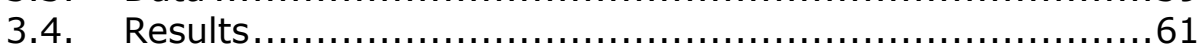

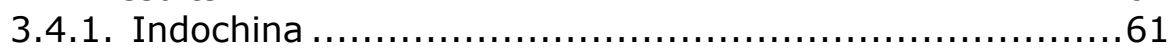

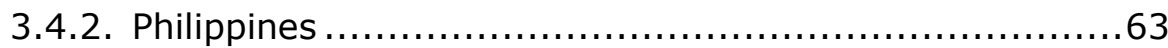

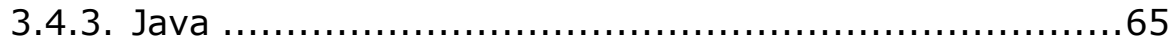

3.4.4. North Australia ...........................................66

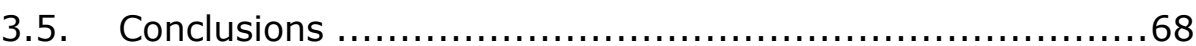

4. Precipitation regime shifts in CMIP6 model experiments .......69

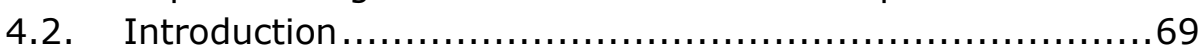

4.3. Data and Methods......................................... 70

4.4. Mean Precipitation and SST in CMIP6 models .................... 72 
4.5. Precipitation Regime Shift in CMIP6 models ..................80

4.6. Conclusions ................................................ 83

5. Machine Learning prediction of the Madden-Julian Oscillation

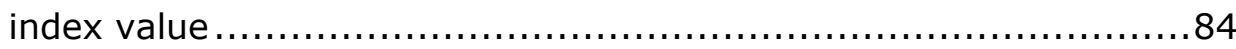

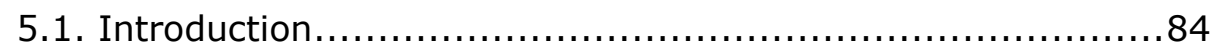

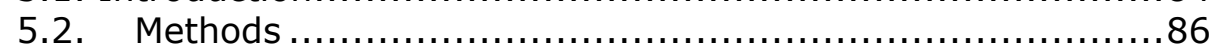

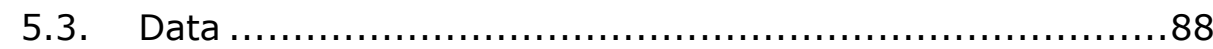

5.4. Convolution Neural Network ............................... 89

5.5. Temporal Convolution Network ........................... 90

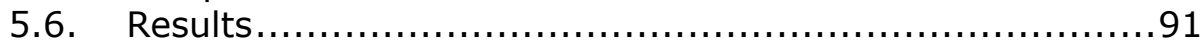

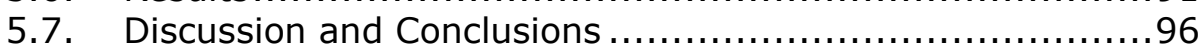

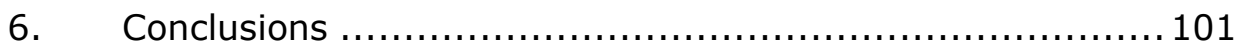

6.1. Physical evidence ............................................ 101

6.2. Statistical evidence ....................................... 102

6.3. GCMs-based evidence ................................... 103

6.4. Machine learning for predicting precipitation regime shift. 103

6.5. Future work ............................................... 104

6.5.1. Bayesian regime shift detections performance............ 104

6.5.2. Studying the economic impact of historical precipitation regime shifts .......................................................... 105

6.6. Societal context............................................. 106

6.6.1. Perceived rate of climate change......................... 106

6.6.2. The impact of fast changes ............................. 107

Bibliography: ....................................................... 109

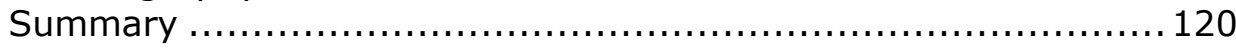

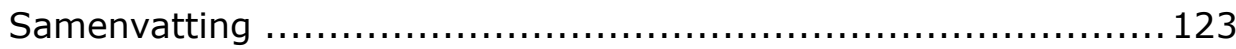




\section{List of figures}

Figure 1.1. Mean monthly anomalies in the $M C$ in air temperature, ${ }^{\circ} \mathrm{C}$ (left) and precipitation, $\mathrm{mm}$ (right) relative to the 1901-2000 norm. Based on CRU TS v 4.04

Figure 1.2. Diagram showing the main processes affecting precipitation in the MC. 1,2- (Yamanaka, 2016), 3 - (Wang et al., 2008, Kim et al., 2013), 4- (Ruppert and Johnson, 2016), 5-(Kokorev et al., 2020a, Wang et al., 2014b), (Hu and Huang, 2009), 6(Hendon, 2003, Supari et al., 2018), 7 - (Yamanaka, 2016), 8-(Tang and Yu, 2008, Hendon et al., 2007), 9- (Jones et al., 2004)-, 10 (Roxy et al., 2019, Tian et al., 2006), 11-(Nur'utami and Hidayat, 2016)

Figure 1.3. Global annual mean temperature anomaly (black line), and PDO, ten years rolling mean (red and blue). Data from HadCRUT4I and HadSST3.

Figure 2.1. The number of months with a specific ENSO/PDO phase combination per month....

Figure 2.2. Difference between in-phase positive ENSO and typical ENSO events during JJA. Data from long-period dataset 1901-2018. Maps show seasonal precipitation anomalies expressed as a percentage of the seasonal mean (shown over land) and seasonal SST anomalies in ${ }^{\circ} \mathrm{C}$ (shown over the sea for ENSO positive months (Nino $3.4>0.75)$ for (a) - JJA, positive PDO (PDO >1); (b) - JJA,

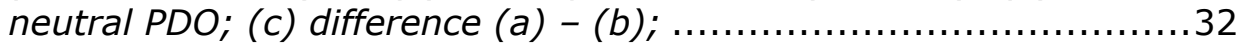

Figure 2.3. Difference between in-phase positive ENSO and typical ENSO events during SON. Data from long-period dataset 1901-2018. Maps show seasonal precipitation anomalies expressed as percentage of seasonal mean (shown over land) and seasonal SST anomalies in ${ }^{\circ} \mathrm{C}$ (shown over sea) for ENSO positive months (Nino $3.4>0.75$ ) for (a) - SON, positive PDO (PDO >1); (b) - SON, neutral PDO; (c) difference (a) - (b); .

Figure 2.4. Difference between in-phase positive ENSO and typical ENSO events during DJF. Data from long-period dataset 1901-2018. Maps show seasonal precipitation anomalies expressed as a percentage of the seasonal mean (shown over land) and seasonal SST anomalies in ${ }^{\circ} \mathrm{C}$ (shown over the sea for ENSO positive months (Nino $3.4>0.75$ ) for (a) - DJF, positive PDO (PDO >1); (b) - DJF,

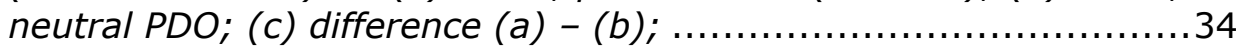

Figure 2.5. Difference between in-phase positive ENSO and typical ENSO events during MAM. Data from long-period dataset 1901-2018. Maps show seasonal precipitation anomalies expressed as a percentage of the seasonal mean (shown over land) and seasonal SST anomalies in ${ }^{\circ} \mathrm{C}$ (shown over the sea for ENSO positive months 
(Nino $3.4>0.75)$ for (a) - MAM, positive PDO (PDO >1); (b) - MAM,

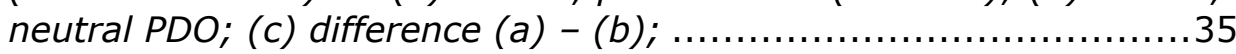
Figure 2.6. Difference between in-phase negative ENSO and typical ENSO events during JJA. Data from long-period dataset 1901-2018. Maps show seasonal precipitation anomalies expressed as a percentage of the seasonal mean (shown over land) and seasonal SST anomalies in ${ }^{\circ} \mathrm{C}$ (shown over the sea) calculated from the longperiod datasets for ENSO negative months (Nino $3.4<-0.75$ ) for (a) - JJA, negative PDO (PDO >1); (b) - JJA, neutral PDO; (c) difference (a) - (b);

Figure 2.7. Difference between in-phase negative ENSO and typical ENSO events during SON. Data from long-period dataset 1901-2018. Maps show seasonal precipitation anomalies expressed as a percentage of the seasonal mean (shown over land) and seasonal SST anomalies in ${ }^{\circ} \mathrm{C}$ (shown over the sea) calculated from the longperiod datasets for ENSO negative months (Nino $3.4<-0.75$ ) for (a) - SON, negative PDO (PDO >1); (b) - SON, neutral PDO; (c) difference (a) - (b);

Figure 2.8. Difference between in-phase negative ENSO and typical ENSO events during DJF. Data from long-period dataset 1901-2018. Maps show seasonal precipitation anomalies expressed as a percentage of the seasonal mean (shown over land) and seasonal SST anomalies in ${ }^{\circ} \mathrm{C}$ (shown over the sea) calculated from the longperiod datasets for ENSO negative months (Nino $3.4<-0.75$ ) for (a) - DJF, negative PDO (PDO >1); (b) - DJF, neutral PDO; (c) difference (a) - (b);

Figure 2.9. Difference between in-phase negative ENSO and typical ENSO events during MAM. Data from long-period dataset 1901-2018. Maps show seasonal precipitation anomalies expressed as a percentage of the seasonal mean (shown over land) and seasonal SST anomalies in ${ }^{\circ} \mathrm{C}$ (shown over the sea) calculated from the longperiod datasets for ENSO negative months (Nino $3.4<-0.75$ ) for (a) - MAM, negative PDO (PDO >1); (b) - MAM, neutral PDO; (c)

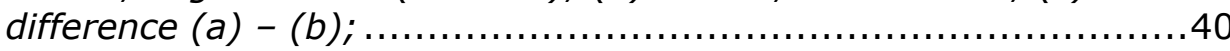
Figure 2.10. A number of days with a specific ENSO/PDO phase combination per month.

Figure 2.11. Difference between in-phase positive ENSO and typical ENSO events during JJA. Data from high-resolution dataset 19812017. Maps show seasonal precipitation anomalies expressed as a percentage of the seasonal mean (shown over land) and seasonal SST anomalies in ${ }^{\circ} \mathrm{C}$ (shown over the sea) calculated from the longterm datasets for ENSO positive months (Nino $3.4>0.75$ ) for (a) $J J A$, positive PDO (PDO >1); (b) - JJA, neutral PDO; (c) difference (a) - (b); 
Figure 2.12. Difference between in-phase positive ENSO and typical ENSO events during SON. Data from high-resolution dataset 19812017. Maps show seasonal precipitation anomalies expressed as a percentage of the seasonal mean (shown over land) and seasonal SST anomalies in ${ }^{\circ} \mathrm{C}$ (shown over the sea) calculated from the longperiod datasets for ENSO positive months (Nino $3.4>0.75$ ) for (a) SON, positive PDO (PDO >1); (b) - SON, neutral PDO; (c) difference (a) - (b); 45 Figure 2.13. Difference between in-phase positive ENSO and typical ENSO events during DJF. Data from high-resolution dataset 19812017. Maps show seasonal precipitation anomalies expressed as a percentage of the seasonal mean (shown over land) and seasonal SST anomalies in ${ }^{\circ} \mathrm{C}$ (shown over the sea) calculated from the longperiod datasets for ENSO positive months (Nino $3.4>0.75$ ) for (a) $D J F$, positive $P D O(P D O>1)$; (b) $-D J F$, neutral PDO; (c) difference (a) - (b);

Figure 2.14. Difference between in-phase positive ENSO and typical ENSO events during MAM. Data from high-resolution dataset 19812017. Maps show seasonal precipitation anomalies expressed as a percentage of the seasonal mean (shown over land) and seasonal SST anomalies in ${ }^{\circ} \mathrm{C}$ (shown over the sea) calculated from the longperiod datasets for ENSO positive months (Nino $3.4>0.75)$ for (a) MAM, positive PDO (PDO >1); (b) - MAM, neutral PDO; (c) difference (a) - (b);

Figure 2.15. Difference between in-phase negative ENSO and typical ENSO events during JJA. Data from high-resolution dataset 19812017. Maps show seasonal precipitation anomalies expressed as a percentage of the seasonal mean (shown over land) and seasonal SST anomalies in ${ }^{\circ} \mathrm{C}$ (shown over the sea) calculated from the longperiod datasets for ENSO negative months (Nino $3.4<-0.75$ ) for (a) - JJA, negative PDO (PDO >1); (b) - JJA, neutral PDO; (c) difference (a) $-(b)$;

Figure 2.16. Difference between in-phase negative ENSO and typical ENSO events during SON. Data from high-resolution dataset 19812017. Maps show seasonal precipitation anomalies expressed as a percentage of the seasonal mean (shown over land) and seasonal SST anomalies in ${ }^{\circ} \mathrm{C}$ (shown over the sea) calculated from the longperiod datasets for ENSO negative months (Nino $3.4<-0.75$ ) for (a) - SON, negative PDO (PDO >1); (b) - SON, neutral PDO; (c) difference $(a)-(b)$; .

Figure 2.17. Difference between in-phase negative ENSO and typical ENSO events during DJF. Data from high-resolution dataset 19812017. Maps show seasonal precipitation anomalies expressed as a percentage of the seasonal mean (shown over land) and seasonal SST anomalies in ${ }^{\circ} \mathrm{C}$ (shown over the sea) calculated from the long- 
period datasets for ENSO negative months (Nino $3.4<-0.75$ ) for (a) - DJF, negative PDO (PDO >1); (b) - DJF, neutral PDO; (c) difference (a) - (b);

Figure 2.18. Difference between in-phase negative ENSO and typical ENSO events during MAM. Data from high-resolution dataset 19812017. Maps show seasonal precipitation anomalies expressed as a percentage of the seasonal mean (shown over land) and seasonal SST anomalies in ${ }^{\circ} \mathrm{C}$ (shown over the sea) calculated from the longperiod datasets for ENSO negative months (Nino $3.4<-0.75$ ) for (a) - MAM, negative PDO (PDO >1); (b) - MAM, neutral PDO; (c) difference (a) - (b);

Figure 2.19. (a) - number of months classified as in-phase positive (Nino $3.4>0.75$ and PDO > 1) in red, in-phase negative (E Nino 3.4 $<-0.75$ and $P D O<-1$ ) in blue, counterphase ((Nino $3.4>0.75$ and $P D O<-1$ ) or (Nino $3.4<-0.75$ and PDO > 1)) in grey; $(b)-P D O$ historical monthly data in blue, ENSO historical data in red, bold lines represent 5 years running mean

Figure 3.1. Map showing the duration of available time series at the closest weather station for stations $<50 \mathrm{~km}$ away. Stations with less than 30 years of data are not shown on the map. The inset histogram shows the distribution of stations by number of years with observations. The four areas with sufficient data density and duration are shown with dark grey boxes. 1 - Indochina, 2 - Philippines, 3 Java, 4 - North Australia Figure 3.2. Precipitation regime shift in Indochina. A - Date (absolute anomaly from regional mean) of regime shift versus standard deviation per station $B$ - Changes in probability of no rainfall $(\Delta \pi)$ and probability of rainfall with intensity of $<20 \mathrm{~mm}$ per day $(\Delta p(0-20])$. Black dots represent individual stations and boxes shows 25, 50, $75 q u a n t i l e s$. Background colours indicate stations that have the regime shift date anomaly within one standard deviation from the regional mean (white), one to two standard deviations (light grey), two to three (grey), and greater than three (dark grey) ...............62 Figure 3.3. Precipitation regime shift in Philippines. A - Date of regime shift versus standard deviation per station. $B$ - Changes in probability of no rainfall $(\Delta \Pi)$ and probability of rainfall with intensity of $<20$ $\mathrm{mm}$ per day ( $\Delta p(0-20])$. Black dots represent individual station and a box shows quantiles 25, 50, 75. Background colours indicate stations that have the regime shift date anomaly within one standard deviation from the regional mean (white), one to two standard deviations (light grey), two to three (grey), and greater than three (dark grey)

Figure 3.4. Precipitation regime shift in Java. A - Date of regime shift versus standard deviation per station. $B$ - Changes in probability of no rainfall $(\Delta \Pi)$ and probability of rainfall with intensity of $<20 \mathrm{~mm}$ 
per day ( $\Delta p(0-20])$. Black dots represent individual station and a box shows quantiles 25, 50, 75. Background colours indicate stations that have the regime shift date anomaly within one standard deviation from the regional mean (white), one to two standard deviations (light grey), two to three (grey), and greater than three (dark grey) .......66 Figure 3.5. Precipitation regime shift in Australia. A - Date of regime shift versus standard deviation per station. $B$ - Changes in probability of no rainfall $(\Delta \Pi)$ and probability of rainfall with intensity of $<20$ $\mathrm{mm}$ per day $(\Delta p(0-20])$. Black dots represent individual station and a box shows quantiles 25, 50, 75. Background colours indicate stations that have the regime shift date anomaly within one standard deviation from the regional mean (white), one to two standard deviations (light grey), two to three (grey), and greater than three (dark grey) Figure 4.1. Precipitation anomalies in the IPWP (20S-20N, 90-160E). Observed (coral), 5-year running mean of observed data (red), CMIP6 models data from historical and future experiments (grey), and 5-year running mean for model data (black).

Figure 4.2 Monthly mean sea surface temperature anomalies in the IPWP (-20-20N, 90-160E). Observed (coral), 5-year running mean of observed data (red), CMIP6 models data from historical and ssp585 experiments (grey), and 5-year running mean for model data (black).

Figure 4.3. Mean annual precipitation on land and SST in the IPWP region, 1901-2000. CMIP6 model minus observations, the difference expressed as a percentage of the observed value. ......................76 Figure 4.4 Taylor diagram showing CMIP6 models skill in reproducing historical changes in Nino34, IPWP SST, IPWP precipitation. ..........78 Figure 4.5. Monthly precipitation anomalies averaged in the Maritime Continent for individual models according to ssp585 scenario (red), five years running mean of those anomalies (blue), and most probable positions of precipitation regime shifts (black vertical lines).

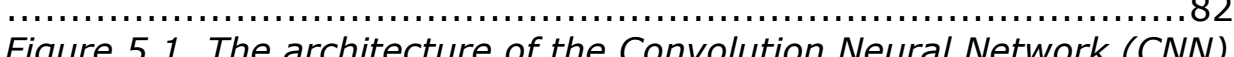
Model.................................................................. 90 Figure 5.2. The architecture of the Temporal Convolution Model (TCN)

Figure 5.3. Bivariate correlation of predicted and observed RMM index value depending on a lead time for versions of the CNN model.......92 Figure 5.4. Bivariate correlation of predicted and observed RMM index value depending on a lead time for versions of the TCN model .......93 Figure 5.5. CNN model predictions - observed (Blue) and seven days lead time prediction (red) for RMM1 (left) and RMM2 (right) for regular input (top row) and 7-day smoothed data (bottom row). ....95 
Figure 5.6. TCN model predictions - observed (Blue) and seven days lead time prediction (red) for RMM1 (left) and RMM2 (right) for 7-day smoothed indexes data (top row) and 7-day smoothed principal components (bottom row)........................................... 95

Figure 5.7. Individual models (light grey), selected ensemble members (grey) and ensemble mean (black). RMM bivariate correlation decline with increasing lead time for an ensemble of TCN models. 96 Figure 6.1. Annual Rice Yield per Hectare in Indonesia 1961-2013. data from [http://ricepedia.org/indonesia] ... 106 Figure 1. Schematic illustration of the difference between gradual (linear) change and regime shift 


\section{List of tables}

The differences in precipitation and SST anomalies between in-phase ENSO and typical ENSO events, accompanied by neutral PDO, are shown in the figures below. Figures $2.2-2.5$ demonstrate the influence of positive and neutral PDO on the seasonal precipitation (shown over land) and SST anomalies (shown over the sea) during the positive ENSO phase for the four seasons (Figure $2.2-\mathrm{JJA}$; Figure 2.3 - SON; Figure 2.4 - DJF; Figure 2.5 - MAM). Results presented in the figures are also summarized in Table 2.1, which shows average differences between in-phase and typical ENSO events and the statistical significance of this difference per country. In Figures 2.2-2.5b, we see the typical ENSO positive pattern for all seasons with cold SST anomalies East of Papua causing significant dry anomalies over most of the Maritime Continent. However, when positive ENSO coincides with positive PDO, a noticeably different pattern forms (Figures 2.2-2.5a). SST anomalies are weakened or reversed in sign. Overall, SST anomalies during in-phase positive events are between +0.25 and 0.75 degrees warmer compared to PDO neutral ENSO+ events (Figures 2.2-2.5c). This is especially noticeable when examining the differences between the $\mathrm{PDO}+/$ ENSO+ and PDO neutral/ENSO+ phase combinations (Figures 2.2-2.5c). Warmer SSTs generally lead to more precipitation, although on a regional scale, there are exceptions. During in-phase positive ENSO events, the dry anomalies in the Maritime Continent are weakened in SON by $5.6 \%$ more precipitation than positive ENSO with the neutral PDO. During DJF, the differences between in-phase positive and typical ENSO events are not statistically significant except for the Philippines, where $12.2 \%$ more precipitation is observed, and the dry anomaly is weakened (Figure 2.4; Table 2.1). During MAM, the whole northern hemispheric part of the Maritime Continent experiences a more robust dry anomaly $(5.7 \%$ less precipitation). The effect is especially pronounced in the Philippines (16.1\% less precipitation) (Figure 2.5; Table 2.1) .....................30 Table 2.1. Precipitation anomalies during ENSO-PDO in-phase events as a percentage of the seasonal mean. In brackets - the difference from typical ENSO events. * - the difference is not significant on $1 \%$ level according to the $t$-test............................................ 41 Table 4.1. Mean precipitation anomalies ( $\mathrm{mm} / \mathrm{month})$ in the IPWP during positive and negative phases for PDO and Nino34, differences between phases (diff), Kolmogorov-Smirnov statistic (KS) testing the statistical significance of differences between phases, a ratio of number of positive events to the number of negatives $(P / N)$ .80 
Table 5.1. Meta information about the data used in this study. For variable short name used through the text, long name, dataset name, spatial resolution, and citation provided. ................................ 99 Table 5.2. List of model variations for CNN and TCN methods, with input and output listed ................................................ 100 


\section{Glossary}

CMIP -Coupled Model Intercomparison Project

CNN - Convolutional Neural Network

CRU TS - High-resolution gridded datasets by Climate Research Unit

DJF - Season consisting of December, January, February

ENSO - El-Niño Southern Oscillation, periodic irregular anomaly of winds and SST in the tropical Pacific Ocean

EOF - Empirical orthogonal function (See PC)

GCM - Global Climate model

IOD - Indian Ocean Dipole, irregular periodic variation of SST in the Indian Ocean similar to ENSO

IPO - Interdecadal Pacific Oscillation, similar to the PDO process that occurs in a large territory.

IPWP - Indo-Pacific Warm Pool, a zone between Pacific and Indian

Oceans characterized by constant warm SST above $28^{\circ} \mathrm{C}$

ITCZ - Intertropical Convergence Zone

ITF - The Indonesian throughflow, an ocean current, transfers warm water from the Pacific to the Indian ocean, the upper branch of the global heat conveyor belt.

JJA - Season consisting of June, July, August

MAM - Season consisting of March, April, May

MC - Maritime Continent. A part of South-East Asia is located

between the Indian and Pacific Oceans and consists of Papua New

Guinea, Indonesia, Philippine archipelagos, and neighboring island countries.

MCMC - Markov Chain Monte-Carlo, numerical approximation technique used among other applications to sample the posterior of Bayesian models.

MJO - Madden-Julian Oscillation, large scale atmospheric circulation in the tropics

ML - Machine learning, a scientific discipline between computational statistics and artificial intelligence that focuses on predictive algorithms that learn from the existing data

Nino3.4 - Index quantifying the ENSO by calculating SST anomaly in the Nino3.4 region (5N-5S, $170 \mathrm{~W}-120 \mathrm{~W}$ ).

PC - Principal Component, eigenvector oriented to preserve the most variance in the data, often used and a dimension reduction technique. PDO - Pacific Decadal Oscillation, long cycle of SST anomaly in the North Pacific; PDO index - the first principal component of SST field in the northern Pacific

SON - Season consisting of September, October, November

SST - Sea Surface Temperature

TCN - Temporal Convolution Network 
TPI - IPO Tripole Index, index similar to PDO and IPO but not based on PC of SST field. TPI is based on the filtered difference in SST between tropical and two mid-latitude regions.

WMO - World Meteorological Organization 


\section{Introduction}

\subsection{Geography of the Maritime continent}

This thesis's primary focus region is South-East Asia, focusing on the Maritime Continent (MC). The MC is a part of South-East Asia located between the Indian and Pacific Oceans and consists of Papua New Guinea, Indonesia, Philippines archipelagos, and neighboring island countries. The Maritime Continent is characterized by unique geography; it is a vast region in the equatorial zone consisting of thousands of islands located within the area with the hottest ocean temperatures called the Indo-Pacific Warm Pool (IPWP).

The most substantial part of the MC is Indonesia - a vast equatorial archipelago located between the Indian and Pacific Oceans; it consists of over 17000 islands with a total area of about $1.91 \mathrm{Mkm}^{2}(1.3 \%$ of land surface worldwide). The largest islands are Java, Sumatra, Kalimantan, Sulawesi, and the Indonesian part of New Guinea. Most small islands belong to larger island groups like the Lesser Sunda Islands and the Maluku Islands.

Philippines archipelago is another significant part of the Maritime continent consisting of over 7500 islands. Luzon and Mindanao are the two largest islands in the Philippines, and the Visayan Islands, are often separated as the third major region.

Most of the MC is located in the Indo-Pacific Warm Pool, the largest warm water pool in the world ocean. The sea surface temperatures in the region are above $28^{\circ} \mathrm{C}$ year-round. IPWP is the most significant heat source in the climate system. The MC connects the Pacific and Indian oceans through the Indonesian throughflow (ITF) that transfers approximately 10-15 Sv of warm water from the Pacific to the Indian ocean (Tillinger and Gordon, 2010). The ITF transport variability is influenced by Kelvin waves intrusions, ENSO, and monsoons (Susanto et al., 2012).

The Maritime Continent is located in an area of high volcanic activity. There are more volcanoes in Indonesia than in any other country; 76 volcanoes are historically active; the Philippines takes the second spot with 54 active volcanoes. Most islands have a volcanic or coral genesis. Due to volcanic origins, Islands are mountainous with dense rain forests.

According to the Köppen classification, most Maritime Continent has an equatorial climate (Af) with average annual rainfall ranging from 600 to $6000 \mathrm{~mm}$ and around $2800 \mathrm{~mm}$. Some regions are classified as having a Monsoon climate (Am) or tropical savanna (Aw) climate. Precipitation is distributed unevenly from month to month, with $80 \%$ of rain precipitating during the wet season. 


\subsection{Role of precipitation in the Maritime Continent}

Agriculture is a crucial economic sector in both Indonesia and the Philippines. In 2019, it amounted to $12.7 \%$ and $8.8 \%$ of GPD of respective countries (World Bank, 2019). The agriculture sector employs $42 \%$ of the Indonesian and $30 \%$ of the Philippine workforce (World Bank, 2019). Agriculture is strongly dependent on the availability of water resources and sensitive to precipitation changes. Despite the tropical climate and a large amount of annual rainfall, Indonesia has suffered from drought in recent years. Interannual variability of precipitation is high due to a strong influence from the El Niño cycle, with $\sim 90 \%$ of drought occurring in the El Niño years (Estimated for 1830-1953 (Quinn et al., 1978, Ortlieb, 2000)). Between 1973 and 1992, during the El Niño years, annual precipitation was $67 \%$ of the climatic average (Amien et al., 1996). Some regions can have lower than average precipitation even during the La Niña, for example, central Sumatera and the west-most part of Kalimantan (RelifWeb, 2016). The strong El Niño in 2015 caused an extensive drought in Indonesia. According to a report by the World Food Program (WFP), Indonesia (WFP Indonesia, 2016), 1.2 million Indonesians were affected by drought and required assistance. In December 2015, WFP surveyed 2400 households and found out that $60 \%$ of households lost income due to drought, and $20 \%$ of households cut spending on food due to drought. In Kupang and Timor Tengah Selatan districts, $48 \%$ and $40 \%$ of households reported a severe adverse impact on income (WFP Indonesia, 2016). In Nusa Tenggara Timur, the extreme dry season eroded already weak purchasing power, and harvests of main crops in 2016 was likely impacted, further exacerbating the situation (WFP Indonesia, 2016). Drought also affected drinking water access, with $39 \%$ of households changing the water source, $6 \%$ forced to use unsafe water source, and $24 \%$ forced to travel longer than usual for water supply (WFP Indonesia, 2016).

During the wet season, the Maritime Continent suffers from flash floods and landslides triggered by extreme precipitation events. The $\mathrm{MC}$ is an area with one of the highest flood-induced mortality rates. Both Indonesia and the Philippines are among the countries with the largest increase in economic loss due to floods (Hu et al., 2018). A study of Jakarta and Manila urban areas showed that due to an increase in extreme precipitation and urbanization, floods economic impact is projected to increase $80 \%$ and $212 \%$, respectively, by the year 2030 (Kefi et al., 2020). Another study project flood losses in Jakarta increased by $300-400 \%$ by 2050 (Fajar Januriyadi et al., 2018). The Indonesian National Disaster Mitigation Agency (BNPB) recorded 3622 natural disasters in 2019, of which $90 \%$ are classified 
as hydrometeorological events. The most common hydrometeorological disasters are tornados, followed by floods and landslides.

\subsection{Climate change in the Maritime Continent}

The Maritime Continent experienced significant climate change in recent decades. The air temperature shows an upward trend since the middle of the nineteen seventies. In the latest five years (20142019), the mean temperature anomalies exceed $0.5^{\circ} \mathrm{C}$, and in a few months, anomalies above $1.0^{\circ} \mathrm{C}$ were registered (Figure 1.1). The Sea Surface Temperature (SST) in the Indo-Pacific Warm Pool also demonstrates a significant warming trend, with both temperature anomalies and pool area increasing twofold (Roxy et al., 2019). The increase in both air and sea surface temperature is linked to anthropogenic climate change caused by burning fossil fuels (Weller et al., 2016, King et al., 2017).
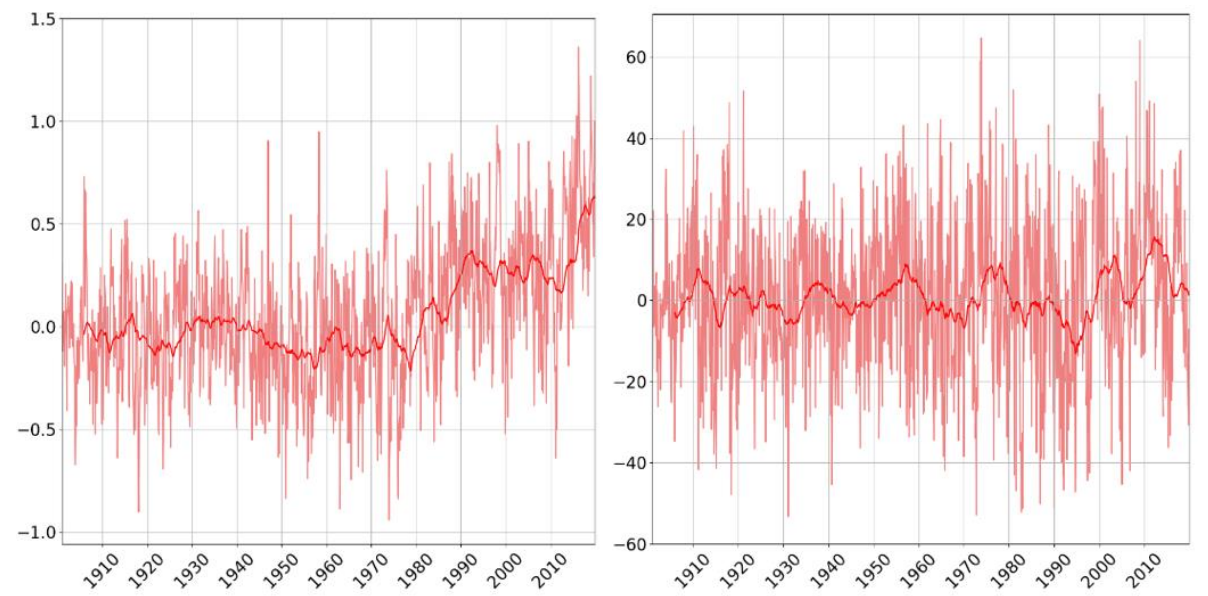

Figure 1.1. Mean monthly anomalies in the MC in air temperature, ${ }^{\circ} \mathrm{C}$ (left) and precipitation, $\mathrm{mm}$ (right) relative to the 1901-2000 norm. Based on CRU TS v 4.04

While changes in air temperature and SST are clear and well documented, changes in precipitation are a subject of debate. There is no clear visible trend in total precipitation on the level of the whole MC mean (Figure 1.1). Some regional changes in precipitation have been reported. For example, in Indonesia, a $12 \%$ increase in total precipitation has been observed, primarily due to increasing amount and intensity during the wet season; during the dry season, precipitation amount is reduced (Ministry of Foreign Affairs of the Netherlands, 2018). The amplification of El-Niño-caused drought in some regions has been attributed to climate change (King et al., 
2017). The overall trend across the MC is an intensification of both dry and wet seasons.

The changes in precipitation regimes have a significant impact on both socio-economic and natural systems. However, as shown below, historical changes in the precipitation regime are inadequately understood and make future changes challenging to predict. While global climate change is expected to affect precipitation worldwide, the existing literature on precipitation regimes in the Maritime Continent highlights the uncertainty of changes in this region. Assessing the changes in meteorological drought is especially tricky. The Technical Summary of the fifth IPCC report states low confidence in drought frequency trends in South East Asia, citing high variability, among other factors, preventing from accruing significant trends using existing observations. In section 1.4, we discuss the reasons for uncertainty in precipitation trends in detail.

For Southeast Asia, the trends of various climate indexes were assessed by Marjuki et al. (Marjuki et al., 2016). The authors analyze a later start of the wet season and more frequent drought periods. They conclude that while a later wet season start is projected, there is no significant evidence that this has already occurred. Java is an exception from this, with a wet season start delay of approximately ten days per decade. It is also noted that only a small percent of stations have trends in the timing of dry periods distinguishable from interannual variability. For the total amount of precipitation in the wet season, some stations show a trend for the increase and some the opposite; for the dry season, no station has a trend significant on a $75 \%$ level. Simultaneously, the number of wet days is increasing for the wet season and is decreasing for the dry season (Marjuki et al., 2016). Other recent studies demonstrate a slight wetting trend. For example, (Roxy et al., 2019) demonstrate a precipitation increase in the Maritime Continent due to increased residence time of MJO clouds, which is caused by increased temperatures in the IPWP. Supari (Supari et al., 2017) found a wetting trend in the extreme precipitation in Indonesia in DJF and MAM but for the south of the country drying trend in JJA and MAM. Similarly, in the Philippines (Villafuerte II et al., 2015) found an increase in the median intensity of RX1 daily precipitation. The number of dry days, on the other hand, is increasing and projected to increase further.

Understanding current and future precipitation trends are required to develop a successful adaptation strategy. This study focuses on creating a conceptual model of historical changes in precipitation regimes in the Maritime Continent and improving the understanding of future changes. To achieve the study's goal, we first need to understand the complexity of the system and the challenges that prevented the previous research from providing a definitive answer. 


\subsection{Elements of complexity}

The precipitation regime in the MC is uniquely complex. This complexity is well illustrated by the fact that no climatological description could be done until the 1980 s despite 2000 rain gauge stations constructed until the end of the 19th century (Yamanaka, 2016). Given a long history of difficulties in conceptualizing precipitation regimes in the $\mathrm{MC}$, it is unsurprising that understanding changes in precipitation regimes in the $\mathrm{MC}$ remains challenging. There are three main reasons for uncertainty in estimating precipitation trends in the Maritime Continent. First, the complexity of the local climate system, defined by the interaction between local land-sea circulations and global circulations. Second, lack of data and the low quality of the older data. Third, the non-linear and nongradual nature of precipitation regime changes. Each of the three components requires a closer look.

\subsubsection{Influence of global circulations}

Several global processes of various timescales influence precipitation regimes in the Maritime Continent. The Madden-Julian Oscillation (MJO) has the shortest timescale out of the process we consider; it is a dominant mode of interseasonal variability on the 30-90 days scale. In the MC, MJO modulates the amplitude of the diurnal cycle, causing anomalies around $20 \%$ of the mean diurnal amplitude (Tian et al., 2006). On a seasonal scale, monsoons are the source of precipitation variability. Monsoons associated with the annual-meridional shift of the ITCZ are driving extreme variability between dry and wet seasons (Yamanaka, 2016). Summer monsoon typically brings heavy rainfall. In the Philippines, the wet season occurs from May to October, in Indonesia, November to March. 


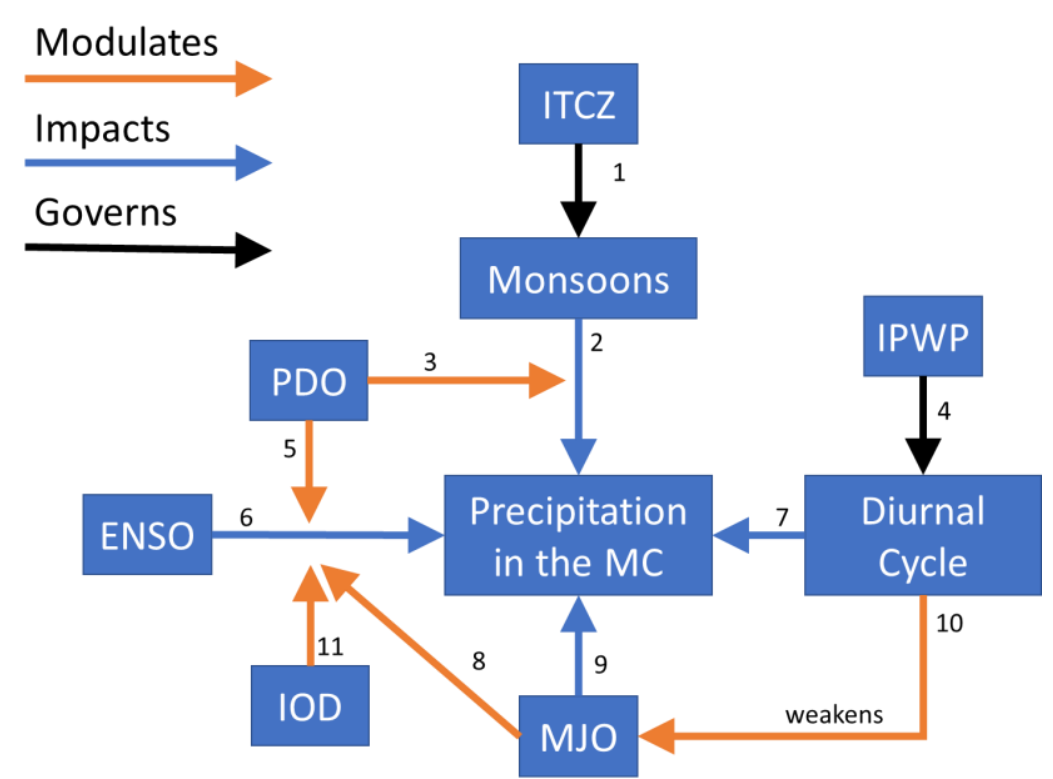

Figure 1.2. Diagram showing the main processes affecting precipitation in the MC. 1,2-(Yamanaka, 2016), 3 - (Wang et al., 2008, Kim et al., 2013), 4- (Ruppert and Johnson, 2016), 5-(Kokorev et al., 2020, Wang et al., 2014b), (Hu and Huang, 2009), 6(Hendon, 2003, Supari et al., 2018), 7 - (Yamanaka, 2016), 8-(Tang and Yu, 2008, Hendon et al., 2007), 9- (Jones et al., 2004)-, 10 (Roxy et al., 2019, Tian et al., 2006), 11- (Nur'utami and Hidayat, 2016)

On the timescale above one year, the precipitation regime is influenced by the El-Niño Southern Oscillation (ENSO) and Indian Ocean Dipole (IOD). ENSO is a semi-periodic oscillation in SST in the equatorial Pacific for 2-7 years. ENSO is perhaps the most researched mode of climate variability; it has a massive impact on the Maritime Continent precipitation. The positive ENSO phase, called EI Nino, causes significant dry anomalies in the $\mathrm{MC}$, and the negative phase (La Nina) wet anomalies (Nur'utami and Hidayat, 2016). When an El Nino event coincides with IOD positive phase, dry anomalies are more substantial than regular El-Niño events (Nur'utami and Hidayat, 2016). Similarly, if La Nina coincides with IOD negative phase, stronger wet anomalies are observed (Nur'utami and Hidayat, 2016). 


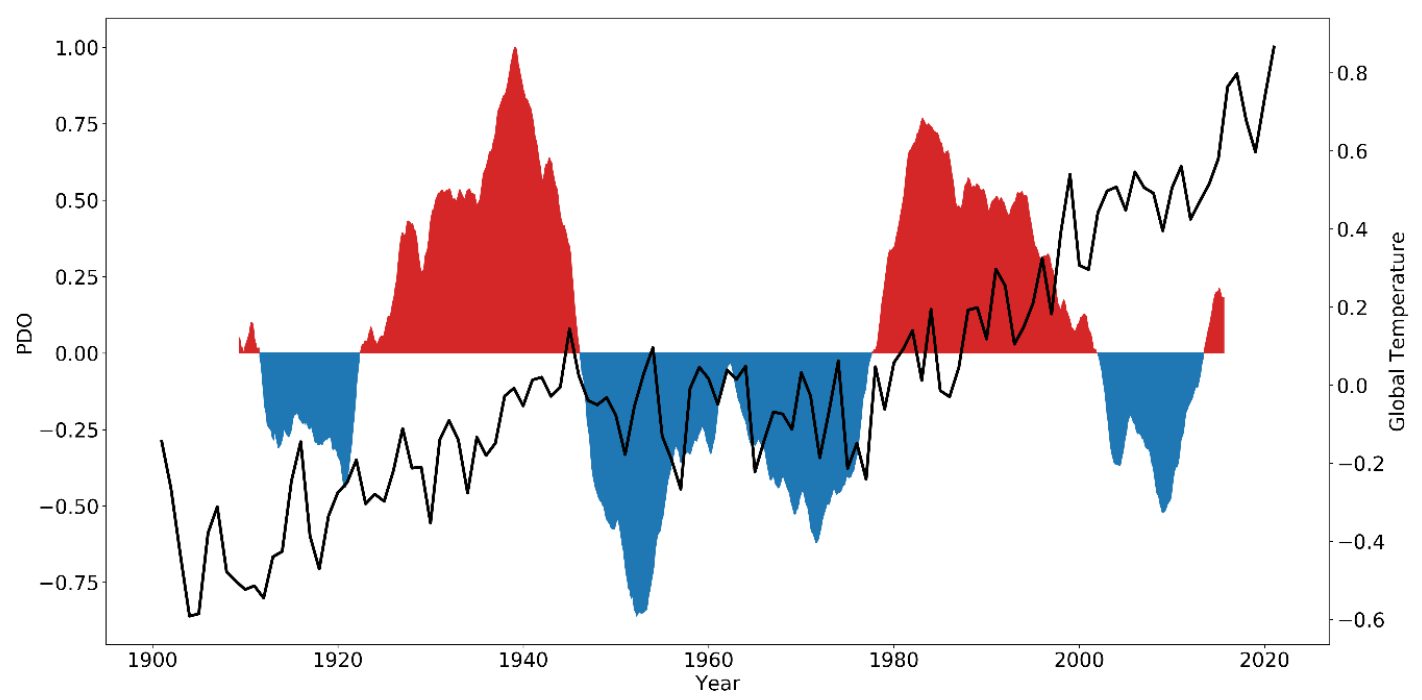

Figure 1.3. Global annual mean temperature anomaly (black line), and PDO, ten years rolling mean (red and blue). Data from HadCRUT4I and HadSST3.

Finally, the precipitation regime is affected by the Pacific Decadal Oscillation (PDO) and anthropogenic climate change on a decadal scale. PDO is detected as an SST anomaly in the Pacific north of $20 \mathrm{~N}$. The PDO cycle typically lasts $20-30$ years and dramatically affects the marine environment in the Pacific Ocean. PDO was first described in the context of its impact on the salmon fishery in Alaska (Mantua et al., 1997, Hare and Mantua, 2000). The best modern description is given by (Newman et al., 2016). The PDO regime shift of 1976/77 described by Mantua and Hare caused dramatic changes in ecosystems due to the speed of the regime change. The PDO regime shifted rapidly. PDO went from negative to positive in only one year. Since then, the impact of the 1976/77 PDO regime shift has been studied on many environmental variables (Powell and Xu, 2012, Wooster and Zhang, 2004, Jiao, 2009). Later studies looked at the impacts of PDO phase change on climate variables (Hartmann and Wendler, 2005, Whitfield et al., 2010), especially on wet/dry anomalies (Zhang et al., 2010, Cook et al., 2014, Wang et al., $2014 b)$. Most notably, the correlation between global temperature changes and the PDO phase was observed (Easterbrook, 2016). During the warm SST anomaly (positive PDO phase), the climate is getting warmer, and during the negative SST anomaly, the climate is cooling or staying stable (Figure 1.3). In the MC and neighboring regions, the PDO phases have been shown to influence the intensity 
of the monsoons (Wang et al., 2008, Kim et al., 2013) and ENSO impacts (Wang and Liu, 2016b, Hu and Huang, 2009).

While the PDO phase shift of $1976 / 77$ is by far the most studied, there are significant evidence that phasxe changes in 1947 and 1999 also had significant environmental and climate impacts. PDO phase changes are clrearly visible on Figure 1.3 . In this thesis we mostly focus on three above mentioned phase changes, since the other periods do no have the sufficient data to analyse the impact of the change.

\subsubsection{Data quality}

The Maritime Continent features high climate spatial variability with a complex topography and coastlines and ocean currents creating a unique microclimate on every island. The complex geography of the $M C$ results in high spatial variability in the precipitation regime. The precipitation regime is dominated by the diurnal cycle generated along coastlines by land-sea temperature contrast (Yamanaka et al., 2018). This dominance of coastal processes creates a significant contrast between precipitation regimes on the coastal and inland areas and makes it challenging to create a representative network of weather stations. The data's high spatial and temporal resolution is needed to estimate the precipitation regime in the MC accurately. The influence of the diurnal cycle is not the only factor increasing temporal variability. The interactions between multiple oceanatmospheric oscillations, as described in section 4.1, are creating high temporal variability on a more extended scale (Sekaranom et al., 2018). High temporal variability masks the effects of climate change and makes it challenging to estimate trends in precipitation regimes.

The fourth IPCC report names the lack of data as one reason for difficulties in assessing changes in precipitation in the Maritime Continent (Hijioka, 2014). A similar sentiment is often reported in other publications (Liu and Zipser, 2014, Yatagai et al., 2012, Sekaranom et al., 2018). The density of weather stations is uneven throughout the region and typically low; this is especially true for the long-period observations. The existing network shows bias in the distribution of weather stations and rain gauges, with many stations being located on the flatlands and few in the mountain areas (Liu and Zipser, 2014, Yatagai et al., 2012, Sekaranom et al., 2018). Longperiod data is critical to assess the climatic changes; however, quality data in sufficient amounts are only available from the early 1980s. An additional challenge is to find if stations are representative of vast regions. High spatial and temporal variability makes both interpolation and reanalysis-based gridded archives less accurate. 
This study relies heavily on the historical observed precipitation data. The critical aspects of this study are made possible by using the Southeast Asian Climate Assessment and Dataset (SACA\&D). SACA\&D is a state-of-the-art dataset developed by (van den Besselaar et al., 2017) at KNMI in collaboration with BMKG and local weather centers. This work also uses a few other data archives, such as CRU TS and ERA5, to evaluate different aspects of precipitation regime changes in the Maritime Continent.

\subsubsection{Non-linear regime changes}

Finally, this thesis suggests that the most important property that masks trends in precipitation regime in the Maritime Continent is the non-gradual and non-linear nature of the change in precipitation regime. Traditionally linear trends are most used to estimate the rate of change in the meteorological parameters. The linear trend is historically popular because it is easy to understand and easy to calculate. However, the linear trend applicability is limited because of its simplicity. In the case of global temperature, the estimated rate of change varies based on the length and starting point of the chosen period (Anisimov et al., 2013). For example, a temperature trend during the period of positive PDO from 1977 to 2000 will be significantly higher than that in the period that includes both positive and negative PDO phases 1977-2016. When it comes to precipitation regimes, linear trends have even more potential limitations. Changes in precipitation can only affect the distribution of daily precipitation without changing seasonal or annual mean. Suppose the increase in heavy precipitation is balanced by a proportional decrease in weak precipitation or an increase in the number of dry days. In that case, the total precipitation will stay the same, and the linear trend of the annual precipitation sum will show no impact. However, changes in precipitation distribution, changes in timings of dry and wet seasons can have a massive impact on society and the environment. Evidence demonstrates that wet-dry anomalies in the Pacific region and beyond are experiencing changes associated with PDO phases (Cook et al., 2014, Zhang et al., 2010, Barlow et al., 2001, Whitfield et al., 2010, Wang et al., 2014b). While no statistically significant linear trend of annual precipitation was observed in the MC, we can expect to find evidence of a non-linear regime change associated with a change in the PDO phase. The change of the PDO phase affects the precipitation anomalies associated with monsoons and ENSO events, changing the precipitation regime in the MC. As we saw from the historical observations (Figure 1.3), the change of the PDO phase can happen in a span of just one year, like was the case in 1976/77 and 1947. Change in the PDO phase immediately changes the precipitation regime to a new state. 


\subsection{Research questions}

Following questions regarding each of the identified elements of complexity must be addressed to realize the ambition of this dissertation and create a conceptual model of changes in precipitation regime in the Maritime Continent.

1. How do multiple sources of temporal variability interact with each other?

2. Is there a regime shift in precipitation in the Maritime Continent?

3. How can we predict the factors governing precipitation regimes in the Maritime Continent?

4. What is the future of the precipitation regime in the Maritime Continent?

This thesis consists of four chapters addressing each of those questions individually. Chapter 2 explores interactions between PDO and ENSO and their relationship to the precipitation regime in the Maritime Continent and demonstrates how the ENSO-PDO modulation effect can cause precipitation regime shifts.

Chapter 3 employs a novel Bayesian statistics method to provide evidence for a historical shift in precipitation regime-the parameters of the detected regime shift match with observed parameters derived in Chapter 2.

Chapter 4 investigates the future of the precipitation regime in the Maritime Continent using model simulations. CMIP6 models can reproduce the precipitation regime in the $M C$, and impacts of ENSOPDO interactions are evaluated. A modified version of the Bayesian regime shift detection method demonstrates precipitation regime shifts in the model simulated climate.

Chapter 5 explores the possibility of using machine learning to forecast the circulation indexes governing the precipitation regime in the Maritime Continent. Two perspective ML architectures are compared for predicting MJO.

This thesis presents a novel view on long-term changes in precipitation regimes in the Maritime Continent. The idea of precipitation regime shift in the Maritime Continent is explored for the first time in this thesis. Three separate lines of evidence of precipitation regime shift in the Maritime Continent are presented - a global circulation mechanism causing the regime shift is revealed, regime shift is demonstrated in the data, and GCMs reproduce regime shift. To the best of the author's knowledge, this is the first of its kind study demonstrating the influence of PDO phases on precipitation regimes. The presented study provides tools for exploring regime shifts in other geographic areas and beyond the precipitation regime. The developed novel Bayesian regime shift detection algorithm can facilitate further studies of the effects of PDO phase changes and 
non-linear changes in general. The conceptual model of the precipitation regime shift presented in this thesis allows resolving much of the complexity around the MC's long-term changes in the precipitation regime. Identifying periods of rapid change in precipitation regime and periods of stability allows improving the evaluation of historical changes and their impacts. Rapid shifts in precipitation regimes have far-reaching consequences for expected future climate changes and adaptation strategies. 


\title{
2. Analysis of PDO-ENSO modulation effect on precipitation anomalies in the Maritime Continent ${ }^{1}$
}

\begin{abstract}
Precipitation regime in the Maritime continent driven by changes in sea surface temperature (SST) in the Pacific and Indian Oceans. The SST anomalies induced by the cycles of Pacific Decadal Oscillation (PDO) and El Niño-Southern Oscillation (ENSO) have a great impact on precipitation regime. This chapter demonstrates that in-phase occurrence of ENSO and PDO creates statistically different pattern of precipitation and SST anomalies compare to ENSO cycle accompanied by neutral PDO. On average in-phase events have stronger impact inphase positive events lead to precipitation increase, in phase negative to precipitation decrease relative to ENSO event with neutral PDO. ENSO-PDO modulation effect produce decadal variability in precipitation regime in Maritime continent.
\end{abstract}

\subsection{Introduction}

The Maritime Continent is a region of Southeast Asia consisting of thousands of islands, including Indonesia, the Philippines, Papua, and Malaysia. The Maritime Continent is located within the Indo-Pacific warm pool, a region characterized by high sea surface temperatures (SST) exceeding $28^{\circ} \mathrm{C}$. The meteorological regime of the Maritime Continent is dominated by coastal land-sea interactions, with the diurnal cycle being dominant both in the rainy and dry seasons (Yamanaka, 2016, Yamanaka et al., 2018). SSTs play a crucial role in governing precipitation and dry-wet anomalies in the Maritime Continent (Aldrian and Dwi Susanto, 2003). SST anomalies, in turn, are driven by large-scale oceanic oscillations: The Pacific Decadal Oscillation (PDO) and the El Niño-Southern Oscillation (ENSO). The precipitation regime of the Maritime Continent is characterized by high interannual and decadal variability. A large part of the interannual variability is explained by ENSO (Lyon and Barnston, 2005). During the positive (warm) phase of ENSO, the cooler SST in

${ }^{1}$ this chapter has been published as - KOKOREV, V., ETTEMA, J., SIEGMUND, P., 2021, Analysis of PDO-ENSO modulation effect on precipitation anomalies in the Maritime Continent, Journal of Earth Science \& Climatic Change, submited 
the Maritime Continent suppresses rainfall and leads to drier conditions (Yamanaka, 2016, Vicente-Serrano et al., 2011, Surmaini et al., 2014). During the negative (cold) ENSO phase, the Maritime Continent, on average, experiences an increase in precipitation. However, the effect depends on location, especially during the rainy season (Qian et al., 2013, Qian et al., 2010). Increased precipitation intensity during the negative ENSO phase causes more floods and landslides in many regions of the Maritime Continent (Rodysill et al., 2019, Lestari et al., 2019).

Another major factor affecting the climate regime in the Maritime Continent is the decadal oscillation in the Pacific Ocean commonly quantified by the Pacific Decadal Oscillation (PDO) index or Interdecadal Pacific Oscillation (IPO) index. This oscillation is characterized by a reoccurring large-scale SST anomaly in the midlatitude Pacific (Mantua and Hare, 2002). The PDO index is defined as the leading Empirical Orthogonal Function (EOF) amplitude of SST anomalies in the Pacific north of $20^{\circ} \mathrm{N}$. The IPO was initially defined as the second EOF of SST in the Pacific Ocean (Power et al., 1999), or in later studies as the first EOF of detrended low-pass filtered SST over $50^{\circ} \mathrm{S}-50^{\circ} \mathrm{N}, 100^{\circ} \mathrm{E}-70^{\circ} \mathrm{W}$ (van Oldenborgh et al., 2012). The IPO is symmetrical around the equator and usually considered to be a long-period component of ENSO (Deser et al., 2004), while the PDO demonstrates more independent behavior and has a known physical connection to ENSO via an atmospheric bridge and oceanic coastally trapped waves (Newman et al., 2016). Historical data for both PDO and IPO show alternating cold and warm periods, each with a duration of 20 to 30 years with similar phase changes in 1945, 1976/7, and 1998/9 (Salinger et al., 2001). The PDO cold/warm phases have a significant impact on climate variables globally, such as air temperature (Anisimov et al., 2013), SST (Yasunaka and Hanawa, 2002), and tropical cyclone activity (Wang and Liu, 2016a). The PDO phase change of 1976 has led to several significant environmental impacts that are well documented in the scientific literature as summarized by (Ebbesmeyer et al., 1991, McGowan et al., 2003). For example, rapid changes in Pacific Ocean SST's resulted in dramatic changes in Alaskan salmon production (Hartmann and Wendler, 2005) and anchovy and sardine populations in the Pacific Ocean (Chavez et al., 2003). While the regime shift of 1976 is the most studied one, studies point to similar changes in ocean ecosystems after other PDO shifts in 1925, 1947, and 1998 (Peterson and Schwing, 2003, Newman et al., 2016). Similarly, the IPO has been shown to modulate interannual ENSO-related climate variability over Australia (Salinger et al., 2001). The next chapter of this thesis (page 56) provides statistical evidence of the PDO phase change of 1976 being the mechanism behind the found precipitation regime 
shift change in the northern hemispheric part of the Maritime Continent, resulting in an increased number of dry days.

On a global scale, the PDO magnifies the wet-dry anomalies caused by ENSO when their phases align, whereas the effect is much smaller when the PDO and ENSO are in counter-phase (Wang et al., 2014a). Multiple studies demonstrate that the PDO can have a modulating effect on teleconnections in many parts of the world (Wang et al., 2014a), such as North America(McAfee, 2014), South America (Andreoli and Kayano, 2005), and Australia (Power et al., 2006). In East Asia, the PDO modulation effect has been shown to affect the East Asian winter monsoon (Wang et al., 2008, Kim et al., 2013) and tropical cyclone rapid intensification (Wang and Liu, 2016a). The purpose of the present study is to determine the influence of phase combinations of the ENSO and PDO on the precipitation regime and SST anomalies in the Marine Continent using multiple long-term observational datasets. Specifically, it is investigated to what extent the PDO phase modulation of ENSO can explain the observed precipitation regime shift of 1976 .

\subsection{Method and data}

To isolate the effect of the PDO on ENSO precipitation and SST anomalies in the Maritime Continent, we compare the anomalies for ENSO and PDO in-phase events with the anomalies for ENSO and neutral PDO phase events. An extended period of observations is necessary to compare the effect of ENSO in different PDO phases because all data must cover at least one cold and one warm PDO phase. Historical monthly data (1901-2018) for ENSO (Nino-3.4) and PDO were obtained from the Royal Netherlands Meteorological Institute (KNMI) Climate Explorer (https://climexp.knmi.nl/). To minimize the influence of climate change in the ENSO data, we use the relative Nino 3.4, where the average SST for $20 \mathrm{~S}-20 \mathrm{~N}$ is subtracted to remove the climate change signal. We separate historical precipitation data into months associated with different phase combinations of ENSO and PDO. All months in 1901-2018 are assigned qualitative values of ENSO and PDO indices: positive, negative, or neutral. The threshold values separating neutral values from positive or negative ones are defined as the $68^{\text {th }}$ percentile of the absolute values of the index. For ENSO, the threshold values are $\pm 0.75^{\circ} \mathrm{C}$, the values between $-0.75^{\circ} \mathrm{C}$ and $+0.75^{\circ} \mathrm{C}$ are considered as neutral. For PDO, the threshold is index values above or below \pm 1 (the PDO index is unitless). We distinguish nine phase combinations - positive ENSO and positive PDO, positive ENSO and neutral PDO, etc. For convenience, we refer to the phase combinations where ENSO and PDO are both positive/negative as an in-phase 
positive/negative event to distinguish from an ENSO positive/negative event accompanied by neutral PDO conditions.

For each phase combination, we calculate the mean values of the anomalies of seasonal precipitation. In order to simplify the analysis, precipitation anomalies are expressed as a percentage from the monthly mean. For precipitation, we use monthly total values from the CRU TS4 dataset - a gridded observations-based time-series dataset with $0.5^{\circ}$ resolution maintained by the UK National Centre for Atmospheric Science (Harris and Jones, 2017, Harris et al., 2020). This dataset is chosen because of the long period of available observations, namely 1901-2018. A dataset is required to stretch back to at least two phases to the 1976 regime shift, ideally to the beginning of the 20th century, to include two cold and warm phases. In addition, we calculate SST anomalies to investigate the mechanisms behind the precipitation anomalies. Daily SST data are obtained from the NOAA Extended Reconstructed Sea Surface Temperature (ERSST.v5) at $2^{\circ}$ resolution and temporal coverage from 1881 to 2020 (Huang et al., 2017). While reconstructed SST datasets such as ERSST.v5 suffer from high uncertainties, especially before the satellite era, no alternative offers a perspective into long-term climatological changes. While we are not focusing specifically on analyzing changes in SSTs, investigating these changes helps to verify the significance of precipitation anomalies and improves our understanding of the underlying processes.

The precipitation and SST anomalies for each of the nine ENSO/PDO phase combinations (Figure 1) are calculated using the following procedure. The monthly precipitation and SST anomalies are calculated for a 1901-2018 monthly climatology. Then the data are split into nine discontinuous data series, one for each specific ENSO/PDO phase combination. The resulting dataset is further aggregated into seasons - DJF (December-February), MAM (MarchMay), JJA (June-August), SON (September-November). Mean values and standard deviations are calculated for each series. The result is a mean anomaly field for precipitation and SST for each of the nine combinations of ENSO and PDO values for each of the four seasons. Due to limited resolution, long-period datasets do not allow for meaningful regional-level analysis. To analyze regional level effects, we reproduce the analysis described above using daily high-resolution datasets - NOAA OISST v2 (Banzon et al., 2016, Reynolds et al., 2007) for SST and SACA\&D (van den Besselaar et al., 2017) for precipitation. These high-resolution datasets only cover the period from 1981 to 2017, but the much shorter temporal resolution is compensated by improved spatial resolution $-0.5^{\circ}$ for SST and $0.25^{\circ}$ for precipitation. 
Statistically significant differences between mean values of different ENSO-PDO phase combinations are verified using Welch's unequal variances $t$-test. This test is an adaptation of the Student's t-test that is more robust when samples have unequal sizes or variability (Welch, 1947). The t-statistics with p-values below 0.01 are considered to be statistically significant. As there is not enough data to calculate meaningful statistics per every cell, we evaluate statistical significance on a country level as a workaround.

\subsection{Results}

\subsubsection{Long-Period Data}

The number of occurrences of each of the nine ENSO/PDO phase combinations in 1901-2018 for each calendar month and season is shown in Figure 2.1. Of the nine phase combinations, the most common combination is neutral, occurring in $47 \%$ of the months from 1901-2018. Precipitation and SST anomalies in these neutral situations are close to average (i.e., zero). This is to be expected: both because of their prevalence and because neutral ENSO and PDO are states with minor SSTs anomalies by definition. The non-neutral ENSO most commonly occurs from October to February. However, inphase positive events are distributed much more evenly over the year than the rest of ENSO positive events. Counter-phase events are rare, each occurring only 11-12 times (1.8\%) during the 1901-2018 period, mainly during DJF. In-phase events are less frequent (12\%) than non-neutral ENSO with neutral PDO events (18\%). Here we only investigate the differences between in-phase ENSO events and typical ENSO events with neutral PDO. We do not analyze counter-phase events, even though they produce distinct precipitation and SST patterns because they are too rare to investigate with the method chosen for this study. We also do not compare in-phase events with PDO events accompanied by neutral ENSO since ENSO's impact is much more significant than PDO. Such comparison would essentially show typical ENSO impacts. 

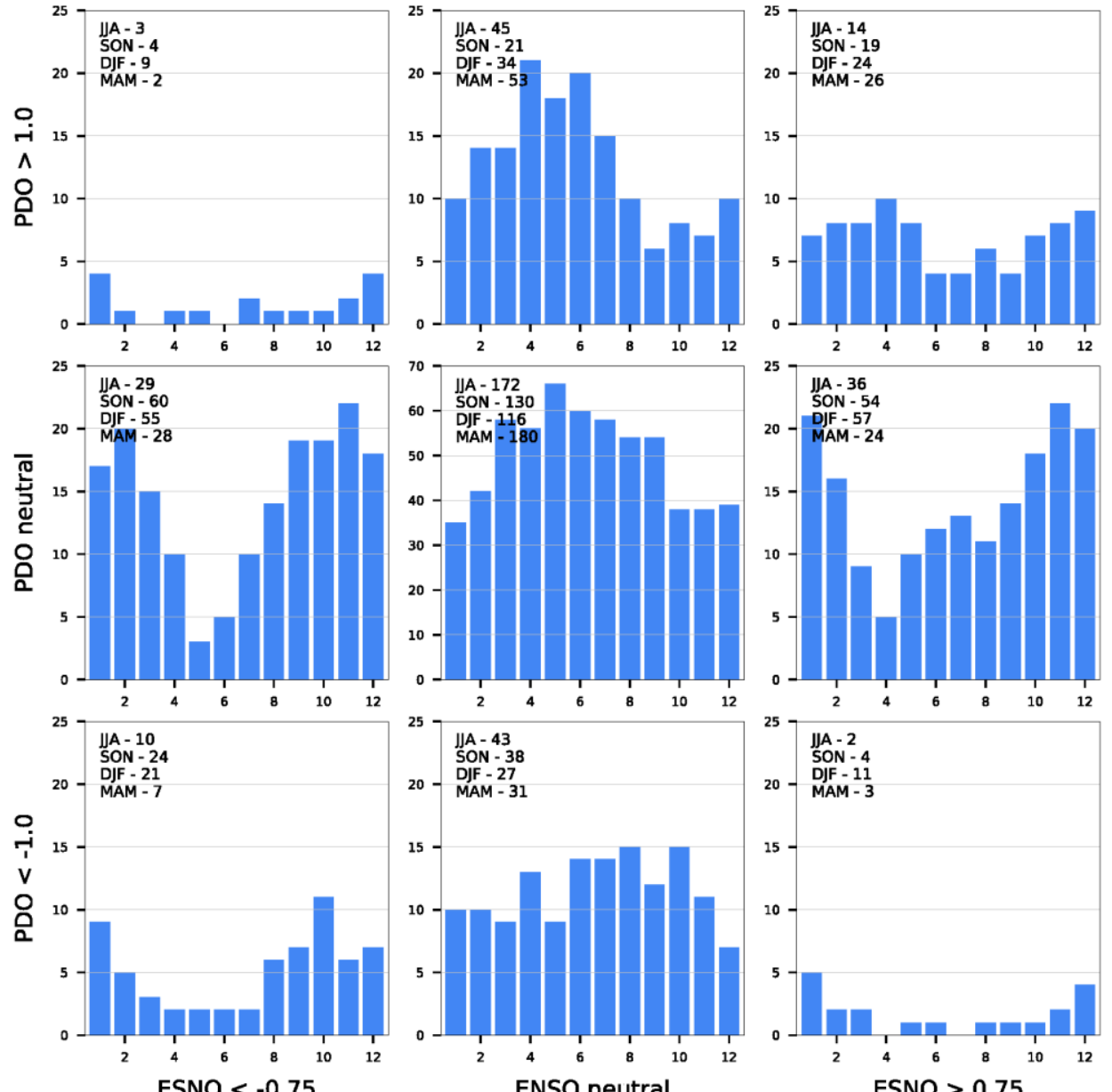

Figure 2.1. The number of months with a specific ENSO/PDO phase combination per month.

The differences in precipitation and SST anomalies between in-phase ENSO and typical ENSO events, accompanied by neutral PDO, are shown in the figures below. Figures $2.2-2.5$ demonstrate the influence of positive and neutral PDO on the seasonal precipitation (shown over land) and SST anomalies (shown over the sea) during the positive ENSO phase for the four seasons (Figure $2.2-\mathrm{JJA}$; Figure 2.3 - SON; Figure 2.4 - DJF; Figure 2.5 - MAM). Results presented in the figures are also summarized in Table 2.3, which shows average differences between in-phase and typical ENSO events and the statistical significance of this difference per country. In Figures 2.2-2.5b, we see the typical ENSO positive pattern for all seasons with cold SST anomalies East of Papua causing significant dry anomalies over most of the Maritime Continent. However, when positive ENSO coincides with positive PDO, a noticeably different 
pattern forms (Figures 2.2-2.5a). SST anomalies are weakened or reversed in sign. Overall, SST anomalies during in-phase positive events are between +0.25 and 0.75 degrees warmer compared to PDO neutral ENSO+ events (Figures 2.2-2.5c). This is especially noticeable when examining the differences between the $\mathrm{PDO}+$ /ENSO+ and PDO neutral/ENSO+ phase combinations (Figures 2.2-2.5c). Warmer SSTs generally lead to more precipitation, although on a regional scale, there are exceptions. During in-phase positive ENSO events, the dry anomalies in the Maritime Continent are weakened in SON by $5.6 \%$ more precipitation than positive ENSO with the neutral PDO. During DJF, the differences between in-phase positive and typical ENSO events are not statistically significant except for the Philippines, where $12.2 \%$ more precipitation is observed, and the dry anomaly is weakened (Figure 2.4; Table 2.1). During MAM, the whole northern hemispheric part of the Maritime Continent experiences a more robust dry anomaly $(5.7 \%$ less precipitation). The effect is especially pronounced in the Philippines (16.1\% less precipitation) (Figure 2.5; Table 2.2) 
(a)

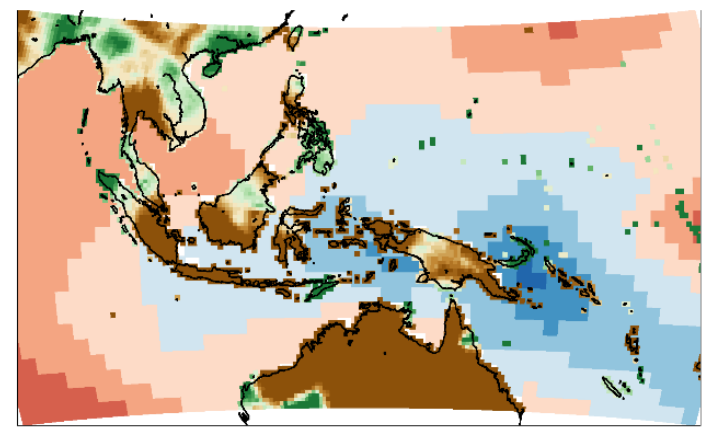

(b)

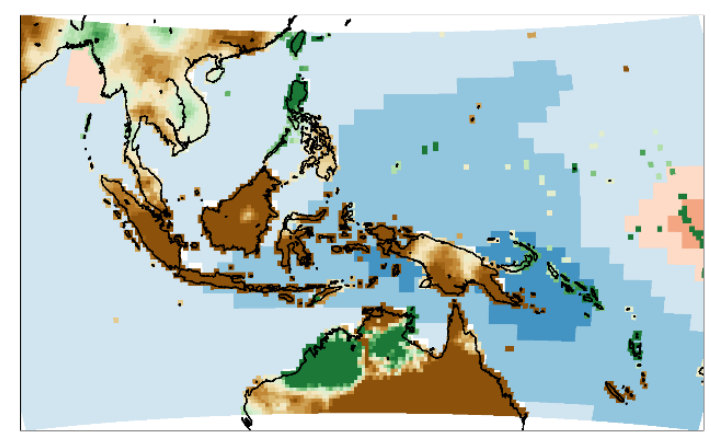

(c)

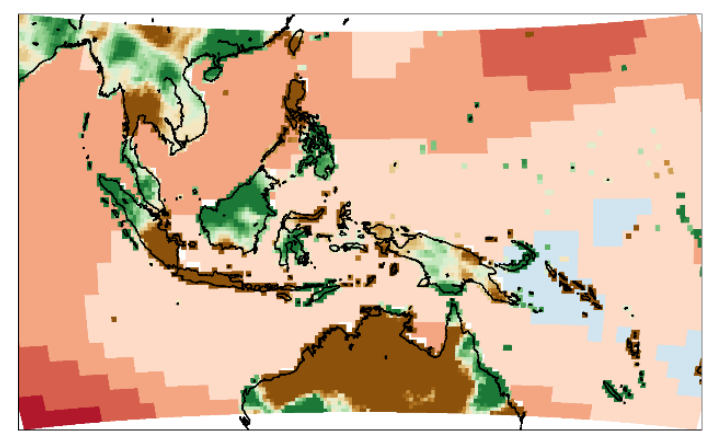

SST anomaly, ${ }^{\circ} \mathrm{C}$

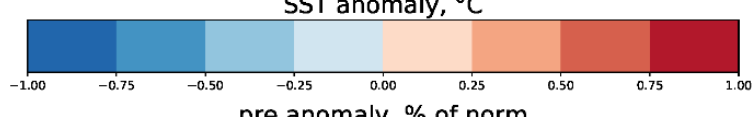

pre anomaly, \% of norm

Figure 2.2. Difference between in-phase positive ENSO and typical ENSO events during JJA. Data from long-period dataset 1901-2018. Maps show seasonal precipitation anomalies expressed as a percentage of the seasonal mean (shown over land) and seasonal SST anomalies in ${ }^{\circ} \mathrm{C}$ (shown over the sea for ENSO positive months (Nino $3.4>0.75$ ) for (a) - JJA, positive PDO (PDO >1); (b) - JJA, neutral PDO; (c) difference (a) - (b); 
(a)

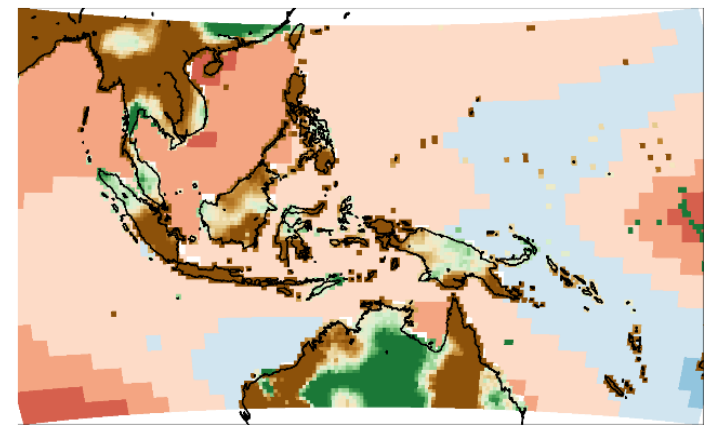

(b)

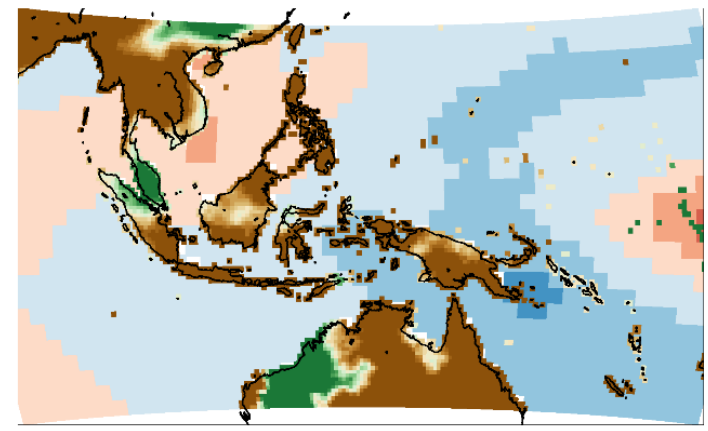

(c)

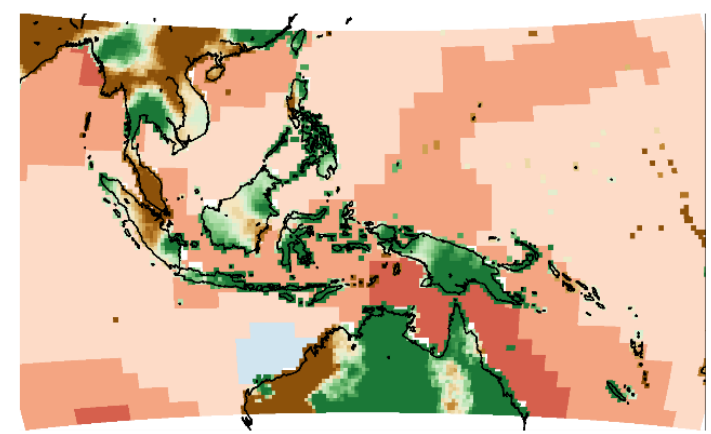

SST anomaly, ${ }^{\circ} \mathrm{C}$

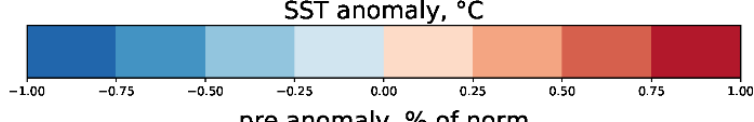

pre anomaly, $\%$ of norm

Figure 2.3. Difference between in-phase positive ENSO and typical ENSO events during SON. Data from long-period dataset 1901-2018. Maps show seasonal precipitation anomalies expressed as percentage of seasonal mean (shown over land) and seasonal SST anomalies in ${ }^{\circ} \mathrm{C}$ (shown over sea) for ENSO positive months (Nino $3.4>0.75$ ) for (a) - SON, positive PDO (PDO >1); (b) - SON, neutral PDO; (c) difference (a) - (b); 
(a)

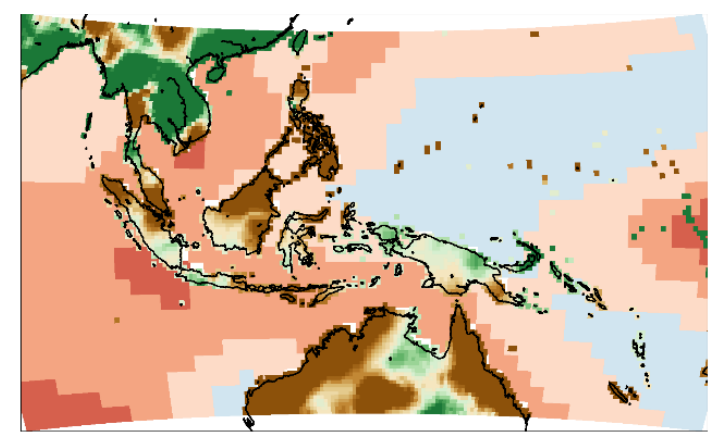

(b)

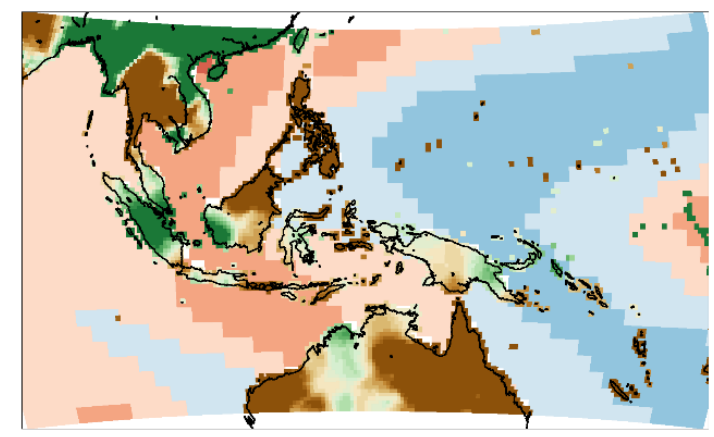

(c)
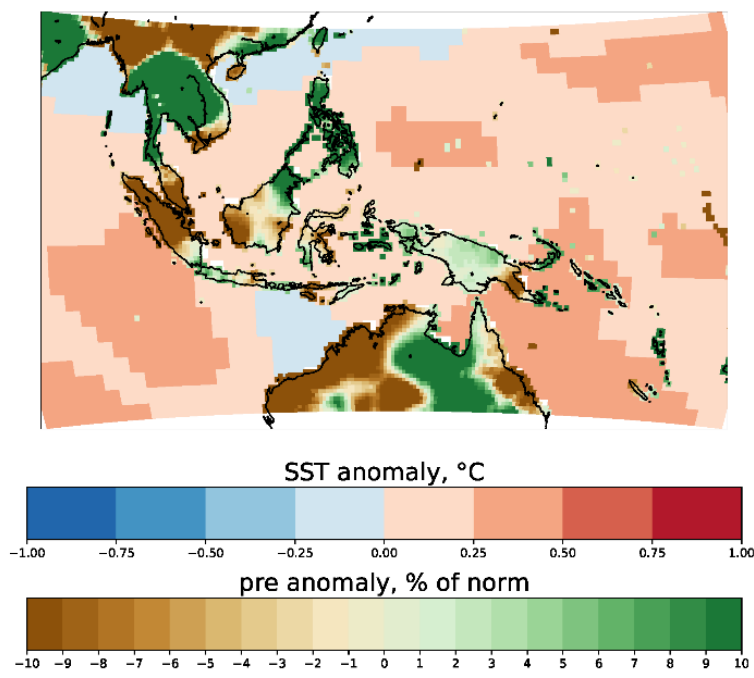

Figure 2.4. Difference between in-phase positive ENSO and typical ENSO events during DJF. Data from long-period dataset 1901-2018. Maps show seasonal precipitation anomalies expressed as a percentage of the seasonal mean (shown over land) and seasonal SST anomalies in ${ }^{\circ} \mathrm{C}$ (shown over the sea for ENSO positive months (Nino $3.4>0.75$ ) for (a) $-D J F$, positive $P D O(P D O>1)$; (b) $-D J F$, neutral PDO; (c) difference (a) - (b); 
(a)

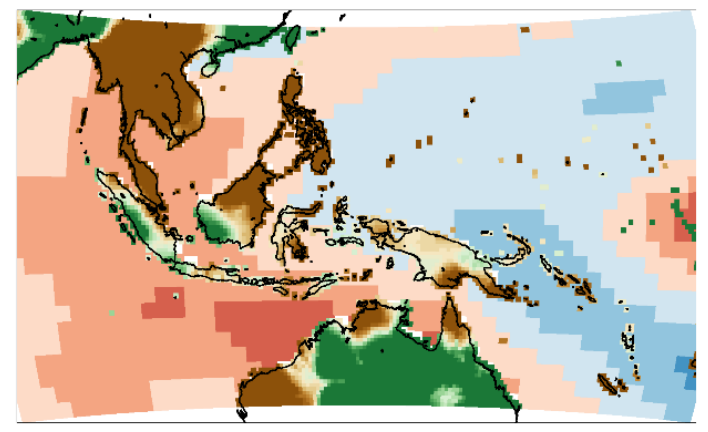

(b)

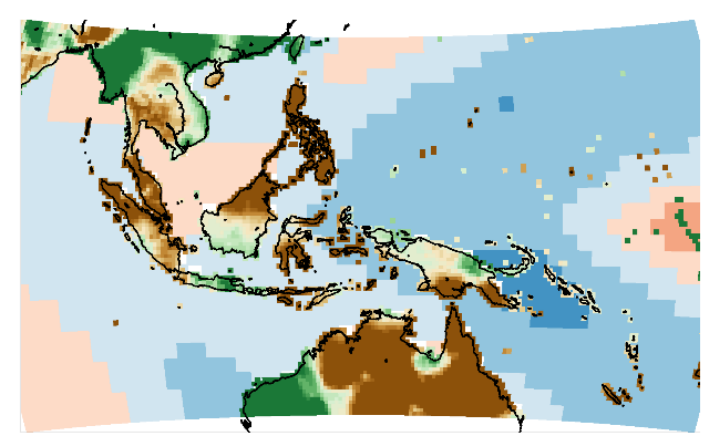

(c)

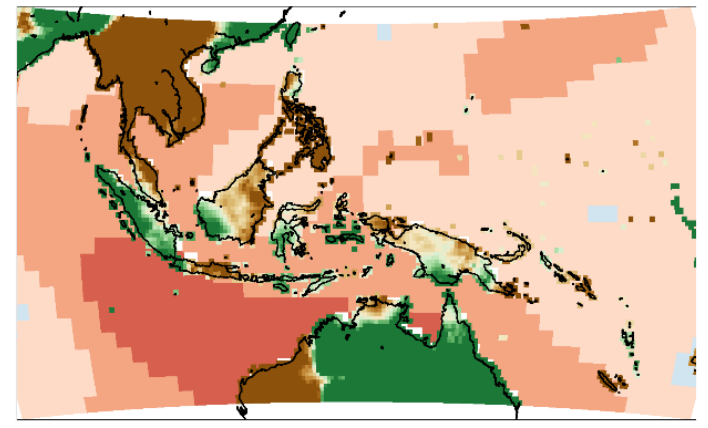

SST anomaly, ${ }^{\circ} \mathrm{C}$
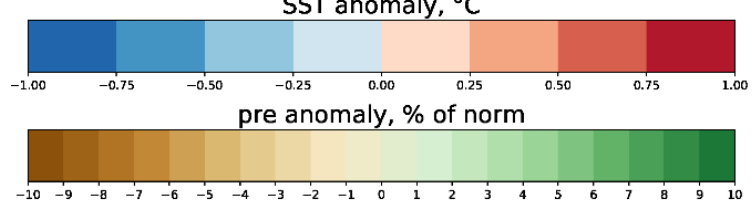

Figure 2.5. Difference between in-phase positive ENSO and typical ENSO events during MAM. Data from long-period dataset 1901-2018. Maps show seasonal precipitation anomalies expressed as a percentage of the seasonal mean (shown over land) and seasonal SST anomalies in ${ }^{\circ} \mathrm{C}$ (shown over the sea for ENSO positive months (Nino $3.4>0.75$ ) for (a) - MAM, positive PDO (PDO >1); (b) - MAM, neutral PDO; (c) difference (a) - (b); 
Similar to Figure 2.2-2.5, Figures 2.6-2.9 show the influence of negative PDO combined with negative ENSO phase on precipitation and SST anomalies, compared to ENSO-/PDO neutral conditions. During JJA (Figure 2.6), in-phase negative events strengthen wet anomalies $(+5.7 \%)$, with the difference being statistically significant through the entire Maritime Continent. In SON (Figure 2.7), similar strengthening of wet anomalies occurs, although it is only statistically significant in the southern hemisphere part of the Maritime Continent. In DJF (Figure 2.8), the differences are slight or not statistically significant, except in the Philippines, where the wet anomaly is weakened ( $9 \%$ less precipitation), and Indochina, where dry ones replace wet anomalies. During MAM (Figure 2.9), the Northern Hemispheric part of the Maritime Continent receives $8.9 \%$ more precipitation. The southern hemispheric part receives $5 \%$ less precipitation, with wet anomalies being replaced by dry ones in Java. The differences in SST during in-phase negative events are mostly within $\pm 0.25^{\circ} \mathrm{C}$.

The differences in seasonal precipitation associated with changes in the ENSO/PDO phase combinations are presented in Table 2.3.

Results are expressed as a percentage of the seasonal mean for the entire Maritime Continent, its northern and southern hemispheric parts, and for each country together with its significance level. For the South Hemispheric part of the Maritime continent, differences between both positive and negative in-phase events and typical ENSO events are significant for every season. For the North Hemispheric part, the differences are significant for JJA and MAM but not for DJF and SON. The differences are almost always significant for regions outside the Maritime Continent, with a few exceptions where differences are too small.

Figure 2.19a shows the time series of the number of occurrences of PDO/ENSO in-phase positive events, in-phase negative events, and counter-phase events. Figure 2.19b shows the time series for the PDO and ENSO indices. Frequencies of occurrence of in-phase positive and negative events correlate with the PDO cold-warm cycle. During warm PDO phases, in-phase positive events amount to over $60 \%$ of all ENSO positive events compared to $3-8 \%$ during a cold phase. During the cold PDO phase of 1948-1976, in-phase negative events amount to $56 \%$ of all ENSO negative events compared to 2$4 \%$ during warm phases. A PDO phase shift can lead to a rapid shift in the precipitation regime in the Maritime Continent, in all seasons except DJF, by altering the frequency of in-phase event occurrence. For most of the Maritime Continent, both positive and negative inphase events lead to a 6-9\% monthly precipitation increase from June to November and a $10-15 \%$ decrease from December to May. 
(a)

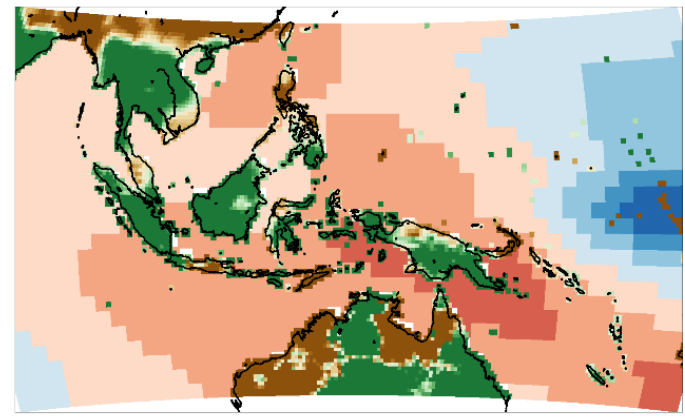

(b)

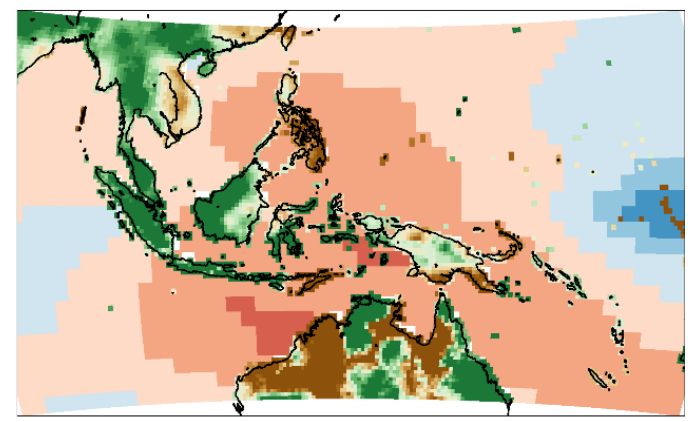

(c)
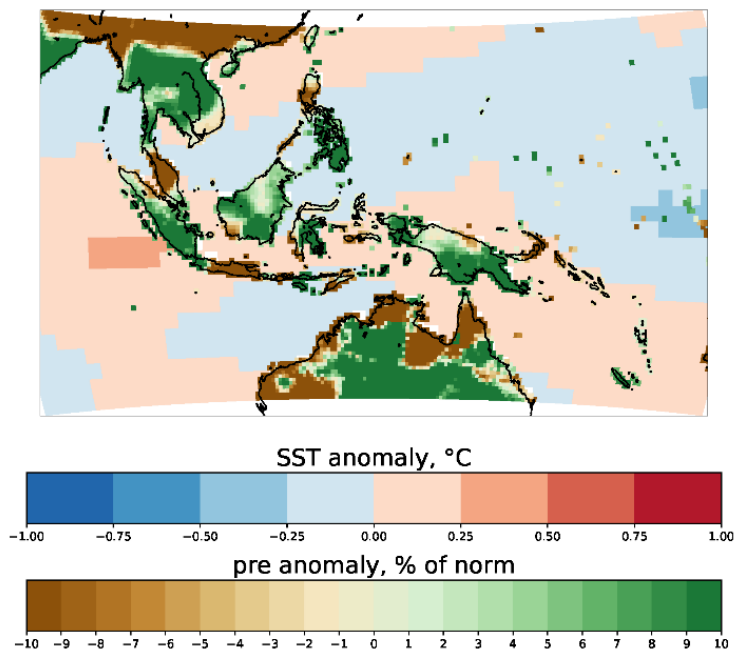

Figure 2.6. Difference between in-phase negative ENSO and typical ENSO events during JJA. Data from long-period dataset 1901-2018. Maps show seasonal precipitation anomalies expressed as a percentage of the seasonal mean (shown over land) and seasonal SST anomalies in ${ }^{\circ} \mathrm{C}$ (shown over the sea) calculated from the longperiod datasets for ENSO negative months (Nino $3.4<-0.75$ ) for (a) - JJA, negative PDO (PDO >1); (b) - JJA, neutral PDO; (c) difference (a) - (b); 
(a)

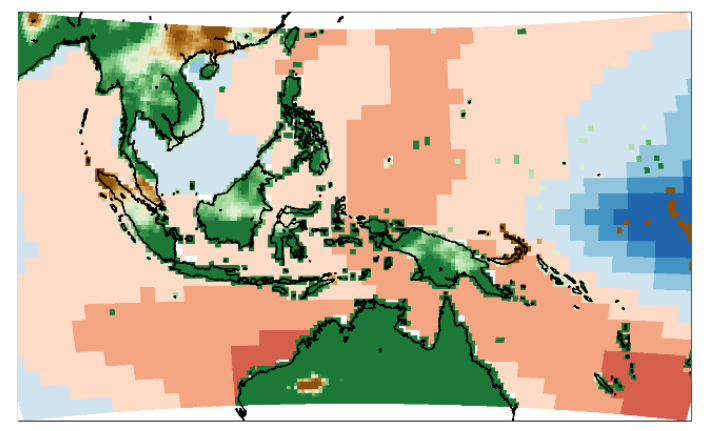

(b)

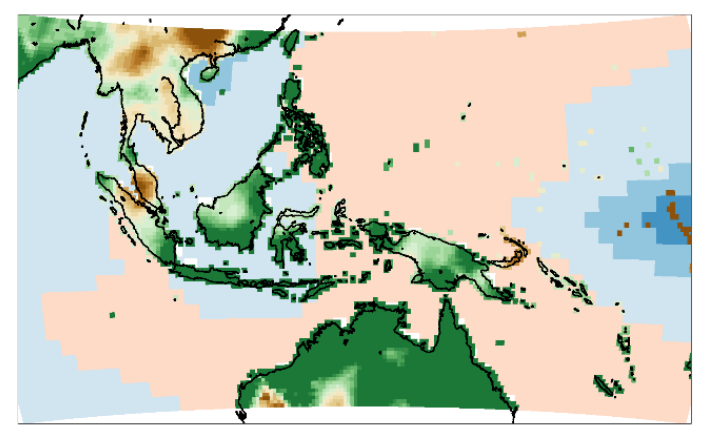

(c)

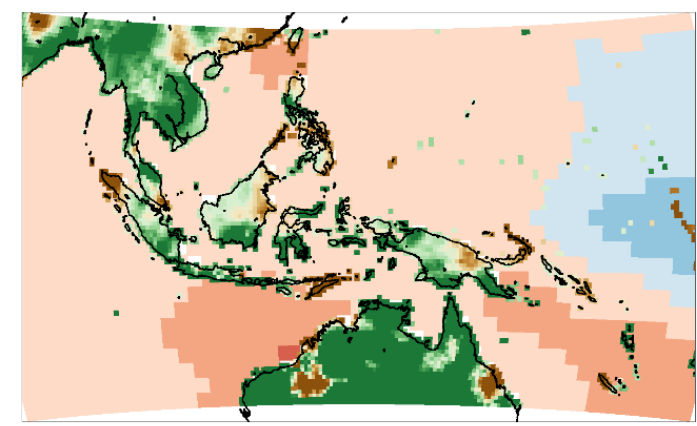

SST anomaly, ${ }^{\circ} \mathrm{C}$

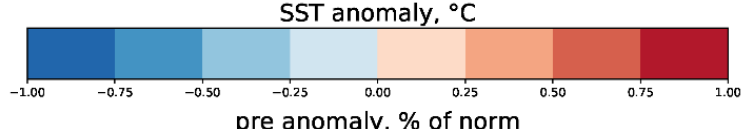

pre anomaly, \% of norm

Figure 2.7. Difference between in-phase negative ENSO and typical ENSO events during SON. Data from long-period dataset 1901-2018. Maps show seasonal precipitation anomalies expressed as a percentage of the seasonal mean (shown over land) and seasonal SST anomalies in ${ }^{\circ} \mathrm{C}$ (shown over the sea) calculated from the longperiod datasets for ENSO negative months (Nino $3.4<-0.75$ ) for (a) - SON, negative PDO (PDO >1); (b) - SON, neutral PDO; (c) difference $(a)-(b)$; 
(a)

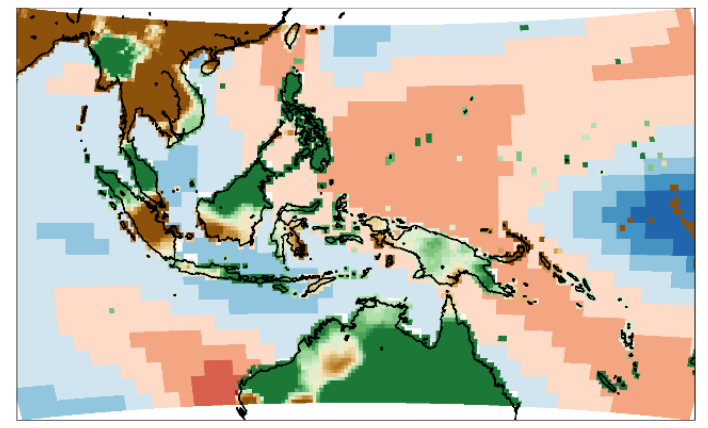

(b)

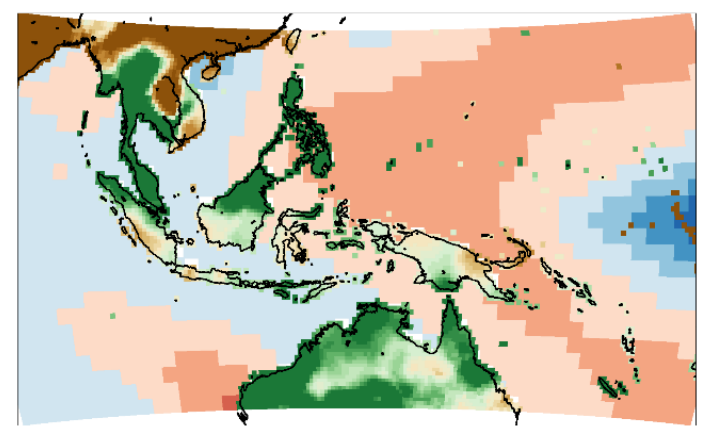

(c)
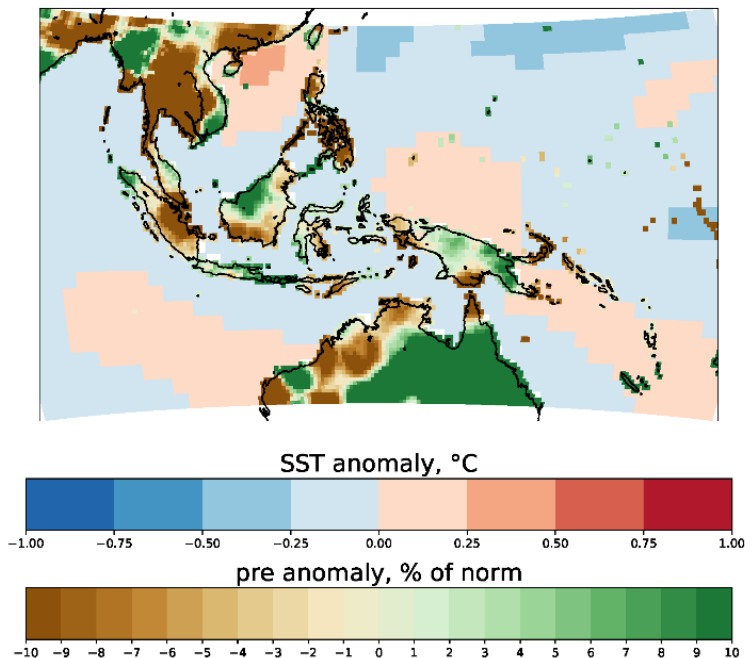

Figure 2.8. Difference between in-phase negative ENSO and typical ENSO events during DJF. Data from long-period dataset 1901-2018. Maps show seasonal precipitation anomalies expressed as a percentage of the seasonal mean (shown over land) and seasonal SST anomalies in ${ }^{\circ} \mathrm{C}$ (shown over the sea) calculated from the longperiod datasets for ENSO negative months (Nino $3.4<-0.75$ ) for (a) 
- DJF, negative PDO (PDO >1); (b) - DJF, neutral PDO; (c) difference (a) - (b);

(a)

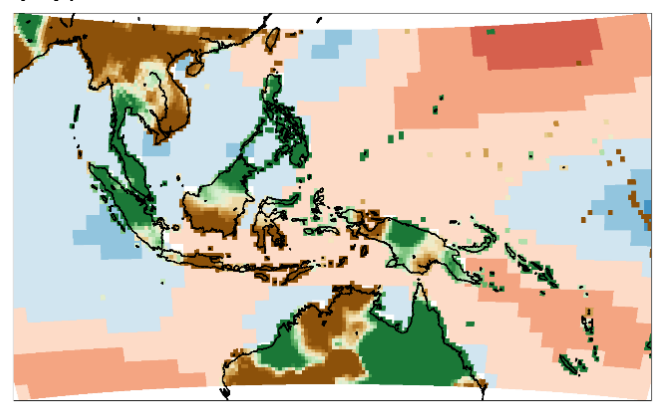

(b)

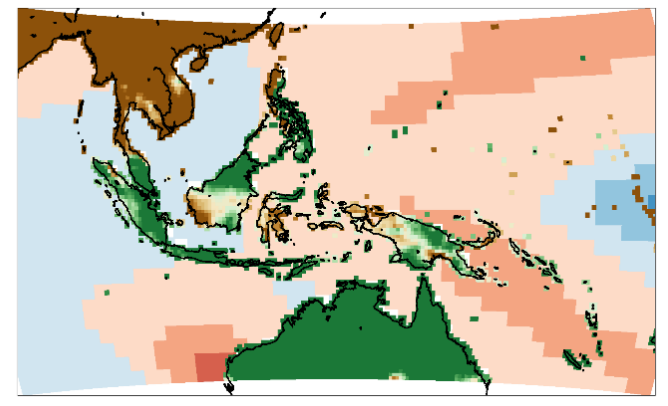

(c)
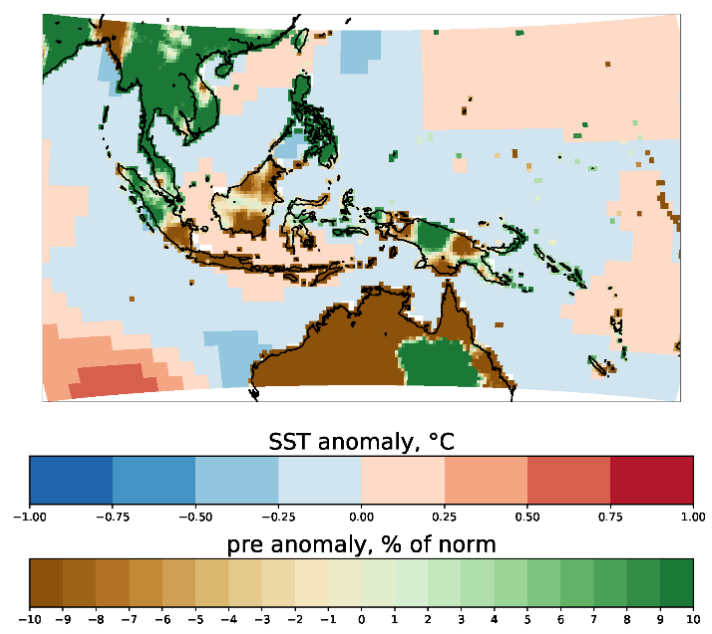

Figure 2.9. Difference between in-phase negative ENSO and typical ENSO events during MAM. Data from long-period dataset 1901-2018. Maps show seasonal precipitation anomalies expressed as a percentage of the seasonal mean (shown over land) and seasonal SST anomalies in ${ }^{\circ} \mathrm{C}$ (shown over the sea) calculated from the longperiod datasets for ENSO negative months (Nino $3.4<-0.75$ ) for (a) - MAM, negative PDO (PDO >1); (b) - MAM, neutral PDO; (c) difference $(a)-(b)$; 
Chapter 2

Table 2.3. Precipitation anomalies during ENSO-PDO in-phase events as a percentage of the seasonal mean. In brackets - the difference from typical ENSO events. * - the difference is not significant on $1 \%$ level according to the $t$-test

\begin{tabular}{|c|c|c|c|c|c|}
\hline & & JJA & SON & DJF & MAM \\
\hline \multirow{14}{*}{ 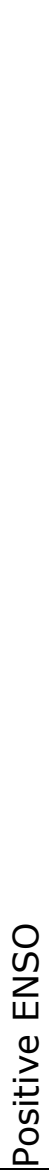 } & Brunei & $2.07(13.71)^{*}$ & $-6.94(3.25)^{*}$ & $\begin{array}{l} \\
25.84(2.09) *\end{array}$ & $\begin{array}{l}-18.31(- \\
4.29)^{*}\end{array}$ \\
\hline & Indonesia & $\begin{array}{l}-18.20(- \\
2.18)^{*}\end{array}$ & $-7.67(5.55)$ & $-3.03(-2.86)$ & $-1.58(1.61)$ \\
\hline & Malaysia & $-1.82(7.83)$ & $-3.17(-4.68)$ & $\begin{array}{l}-14.24(- \\
2.90) *\end{array}$ & $-15.77(-4.53)$ \\
\hline & Philippines & $-0.22(-2.93)$ & $-13.26(5.91)$ & - $17.31(12.16)$ & $\begin{array}{l}-38.43(- \\
16.12)\end{array}$ \\
\hline & $\begin{array}{l}\text { Papua New } \\
\text { Guinea }\end{array}$ & $\begin{array}{l}-8.23(- \\
0.66)^{*}\end{array}$ & $-2.71(12.40)$ & $1.28(0.89)^{*}$ & $-4.37(-1.49)^{*}$ \\
\hline & Timor-Leste & $37.53(48.61)$ & $1.46(12.70)$ & $-3.81(1.88)^{*}$ & $-0.02(2.48)^{*}$ \\
\hline & Whole MC & $\begin{array}{l}-12.44(- \\
0.56)^{*}\end{array}$ & $-6.96(5.58)$ & $\begin{array}{l}-5.20(- \\
0.60)^{*}\end{array}$ & $-7.69(-1.52)$ \\
\hline & $\mathrm{MC}, \mathrm{NH}$ only & $-2.34(4.36)$ & $-5.65(1.01)^{*}$ & $\begin{array}{l} \\
12.79(0.69) *\end{array}$ & $-18.66(-5.69)$ \\
\hline & MC, SH only & $\begin{array}{l}-18.53(- \\
3.53)\end{array}$ & $-7.75(8.33)$ & $-0.65(-1.37)$ & $-1.07(0.99)$ \\
\hline & $\begin{array}{l}\text { Australia( Lat > - } \\
25^{\circ} \text { ) }\end{array}$ & $\begin{array}{l}-30.17(- \\
17.59)\end{array}$ & $-6.10(11.51)$ & $-5.45(3.05)$ & $12.90(18.51)$ \\
\hline & Laos & $1.40(4.20)$ & $\begin{array}{l}-19.65(- \\
8.05)\end{array}$ & $23.79(24.36)$ & $\begin{array}{l}-22.31(- \\
20.18)\end{array}$ \\
\hline & Cambodia & $-3.66(-2.49)$ & $-8.49(2.58)$ & $22.61(32.34)$ & $\begin{array}{l}-17.51(- \\
13.30)\end{array}$ \\
\hline & Thailand & $-6.17(-3.53)$ & $\begin{array}{l} \\
11.37(1.01)^{*}\end{array}$ & $13.95(32.74)$ & $\begin{array}{l}-26.08(- \\
22.32)\end{array}$ \\
\hline & Vietnam & $\begin{array}{l}-1.40(- \\
0.04)^{*}\end{array}$ & $\begin{array}{l}-11.13(- \\
5.74)\end{array}$ & $3.56(-4.51)$ & $\begin{array}{l}-12.90(- \\
18.77)\end{array}$ \\
\hline & & JJA & SON & DJF & MAM \\
\hline \multirow{6}{*}{ 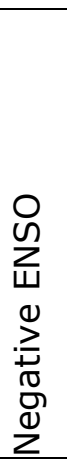 } & Brunei & $\begin{array}{l}13.91(- \\
0.35)^{*}\end{array}$ & $8.88(2.34)^{*}$ & $35.44(6.87)^{*}$ & $10.46(-5.91)^{*}$ \\
\hline & Indonesia & $13.37(5.62)$ & $15.88(5.36)$ & $0.97(-1.75)$ & $-0.59(-4.38)$ \\
\hline & Malaysia & $\begin{array}{l}10.63(- \\
2.61)^{*}\end{array}$ & $2.78(1.95)^{*}$ & $19.80(1.90)^{*}$ & $11.42(-1.79)^{*}$ \\
\hline & Philippines & $-0.23(5.41)$ & $13.15(0.85)^{*}$ & $20.45(-9.03)$ & $33.61(31.64)$ \\
\hline & $\begin{array}{l}\text { Papua New } \\
\text { Guinea }\end{array}$ & $11.29(12.32)$ & $9.10(1.81)^{*}$ & $0.58(0.45)^{*}$ & $3.27(-0.52)^{*}$ \\
\hline & Timor-Leste & $\begin{array}{l}-40.23(- \\
2.88)^{*}\end{array}$ & $\begin{array}{l}13.20(- \\
16.92)\end{array}$ & $-2.97(-5.18)$ & $\begin{array}{l}-23.39(- \\
39.57)\end{array}$ \\
\hline
\end{tabular}




\begin{tabular}{|c|c|c|c|c|}
\hline Whole MC & $10.89(5.68)$ & $13.05(3.78)$ & $5.15(-1.80)$ & $5.00(0.27)^{*}$ \\
\hline $\mathrm{MC}, \mathrm{NH}$ only & $8.28(2.58)$ & $6.05(0.63)^{*}$ & $\begin{array}{l}15.39(- \\
1.98)^{*}\end{array}$ & $15.64(8.92)$ \\
\hline MC, SH only & $12.46(7.54)$ & $17.26(5.67)$ & $-0.98(-1.69)$ & $-1.41(-4.94)$ \\
\hline $\begin{array}{l}\text { Australia (Lat }>- \\
25^{\circ} \text { ) }\end{array}$ & $13.84(10.87)$ & $41.93(28.59)$ & $26.62(16.70)$ & $19.86(-15.92)$ \\
\hline Laos & $19.80(19.19)$ & $6.32(6.90)$ & $\begin{array}{l}-18.42(- \\
20.58)\end{array}$ & $-4.51(11.48)$ \\
\hline Cambodia & $7.36(8.01)$ & $12.47(13.47)$ & $\begin{array}{l}-15.36(- \\
24.07)\end{array}$ & $-5.53(7.67)$ \\
\hline Thailand & $19.31(11.64)$ & $6.82(6.58)$ & $\begin{array}{l}-25.10(- \\
38.63)\end{array}$ & $3.80(20.97)$ \\
\hline Vietnam & $1.37(-0.47)^{*}$ & $2.69(2.69)$ & $-5.32(0.11)^{*}$ & $-13.35(11.34)$ \\
\hline
\end{tabular}

\subsubsection{High-Resolution Data}

For the recent period 1981-2018, we have access to high-resolution data of both SST and precipitation. However, this period contains only one incomplete PDO cycle. Both PDO and IPO indexes identify a phase change in 1998 (IPO) and 1999 (PDO), which allows us to perform the analysis presented in the previous section but with highresolution datasets. The number of days for each of the phase combinations is presented in Figure 2.10. The figure shows that the frequency of occurrence of each of the nine-ENSO/PDO phase combinations for $1981-2018$ is similar to that of the long period dataset.

By switching to a shorter period dataset, we are sacrificing the option to analyze the average of multiple PDO cycles, but we gain many spatial details. Results from high- resolution dataset generally confirm patterns from the long-period dataset for the seasons and phase combinations with a sufficient amount of data. During in-phase positive ENSO, SON and JJA (Figure 2.11, Figure 2.12) demonstrate the same general patterns as in the long-period dataset: SST is warmer during in-phase events, and dry anomalies are weaker, especially during SON. High-resolution data clearly shows the difference between the Southern and Northern hemispheres, and an equatorial line is visible in the precipitation anomalies (Figures 2.11$2.13 a, b)$. But the primary reaction to in-phase events is similar for both hemispheres (Figures 2.11-12c)

SST anomalies are stronger during in-phase negative events than typical ENSO negative events, which matches the result from the long-period dataset. Precipitation anomalies, however, often show large differences and even opposite signs compared to results from the long-period dataset. Due to the lower natural variability of SST, a small amount of data is enough to produce the same patterns 
observed in the long-period dataset. For precipitation, however, the natural variability is much higher, and 30-300 days of data is not enough to calculate the average.
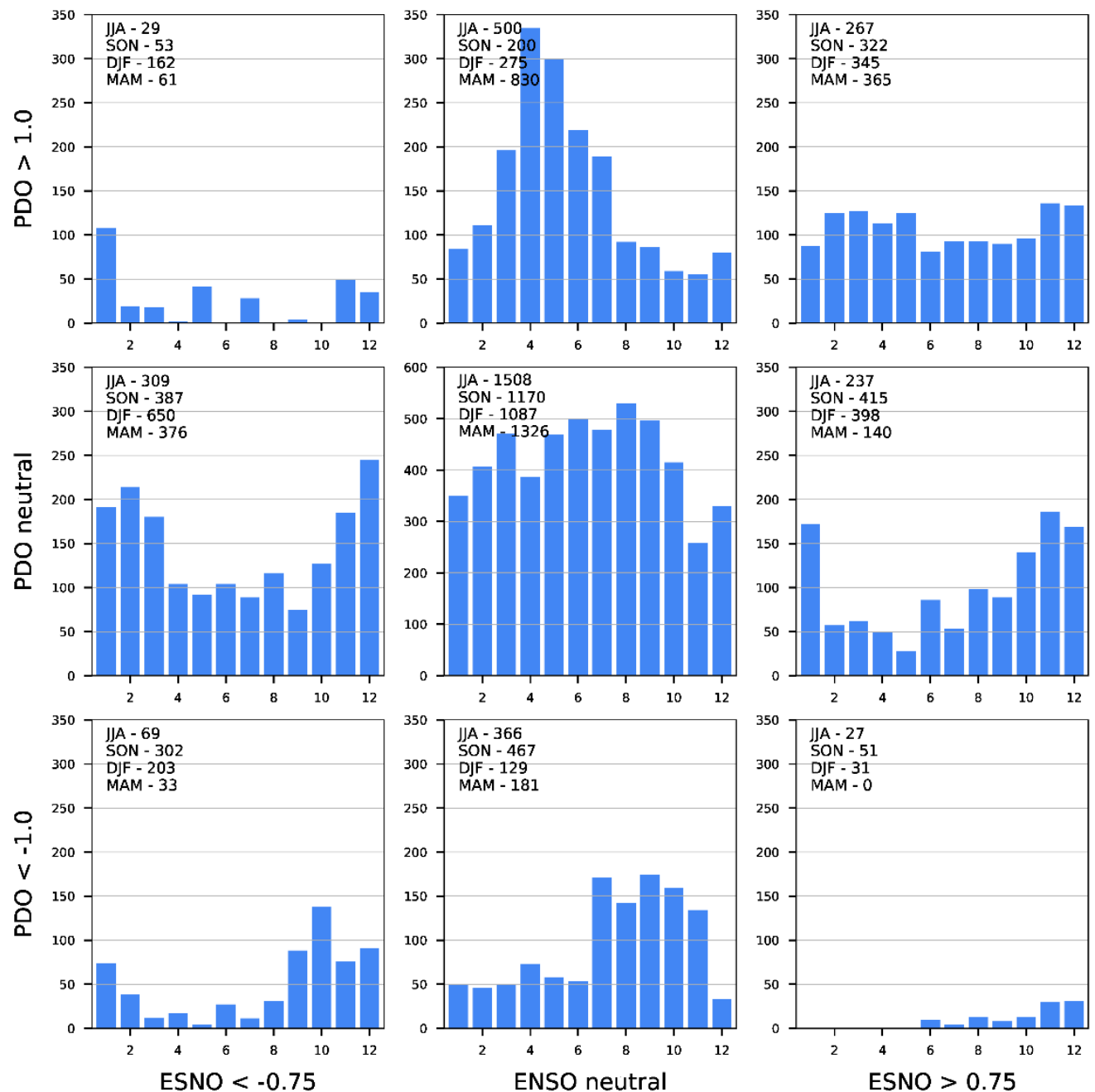

Figure 2.10. A number of days with a specific ENSO/PDO phase combination per month. 
(a)

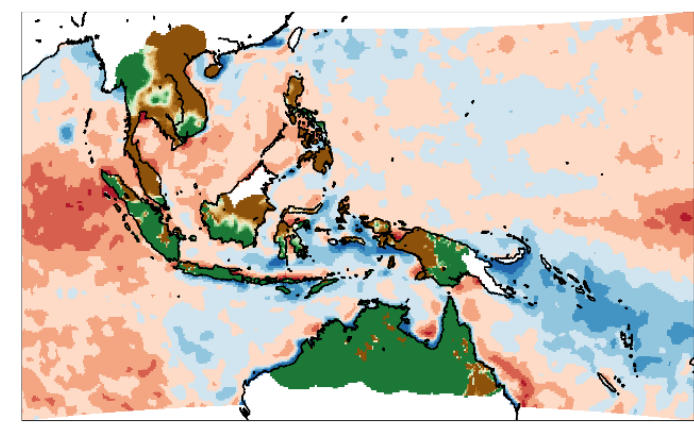

(b)

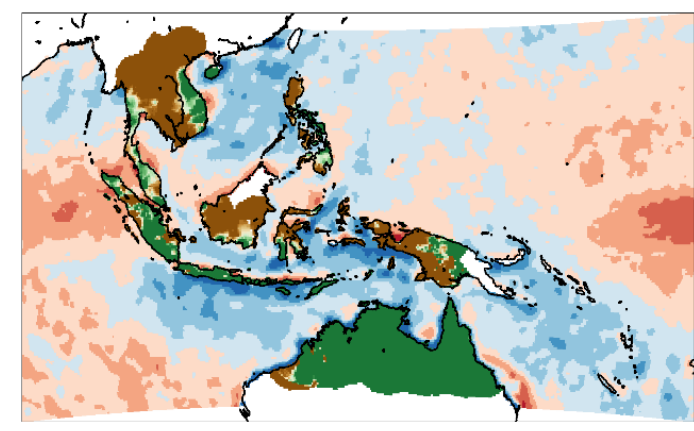

(c)

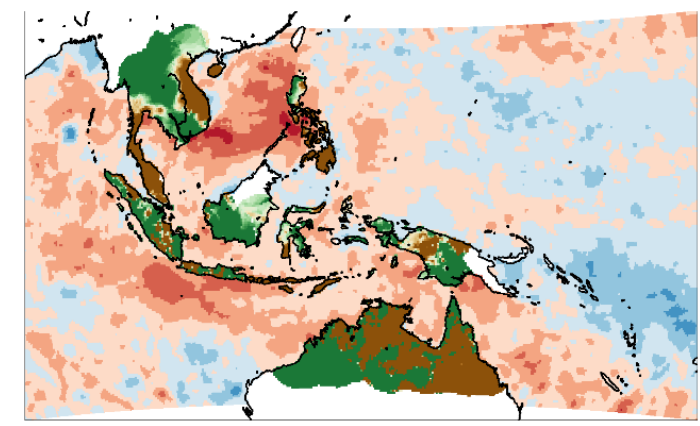

SST anomaly, ${ }^{\circ} \mathrm{C}$

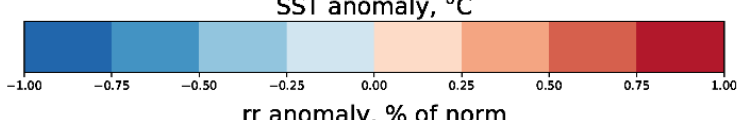

rr anomaly, \% of norm

Figure 2.11. Difference between in-phase positive ENSO and typical ENSO events during JJA. Data from high-resolution dataset 19812017. Maps show seasonal precipitation anomalies expressed as a percentage of the seasonal mean (shown over land) and seasonal SST anomalies in ${ }^{\circ} \mathrm{C}$ (shown over the sea) calculated from the longterm datasets for ENSO positive months (Nino $3.4>0.75$ ) for (a) $J J A$, positive PDO (PDO >1); (b) - JJA, neutral PDO; (c) difference (a) $-(b)$; 
(a)

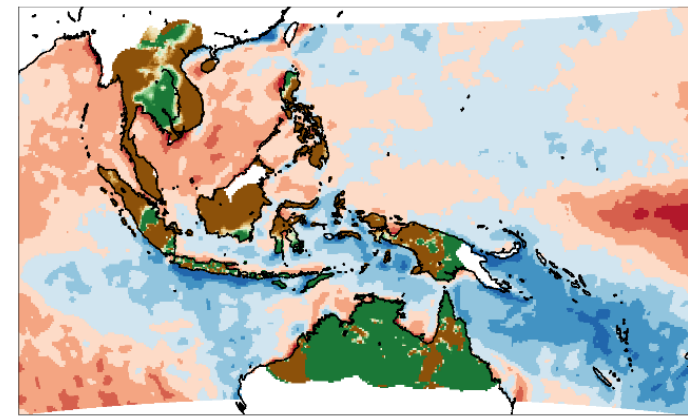

(b)

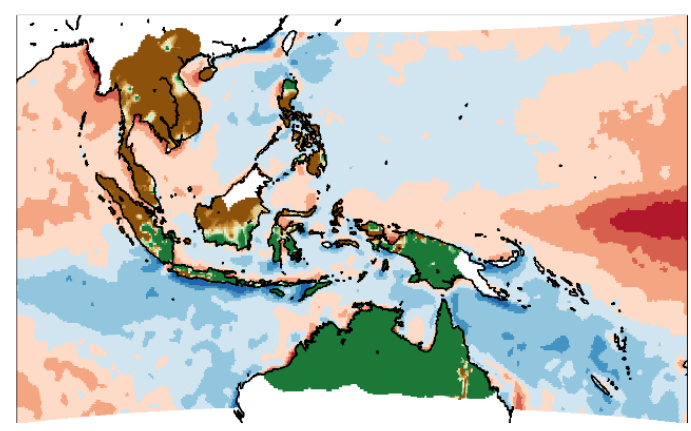

(c)

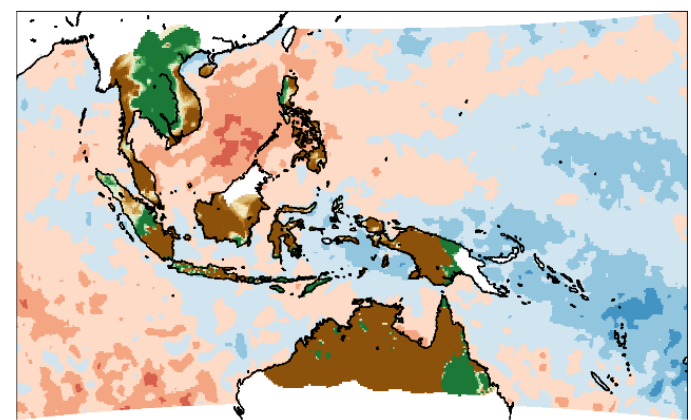

SST anomaly, ${ }^{\circ} \mathrm{C}$

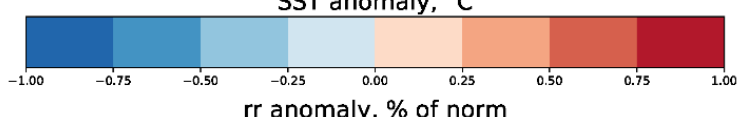

rr anomaly, $\%$ of norm

Figure 2.12. Difference between in-phase positive ENSO and typical ENSO events during SON. Data from high-resolution dataset 19812017. Maps show seasonal precipitation anomalies expressed as a percentage of the seasonal mean (shown over land) and seasonal SST anomalies in ${ }^{\circ} \mathrm{C}$ (shown over the sea) calculated from the longperiod datasets for ENSO positive months (Nino $3.4>0.75$ ) for (a) SON, positive PDO (PDO >1); (b) - SON, neutral PDO; (c) difference (a) - (b); 
(a)

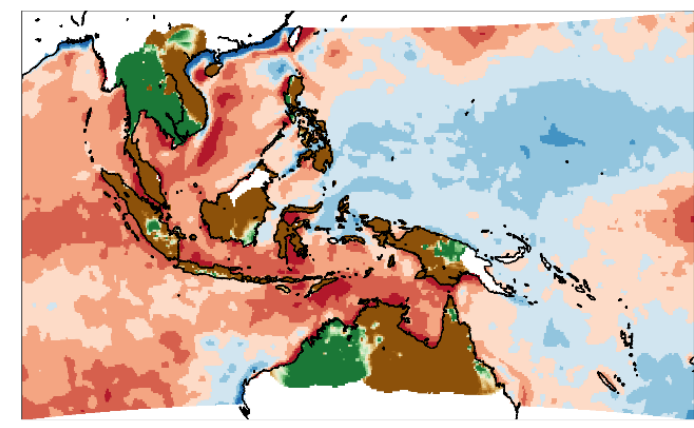

(b)

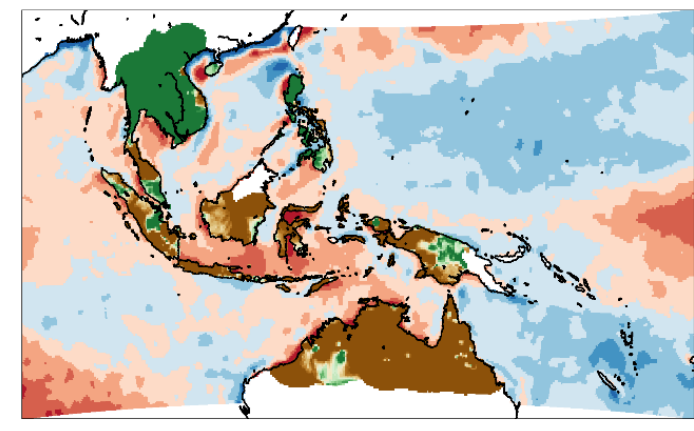

(c)

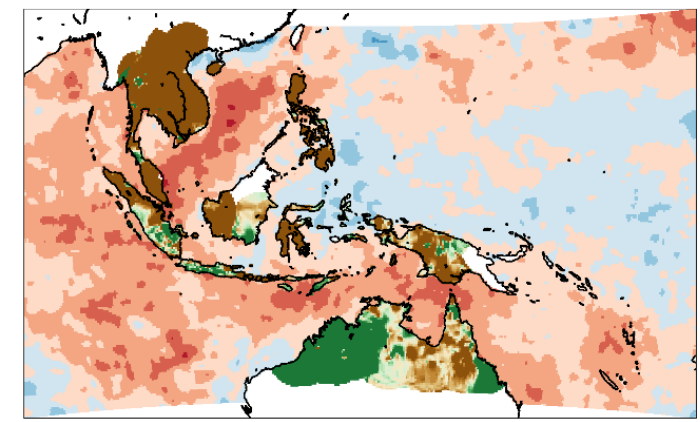

SST anomaly, ${ }^{\circ} \mathrm{C}$

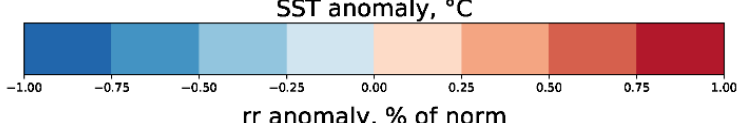

rr anomaly, $\%$ of norm

Figure 2.13. Difference between in-phase positive ENSO and typical ENSO events during DJF. Data from high-resolution dataset 19812017. Maps show seasonal precipitation anomalies expressed as a percentage of the seasonal mean (shown over land) and seasonal SST anomalies in ${ }^{\circ} \mathrm{C}$ (shown over the sea) calculated from the longperiod datasets for ENSO positive months (Nino $3.4>0.75$ ) for (a) $D J F$, positive PDO (PDO >1); (b) - DJF, neutral PDO; (c) difference (a) - (b); 
(a)

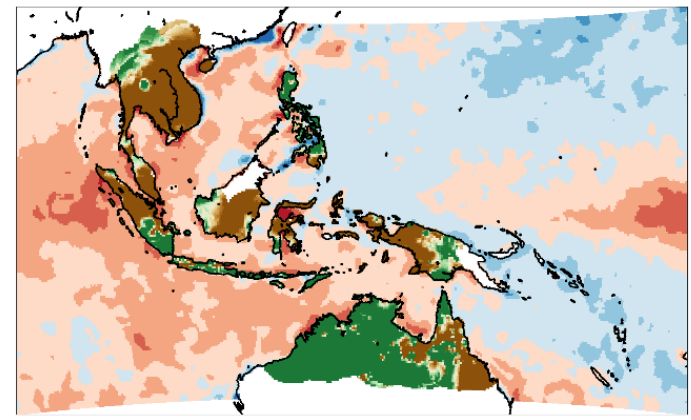

(b)

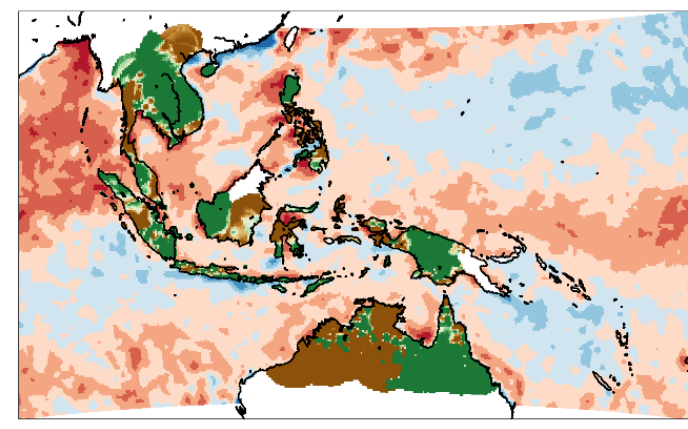

(c)

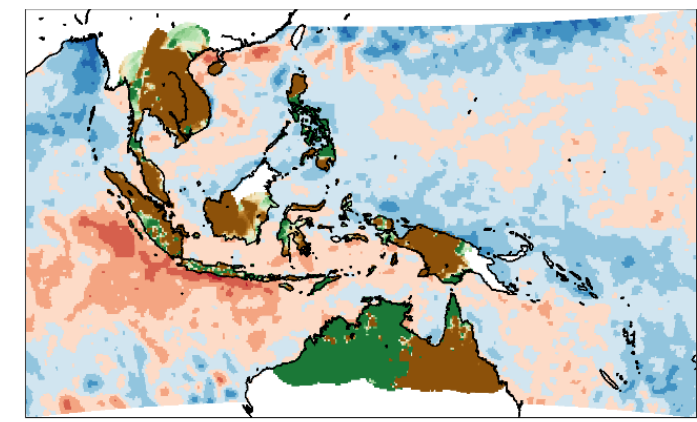

SST anomaly, ${ }^{\circ} \mathrm{C}$

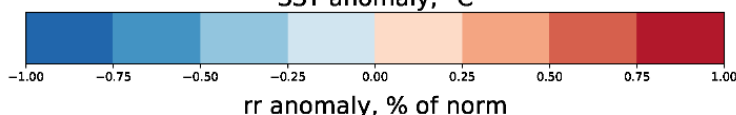

Figure 2.14. Difference between in-phase positive ENSO and typical ENSO events during MAM. Data from high-resolution dataset 19812017. Maps show seasonal precipitation anomalies expressed as a percentage of the seasonal mean (shown over land) and seasonal SST anomalies in ${ }^{\circ} \mathrm{C}$ (shown over the sea) calculated from the longperiod datasets for ENSO positive months (Nino $3.4>0.75)$ for (a) MAM, positive PDO (PDO >1); (b) - MAM, neutral PDO; (c) difference (a) - (b); 
(a)

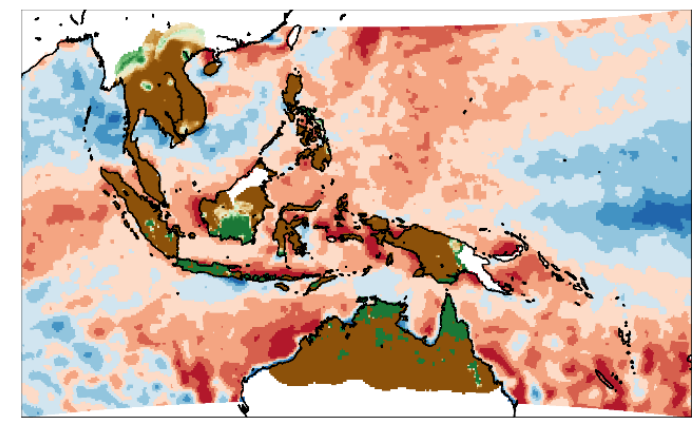

(b)

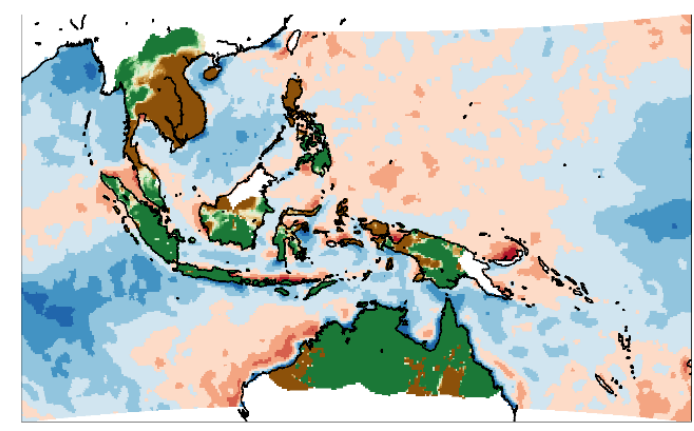

(c)

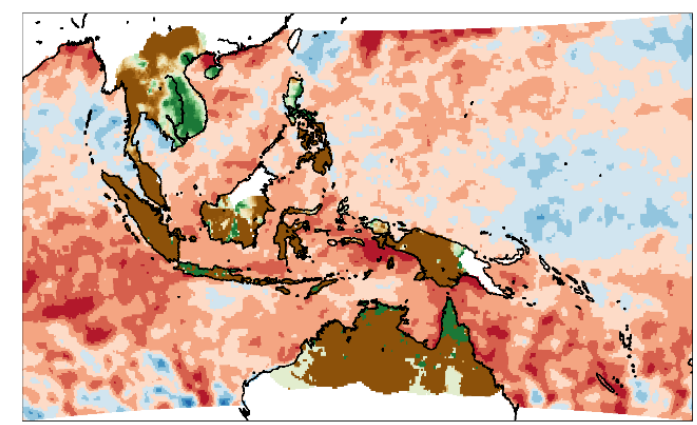

SST anomaly, ${ }^{\circ} \mathrm{C}$

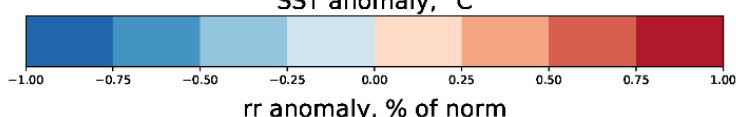

$\mathrm{rr}$ anomaly, $\%$ of norm

Figure 2.15. Difference between in-phase negative ENSO and typical ENSO events during JJA. Data from high-resolution dataset 19812017. Maps show seasonal precipitation anomalies expressed as a percentage of the seasonal mean (shown over land) and seasonal SST anomalies in ${ }^{\circ} \mathrm{C}$ (shown over the sea) calculated from the longperiod datasets for ENSO negative months (Nino $3.4<-0.75$ ) for (a) - JJA, negative PDO (PDO >1); (b) - JJA, neutral PDO; (c) difference (a) - (b); 
(a)

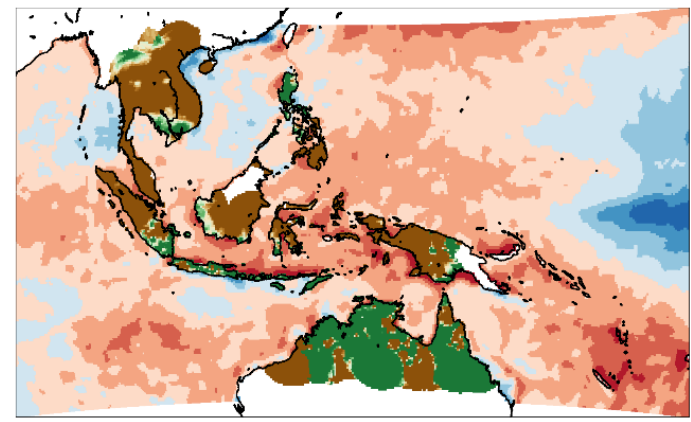

(b)

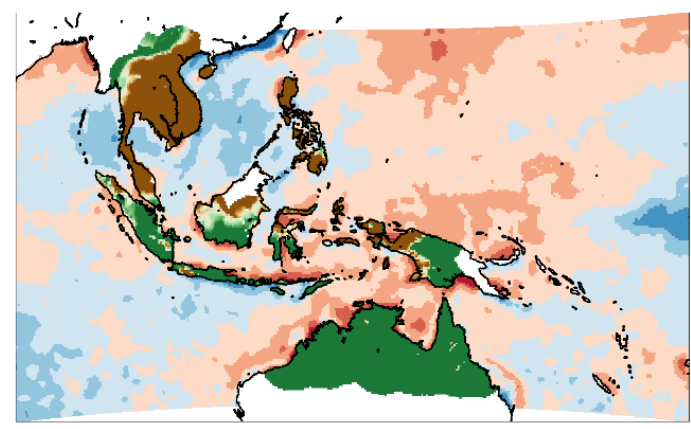

(c)

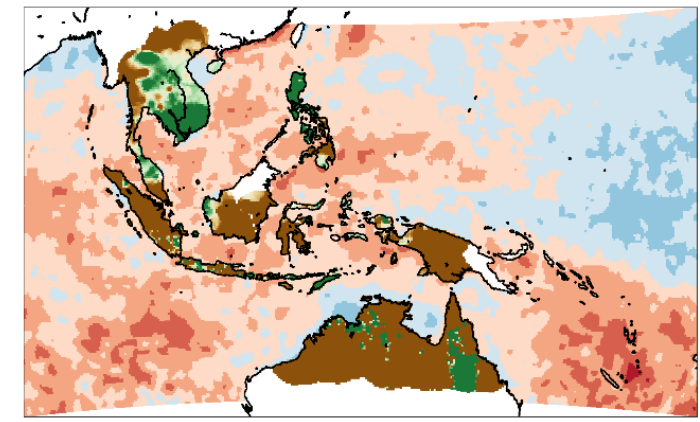

SST anomaly, ${ }^{\circ} \mathrm{C}$

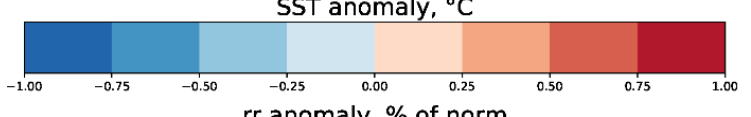

anomaly, $\%$ of norm

Figure 2.16. Difference between in-phase negative ENSO and typical ENSO events during SON. Data from high-resolution dataset 19812017. Maps show seasonal precipitation anomalies expressed as a percentage of the seasonal mean (shown over land) and seasonal SST anomalies in ${ }^{\circ} \mathrm{C}$ (shown over the sea) calculated from the longperiod datasets for ENSO negative months (Nino $3.4<-0.75$ ) for (a) - SON, negative PDO (PDO >1); (b) - SON, neutral PDO; (c) difference (a) - (b); 
(a)

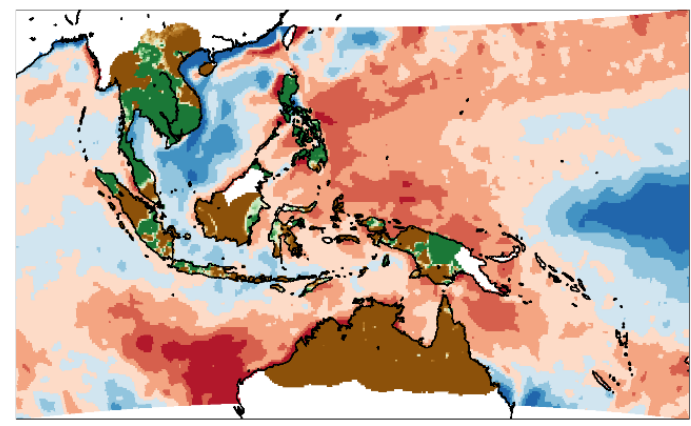

(b)

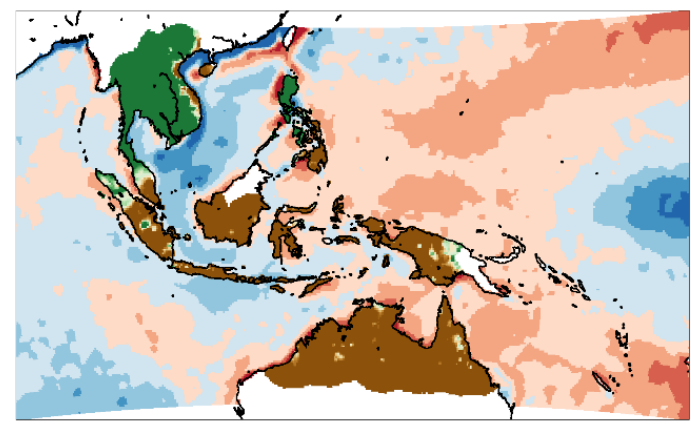

(c)
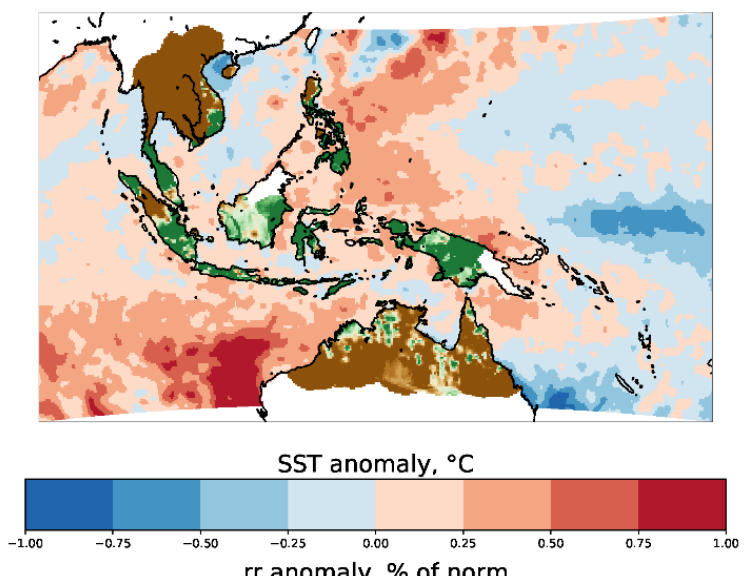

$\mathrm{rr}$ anomaly, $\%$ of norm

Figure 2.17. Difference between in-phase negative ENSO and typical ENSO events during DJF. Data from high-resolution dataset 19812017. Maps show seasonal precipitation anomalies expressed as a percentage of the seasonal mean (shown over land) and seasonal SST anomalies in ${ }^{\circ} \mathrm{C}$ (shown over the sea) calculated from the longperiod datasets for ENSO negative months (Nino $3.4<-0.75$ ) for (a) - DJF, negative PDO (PDO >1); (b) - DJF, neutral PDO; (c) difference (a) - (b); 
(a)

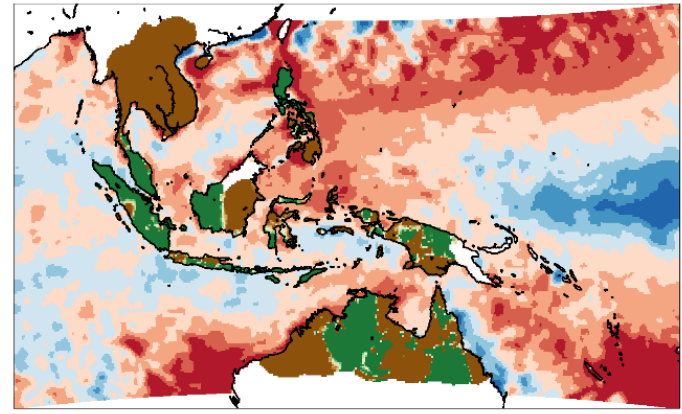

(b)

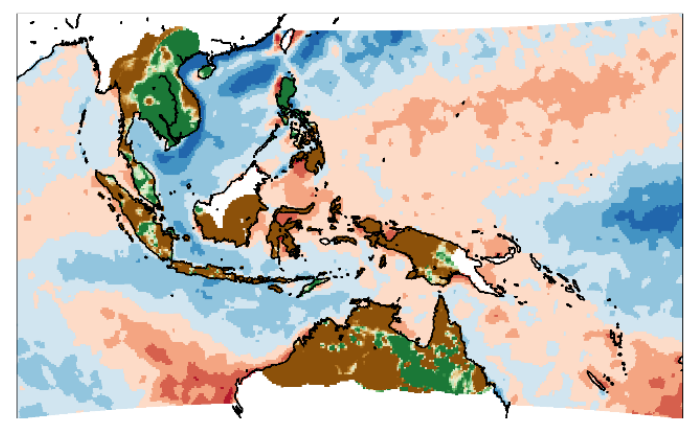

(c)
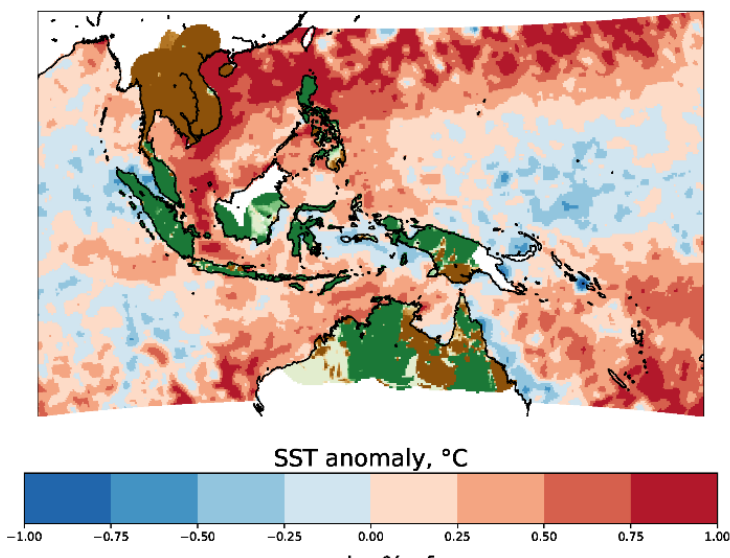

rr anomaly, \% of norm

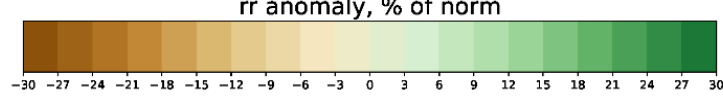

Figure 2.18. Difference between in-phase negative ENSO and typical ENSO events during MAM. Data from high-resolution dataset 19812017. Maps show seasonal precipitation anomalies expressed as a percentage of the seasonal mean (shown over land) and seasonal SST anomalies in ${ }^{\circ} \mathrm{C}$ (shown over the sea) calculated from the longperiod datasets for ENSO negative months (Nino $3.4<-0.75$ ) for (a) - MAM, negative PDO (PDO >1); (b) - MAM, neutral PDO; (c) difference $(a)-(b)$; 


\subsection{Discussion}

This study contributes to a growing amount of evidence demonstrating the impact of PDO/ENSO interactions on the global climate by filling in details for the Maritime Continent. The PDO cycle appears to impact the rate of global near-surface temperature increase through changes in ocean heat uptake and vertical redistribution of ocean heat content (Drijfhout, 2018). The influence of the PDO helps to explain the so-called global warming hiatus (Trenberth and Fasullo, 2013). Warm PDO phases from 1925 to 1947 and 1976 to 1998 correspond to periods with a rapid increase in global temperature, while cold PDO phases correspond to periods with relatively stable global temperatures (Figure 2.19).

The impact of the PDO cycle on global climate and the precipitation regime in the Maritime Continent has important implications for climate predictions on a 20- to 30-year timescale. Based on an expected PDO cycle length of 20-30 years, we can expect the next phase to change from negative to positive between 2020 and 2030. The current data (Figure 2.19b) suggest that this change might already have happened, but we need more data to confirm this. The new regime, associated with the positive PDO phase, will increase the frequency of in-phase positive events and reduce the frequency of inphase negative events. In recent history, long-lasting in-phase positive conditions were observed in 1987, 1997, and 2016 (Figure 2.19) - three years associated with strong precipitation and temperature anomalies, both positive and negative, as well as dramatic economic impacts from floods and droughts.

A previous study of the influence of PDO-ENSO modulation on global wet-dry anomalies suggests that on a global scale, in-phase events intensify typical wet-dry anomalies associated with ENSO (Wang et al., 2014a). However, our study demonstrates that precipitation on the scale of the Maritime Continent does not always follow this simple pattern. The analysis of long-period datasets reveals that impacts of in-phase events on precipitation and SST anomalies in the Maritime Continent often lead to the weakening of precipitation anomalies in contrast to the global pattern. Analysis of a high-resolution dataset exposes the spatial and seasonal complexity of the impacts of the inphase event. While some patterns are present in both the long-period and the high-resolution dataset, as well as in thhapter of this thesis, a lot of regional details are different. The high spatial resolution dataset uses daily observations to delineate different phase combinations more precisely, making differences between different phase combinations more noticeable. Unfortunately, the temporal coverage of the data available in high resolution is not sufficient. It is difficult to conclude which different details are related to the higher 
quality of the dataset and which are just statistical anomalies caused by insufficient temporal coverage.

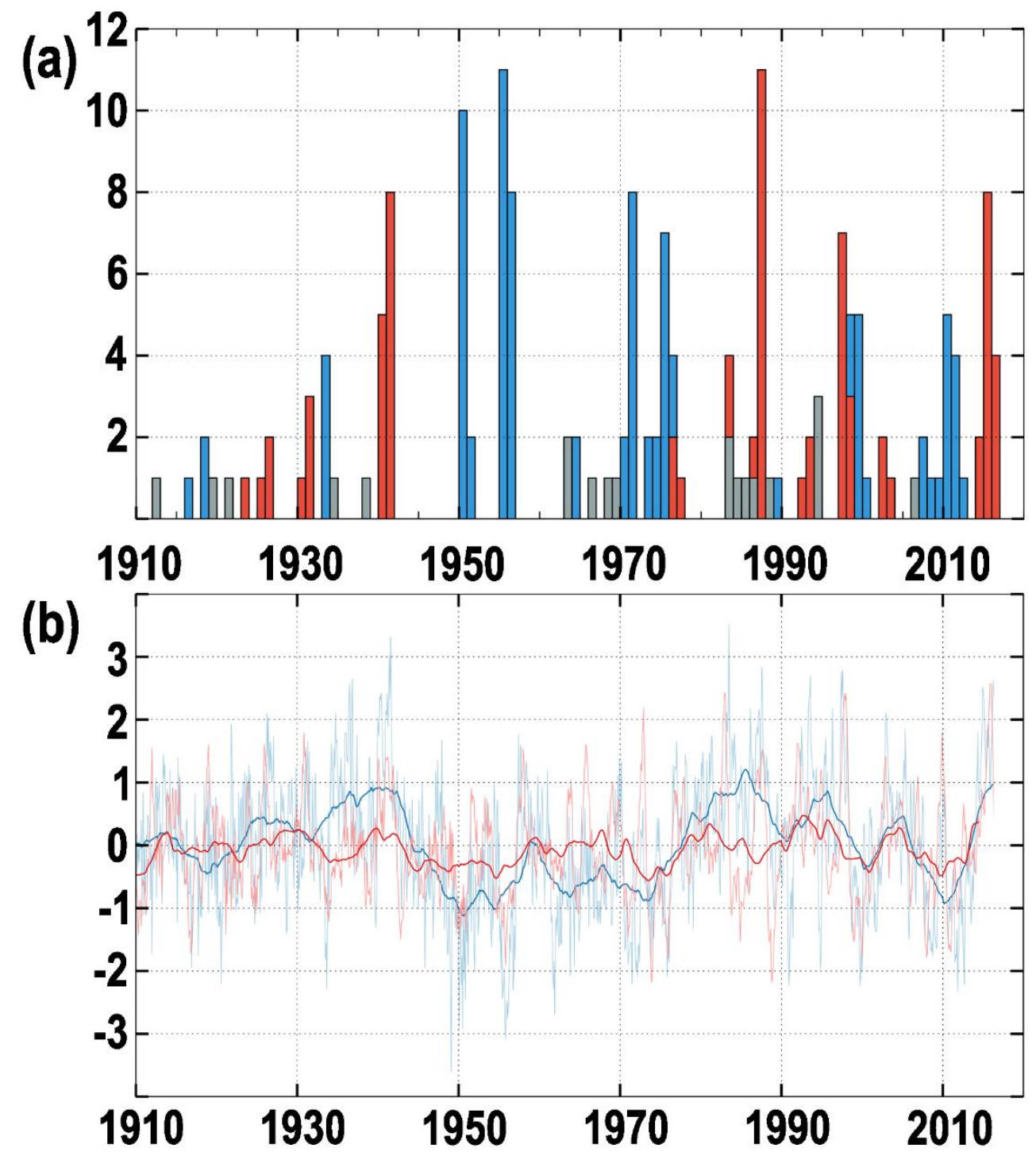

Figure 2.19. (a) - number of months classified as in-phase positive (Nino $3.4>0.75$ and PDO $>1$ ) in red, in-phase negative ( $E$ Nino 3.4 $<-0.75$ and $P D O<-1$ ) in blue, counterphase ((Nino $3.4>0.75$ and $P D O<-1$ ) or (Nino $3.4<-0.75$ and PDO > 1)) in grey; $(b)-P D O$ historical monthly data in blue, ENSO historical data in red, bold lines represent 5 years running mean 


\subsection{Conclusions}

We have shown that the PDO phase significantly impacts ENSOrelated precipitation and SST anomalies in the Maritime Continent in 1901-2018. In-phase ENSO/PDO events produce a distinct pattern of precipitation anomalies compared to typical ENSO events. In contrast to global patterns presented by (Wang et al., 2014a), in-phase positive ENSO events weaken dry anomalies in the Maritime Continent. Conversely, in-phase negative ENSO demonstrates stronger wet anomalies compared to typical ENSO, which agrees with global patterns.

In most Maritime Continent, both positive and negative in-phase events produce wetter conditions in JJA and SON than typical ENSO/PDO-neutral events. However, during DJF, both in-phase positive and negative events produce small or statistically insignificant precipitation anomalies throughout the Maritime Continent except in the Philippines.

The SST is $0.25-0.75{ }^{\circ} \mathrm{C}$ warmer during in-phase positive events, while in-phase negative has a $\pm 0.25^{\circ} \mathrm{C}$ difference with typical ENSO events.

High-resolution data reveal the full extent of spatial and season complexity of the ENSO-PDO modulation effect. The sharp contrast in precipitation anomalies around the equator is visible in Figures 2.112.15, but the differences between in-phase and typical events are usually more spatially coherent. High-resolution SST data show a complex pattern of local bathymetry and ocean currents that can help explain some of the regional differences in precipitation.

The analyzed in-phase negative events mainly occur during cold PDO phases, and the in-phase positive events occur exclusively during warm PDO phases. The domination of in-phase positive events during warm PDO phases produces a precipitation regime significantly different from that observed during the PDO cold phase. We observe more precipitation during both in-phase positive and negative events, leading to weaker dry anomalies and stronger wet anomalies. Increase in precipitation leads to stronger anomalies during the negative PDO phase since both ENSO positive and negative anomalies are stronger than the in-phase positive ENSO. This effect is consistent with the results presented in the next chapter. We demonstrate evidence of a shift around 1976 to fewer dry days in the Maritime Continent after the PDO phase changing from negative to positive. Although this is a very general pattern and for some regions, our results demonstrate different behavior, we conclude that overall, the regional results for different seasons and nine ENSO/PDO phase combinations are robust. 
The source code used to produce the results and additional materials not included in this publication is available on GitHub

(https://github.com/kokorev/ENSO-PDO modulation). 


\title{
3. PDO Associated Precipitation Regime Shift in the Maritime Continent ${ }^{2}$
}

\begin{abstract}
Recent changes in precipitation regime in South-East Asia is a subject of ongoing discussion. In this chapter, for the first time, evidence of a precipitation regime shift during the mid-1970s in the Northern Hemispheric part of South-East Asia is demonstrated. The detection of regime shifts is made possible by using a new comprehensive dataset of daily precipitation records (South-East Asian Climate Assessment and Dataset) and applying a novel Bayesian approach for regime shift detection. After the detected regime shift event in the mid-1970s, significant changes in precipitation distribution occurred in the Northern Hemispheric regions - Indochina Peninsula and the Philippines. More specifically, dry days became up to $10 \%$ more frequent in some regions. However, no precipitation regime shift is detected in Southern Hemisphere regions - Java and Northern Australia, were the number of observed dry days increased gradually.
\end{abstract}

\subsection{Introduction.}

Precipitation extremes are changing worldwide (Bulygina et al., 2007, Groisman et al., 2012, O'Gorman, 2012), leading to increased drought frequencies. One of the affected regions is the Maritime Continent, the part of South East Asia consisting of several archipelagos, including Indonesia, the Philippines, and Malaysia. South East Asia is highly vulnerable to climate change effects (Hijioka et al., 2014). The air temperature changes in the Maritime Continent are well understood; in recent decades, the number of cool days and cool nights has decreased, while hot days and hot nights increased. Both daily maximum and minimum temperatures have increased significantly, with minimum temperatures increasing almost twice as fast (Supari et al., 2017, Marjuki et al., 2016).

In contrast, precipitation changes are much less understood. The existing studies fail to identify statistically significant trends in the

\footnotetext{
2 this chapter has been published as - KOKOREV, V., ETTEMA, J., SIEGMUND, P. \& VAN DER SCHRIER, G. 2020. Precipitation Regime Shift Associated With The Pacific Decadal Oscillation In The Maritime Continent. American Journal of Climate Change, 9.
} 
onset of the wet season or the length of dry spells (Marjuki et al., 2016), or in precipitation extremes (Klein Tank et al., 2006), or found precipitation trends to be not significant and spatially coherent (Supari et al., 2017). The IPCC Fifth Assessment report shows that in South-East Asia, both the number and the quality of observations are insufficient for estimating current precipitation trends (Hijioka et al., 2014). That same report states that precipitation trends are highly variable, and both positive and negative trends have been observed. High variability and a lack of data mask trends and changes in distribution parameters, as well as large-scale regime shifts. One of the main factors governing precipitation in South East Asia is the sea surface temperature (SST) (Hendon, 2003). Studying SST variability and trends can provide valuable insight into changes in precipitation regimes. Long-period oceanic oscillations such as El Niño/Southern Oscillation (ENSO), Pacific Decadal Oscillation (PDO), and Indian Ocean Dipole (IOD) have a significant effect on local SST (Kusuma et al., 2017) and, therefore, contribute to the high variability of precipitation in the Maritime Continent. Changes in SST in the Maritime Continent are well established in the satellite era but have high uncertainty in the period before. In recent decades positive SST trends were observed. Since 1950 the Indian ocean has warmed by $0.65^{\circ} \mathrm{C}$, and the Pacific by $0.31^{\circ} \mathrm{C}$ (Hoegh-Guldberg et al., 2014). The PDO index shows 20-30 years cycles in SST in the Pacific, with rapid changes in SST during phase changes. There is an overwhelming amount of literature documenting environmental impact of PDO phase change (Mantua and Hare, 2002, Newman et al., 2016, Hare and Mantua, 2000). The best-known Pacific decadal oscillation phase change occurred in 1976, when a warm phase followed a cold phase causing an SST increase of about $0.5^{\circ} \mathrm{C}$. Since SST is a main driver of the precipitation regime in the Maritime Continent, a significant change in SST should lead to a measurable shift in precipitation. Such a shift is described by (Yang and Fu, 2017), who observed the precipitation regime shift in China and USA around 1978 caused by PDO phase change. Our recent article suggests a mechanism of PDO-ENSO interactions causing precipitation regime shift in the Maritime Continent, but a quantitative evidence of observing such regime shift is lacking (Kokorev et al., 2020).

Here we focus on identifying and quantifying recent precipitation regime shifts and changes in the precipitation distribution in South East Asia. We apply a Bayesian approach to detect precipitation regime shifts, uncover changes in distribution parameters even if the mean is stationary. The proposed method provides uncertainty estimates for each detected regime shift event. The goal of this study is to apply Bayesian regime shift detection to state-of-the-art 
precipitation datasets, and thereby bring about an improved understanding of recent changes in South East Asian precipitation regimes. Knowing regime shift points allows us to better estimate recent trends in precipitation and improves our understanding of modern climate changes in the Maritime Continent.

\subsection{Method}

This study uses a Bayesian approach for detecting precipitation regime shifts, which was adopted from (Ó Ruanaidh and Fitzgerald, 1996). A similar approach has been used in several studies (Ruggieri, 2013, Western and Kleykamp, 2017, Chu and Zhao, 2004). Simple example of the Python realization of this approach can be found in (Davidson-Pilon, 2015), the realization used in this study is available at http://github.com/kokorev/prs. To the best of our knowledge this is the first study in which this method is adopted for precipitation regime shift detection.

To adopt the method for regime shift detection a distribution that describes daily precipitation data should be chosen. Few distributions commonly used for this purpose, for example Weibull and Pearson Type 3. In this study, a modified version of the Gamma distribution, known as the Zero Inflated Gamma distribution, is used to describe observed daily precipitation data. This choice is motivated by ease of interpretation of the results due to having percent of zero precipitation days as an explicit parameter. The Zero Inflated Gamma distribution adds the probability of zero as an additional parameter, so the resulting distribution has three parameters - a shape parameter $\boldsymbol{\alpha}$, a rate or inverse scale parameter $\boldsymbol{\beta}$, and a probability of zero rainfall $\boldsymbol{\pi}$. Therefore, daily rainfall $\mathbf{R}$ is expressed as:

$R \sim \gamma(\alpha, \beta, \pi) \quad[1]$

After a regime shift at time $\boldsymbol{\tau}$, at least one distribution parameter has changed significantly. Therefore, there is one set of parameters up to time $\boldsymbol{\tau}$ and another set of parameters thereafter [2].

$\alpha, \beta, \pi= \begin{cases}\alpha_{1}, \beta_{1}, \pi_{1} & \text { if } t<\tau, \\ \alpha_{2}, \beta_{2}, \pi_{2} & \text { if } t \geq \tau\end{cases}$

This Bayesian model has seven unknown parameters for which prior formulas (Equations 3-6) are defined. Prior values describe the situation in which there is no regime shift, and in which the distributions before and after the regime shift are equal: $\gamma\left(\alpha_{1}, \beta_{1}, \pi_{1}\right)=$ $\gamma\left(\alpha_{2}, \beta_{2}, \pi_{2}\right)$. The priors for $\alpha$ and $\beta$ follow the normal distributions defined by mean value $\mu$ and standard deviation $\sigma$ (Equations 3-4). $\alpha_{1}=\alpha_{2}=\operatorname{Normal}(\mu=1, \sigma=1.5)$

$\beta_{1}=\beta_{2}=\operatorname{Normal}(\mu=0.1, \sigma=0.5)$

The values of $\mu$ and $\sigma$ in equations were selected based on the mean values from observational data. 
The prior probability of zero rainfall $\pi$ is uniformly distributed from zero to one (Equation 5 ).

$\pi_{1}=\pi_{2}=$ Uniform $(\min =0, \max =1)$ [5]

Finally, the prior for regime shift is defined as uniform distribution between all timesteps, except for the first and final five years (Eq. 6).

Excluding first and last few years from possibly having a regime shift is necessary to make sure that there is enough data for regime shift detection in the period before and after the shift. According to Beaulieu et al. (2012), at least four year data are needed to detect regime shifts with a magnitude of one standard deviation. In this study we increase this minimal necessary period to 5 years to improve the robustness of regime shift detection.

$T=$ Uniform $\left(t \_0+365 * 5, t \_n-365 * 5\right) \quad$ [6]

This approach can provide a robust quantification of a regime shift and the uncertainty of its position as well as that of the distribution parameters before and after the regime shift.

\subsection{Data}

Lack of data is one of the main obstacles in understanding historical precipitation changes in South-East Asia. This study uses the SouthEast Asian Climate Assessment \& Dataset (SACA\&D, http://sacad.database.bmkg.go.id, Marjuki et al. 2016). SACA\&D is a state-of-the-art database covering Southeast Asia, specifically the ASEAN countries (Association of Southeast Asian Nations) and a part of WMO region $\mathrm{V}$. The database is specifically designed for climate monitoring and puts particular emphasis on changes in extremes. The daily data is acquired through cooperation with regional National Meteorological Services. At the time of writing (April 2019), SACA\&D receives data from 23 participants in 15 countries and the SACA dataset contains a total of 5926 series of observations. These series are obtained from 4066 meteorological stations. To our knowledge, this is the most comprehensive archive of observed daily precipitation data currently available for this region. In this study, we use only precipitation data; however, also other parameters are available in the dataset. Precipitation and temperatures have the most comprehensive spatial and temporal coverage, but relative humidity, sunshine duration and wind parameters are also available.

The data used in this study have passed series of quality checks including sanity tests, homogeneity tests, consistency tests, and outlier tests. The test specifics are described in the Algorithm Theoretical Basis Document (ECA\&D Team 2013) and only the data that passed all tests are used in this study. Long climatological observation records are often inhomogeneous as a result of station relocation, changes in methodology or changes in instrumentation. Within SACA\&D, series homogeneity is classified using the methods 
suggested by (Wijngaard et al., 2003). The procedure applies four tests: the Standard Normal Homogeneity Test (Alexandersson, 1986), the Buishand Range test (Buishand, 1982), the Pettitt test (Pettitt, 1979) and the Von Neumann Ratio test (von Neumann, 1941). Precipitation series are tested using the annual wet day count (using a threshold of $1 \mathrm{~mm}$ ). If the null-hypothesis of no break in the series is rejected by none or just one test, the series is classified as "useful"; if two tests reject the null-hypothesis, the series is classified as "doubtful" and if three or four tests reject the null-hypothesis, the label of "suspect" is given to the series (Marjuki et al. 2016).

Despite the high number of observations, insufficient coverage remains a critical problem for many regions due to the highly unequal spatial distributions of stations. For example, more than half of the stations (2885) are in Indonesia, of which the majority are located on the island of Java. Northern Australia accounts for another 1043 stations. Other countries have a much lower density of stations; for example, the Philippines has 37 stations followed by Thailand (30), Micronesia (28), Vietnam (15). The remaining nine stations are distributed between Papua New Guinea, Fiji, Samoa, the Solomon Islands, Kiribati, and Singapore.

Such an uneven spatial distribution does not allow statistics to be reliably calculated for the whole dataset, as the regions with higher number of stations would be disproportionally represented.

The durations of the available data series also vary significantly from region to region. Typically, 30 years is considered a minimal period for calculating climate reliable statistics (WMO, 2017). Even longer series are preferable for our study as we estimate climate parameters both before and after the regime shift. Therefore, in this study, we have only considered stations that have observational periods of at least 50 years. Figure 3.1 shows the length of the available data series per station, with each station represented by a Voronoi polygon cropped to a $100-\mathrm{km}$ radius around the station. Green indicate stations for which there are at least 50 years of data, while yellow and red indicate stations with insufficient data for this study. Four regions satisfy the data requirement for this study and were selected for detailed analysis, namely the Indochina peninsula, the Philippines, the island of Java, and Northern Australia. The regions selected for analyses are shown in Figure 3.1.

Some of the long-period stations remain outside the selected regions and have not been analyzed. Analyzing separate stations could introduce random bias into the results, due to the high variability of the data. Having a spatially dense observation network reduces random errors by spatially averaging the results. For this reason, long-period stations in South Sumatra, Malaysia and Papua were not included in the analysis. 


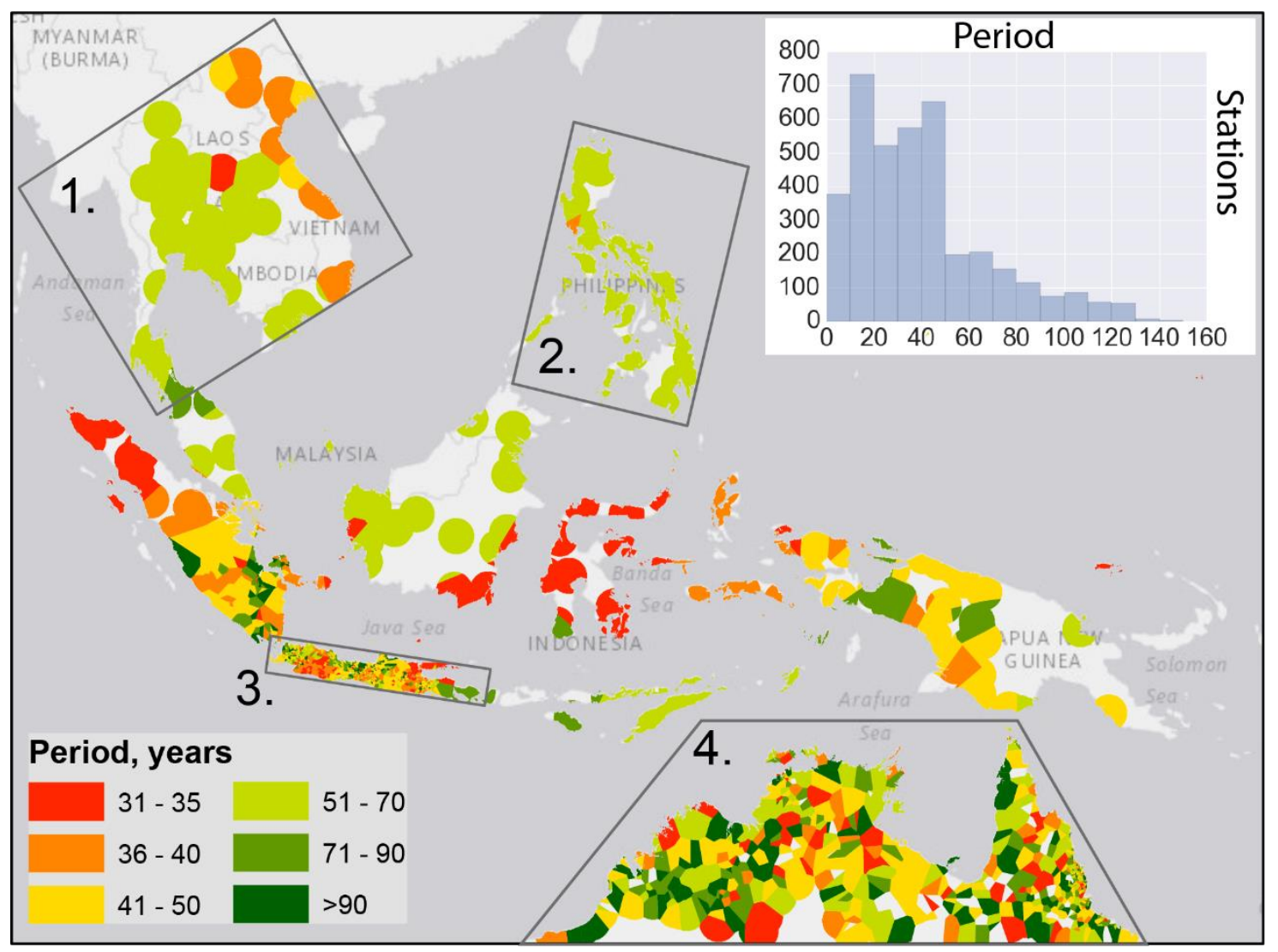

Figure 3.1. Map showing the duration of available time series at the closest weather station for stations $<50 \mathrm{~km}$ away. Stations with less than 30 years of data are not shown on the map. The inset histogram shows the distribution of stations by number of years with observations. The four areas with sufficient data density and duration are shown with dark grey boxes. 1 - Indochina, 2 - Philippines, 3 Java, 4 - North Australia

\subsection{Results}

\subsubsection{Indochina}

The results from the Bayesian model show that Indochina is a region characterized by a clear and coherent precipitation regime shift. Most stations experienced a regime shift in 1974, with some outliers shifting the region mean to 1975 . Below this is described in more detail.

Figure 3.2 shows the timing of the regime shift at individual stations. In Figure 3.2a the abscissa shows the regime shift date as an 
absolute anomaly, in years, from the regional mean regime shift date; the ordinate shows the standard deviation of the regime shift date $\sigma(\tau)$ in years. The $\sigma(\tau)$ characterizes the confidence in the regime shift position. The figure shows that stations that have a regime shift date further from the regional mean have higher uncertainty in regime shift position. The darker the background color, the less chance there is of a station having its regime shift simultaneously with the regional mean. For stations within two standard deviations (white or light grey), there is a significant chance that the actual regime shift occurred simultaneously with the regional mean. For the Indochina region, Figure 3.2a shows that the uncertainty increases with increasing anomaly, and that almost all stations lie within two standard deviations of the mean regime shift date. There is a significant probability that the regime shift at those stations occurred at the same time as for most of the region. We confidently conclude that the regime shift in Indochina was observed around 1975.
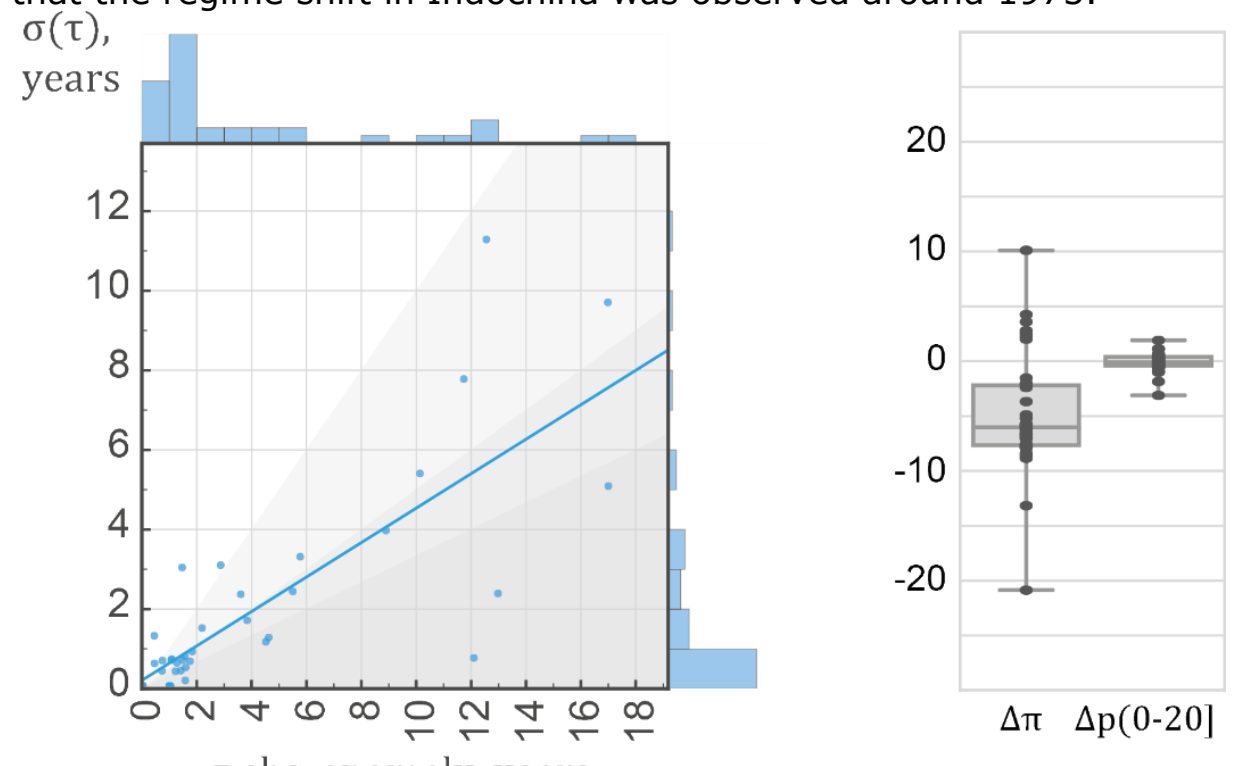

A.

$\tau$ abs. anomaly, years

B.

Figure 3.2. Precipitation regime shift in Indochina. A - Date (absolute anomaly from regional mean) of regime shift versus standard deviation per station $B$ - Changes in probability of no rainfall $(\Delta \pi)$ and probability of rainfall with intensity of $<20 \mathrm{~mm}$ per day $(\Delta p(0-20])$. Black dots represent individual stations and boxes shows 25, 50, $75 q u a n t i l e s$. Background colours indicate stations that have the regime shift date anomaly within one standard deviation from the regional mean (white), one to two standard deviations (light grey), two to three (grey), and greater than three (dark grey) 
Only five stations exceed three standard deviations from the mean; two of those stations are in the Phetchabun mountains and the other three are in North Vietnam.

Figure $3.2 \mathrm{~b}$ shows the changes in the probability distributions of no and $<20 \mathrm{~mm}$ per day rainfall that occurred after the detected regime shift. The ordinate shows the change in probability of rainfall in percent, with the box representing values for quantiles $25,50,75 \%$. For stations with a regime shift in 1974-75, the probability of a dry day (no rainfall) decreases $1-9 \%$ after the shift. Outlier stations in the Phetchabun mountain region, with different regime shift dates, have a $2-4 \%$ increase in the probability of no rainfall. On average for the region, the probability of dry days decreased $5 \%$ after the regime shift. For weak precipitation of an intensity above 0 but below $20 \mathrm{~mm}$ per day, the regional mean change is zero, but individual stations experienced small changes, typically $\pm 1-2 \%$.

\subsubsection{Philippines}

In the Philippines, the regional mean regime shift occurred in 1975, similar to the Indochina region. However, unlike Indochina, there is more uncertainty in determining the precise timing of the regime shift. As seen in Figure 3.3, individual stations have much higher $\sigma(\tau)$ values compared to the Indochina region and the regime shift timing varies significantly from station to station. Four stations with $\sigma(\tau) \leq$ 1 year had tipping points in 1973,1976, 1977, and 1980. Figure 3.3a shows that, similarly to Indochina region, stations at which the regime shift was detected further from 1975 have higher standard deviations of the regime shift position $\sigma(\tau)$. However, most stations were still within three standard deviations from the regional mean regime shift in 1975. 


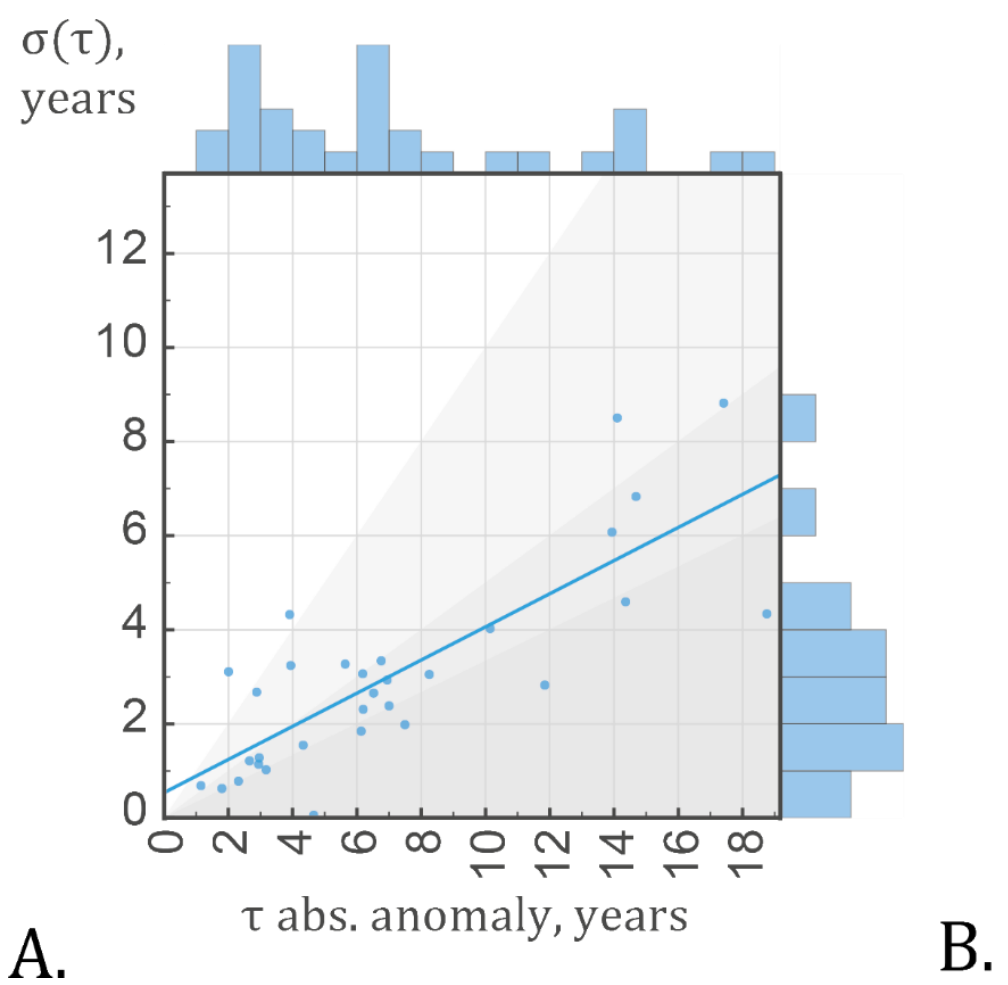

Figure 3.3. Precipitation regime shift in Philippines. $A$ - Date of regime shift versus standard deviation per station. $B$ - Changes in probability of no rainfall $(\Delta \pi)$ and probability of rainfall with intensity of $<20$ $\mathrm{mm}$ per day ( $\Delta p(0-20])$. Black dots represent individual station and a box shows quantiles 25, 50, 75. Background colours indicate stations that have the regime shift date anomaly within one standard deviation from the regional mean (white), one to two standard deviations (light grey), two to three (grey), and greater than three (dark grey)

Philippines have much higher uncertainty in the regime shift position compared to Indochina. Given that the magnitude of the regime shift in the Philippines is similar to that in the Indochina region, high uncertainty can mean that the transition between two regimes is smoother and occurred over several years. If high uncertainty is caused by smooth transition between regimes and we assume that the regime shifts in Philippines and Indochina have the same trigger, we can expect that the mean regime shift date for the Philippines is the same as for Indochina which is confirmed by the data.

Alternatively, high uncertainty can indicate lower observation quality, leading to inconclusive results. In complex terrain weather stations, often not representative of the surrounding region, variability 
between the stations is high. In such situations, much more data is needed to obtain conclusive results.

The spatial variability in the probability of no rainfall changes is high as well (Figure $3.3 \mathrm{~b}$ ). Values vary from -10 to $+10 \%$, with the mean slightly above zero. The low confidence in the tipping point position does not explain the variability in the probability of no rainfall change. Values calculated from observed data, with the tipping point fixed at 1975 , closely follow values from the posterior, e.g., a difference of less than $1 \%$ for the majority of stations. The probability of weak rainfall $(1-20 \mathrm{~mm}) \mathrm{mm} /$ day decreased $0-3 \%$.

\subsubsection{Java}

Java, unlike the other two previously examined regions, is located in the Southern Hemisphere, and no clear regime shift can be observed. The spatial and temporal variability in regime shift position is larger, and the regime shift distribution is much more uniform (Figure 3.4). The mean regime shift year is 1960 , with another probable shift around 1973 . However, only about $6 \%$ of the stations showed a regime shift in 1960; in comparison, the Indochina region has about $30 \%$ of stations showing a regime shift in 1974 . Moreover, there is no correlation between the level of uncertainty and regime shift position, suggesting that there was no single regime shift year for the island of Java.
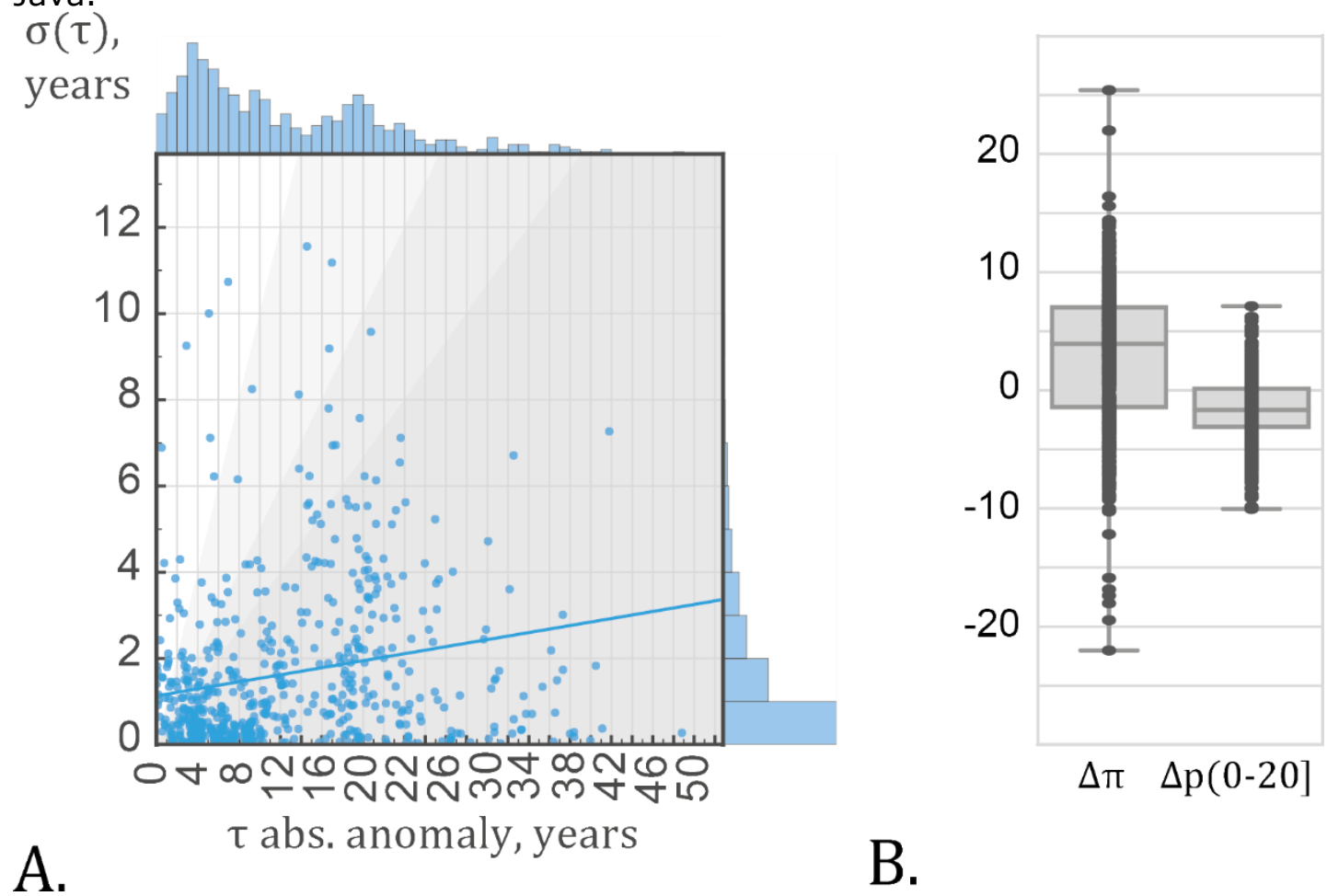
Figure 3.4. Precipitation regime shift in Java. $A$ - Date of regime shift versus standard deviation per station. $B$ - Changes in probability of no rainfall $(\Delta \pi)$ and probability of rainfall with intensity of $<20 \mathrm{~mm}$ per day $(\Delta p(0-20])$. Black dots represent individual station and a box shows quantiles 25, 50, 75. Background colours indicate stations that have the regime shift date anomaly within one standard deviation from the regional mean (white), one to two standard deviations (light grey), two to three (grey), and greater than three (dark grey)

The magnitude of changes in the precipitation distribution for Java is much higher than for the other two regions. Large change together with no regime change point form a clear picture of steady linear trend toward drier climate in the observed period. The probability of a dry day increased $4-6 \%$ for the majority of stations and variations as high as $+10 \%$ are not uncommon. For weak precipitation with an intensity above zero but below $20 \mathrm{~mm}$, the median probability decreases around $2 \%$ but interregional variability is very high. Higher variability in all the parameters compared to Indochina and the Philippines is very characteristic for Java. While the majority of stations show significant changes toward a drier climate, a number of stations indicate the opposite. Stations with changes toward a drier climate often cluster together spatially, suggesting the influence of topography or sea currents.

\subsubsection{North Australia}

In North Australia, similar to Java, no clear regime shift is observed, and many stations have a very high standard deviation of the regime shift position (Figure 3.5). The most common regime shift dates for individual stations are in the period 1958-1960. The similarity between results for Java and Australia suggest that there was no regime shift in the Southern Hemisphere. This is consistent with the hypothesis of PDO influence causing precipitation regime shifts since PDO influence is observed primarily in Northern Hemisphere.

The probability of no rainfall decreased slightly $(-2.5 \%)$ in the last $30-50$ years. For precipitation of intensity above $0 \mathrm{~mm}$ and below 20 $\mathrm{mm}$, no changes were detected. 


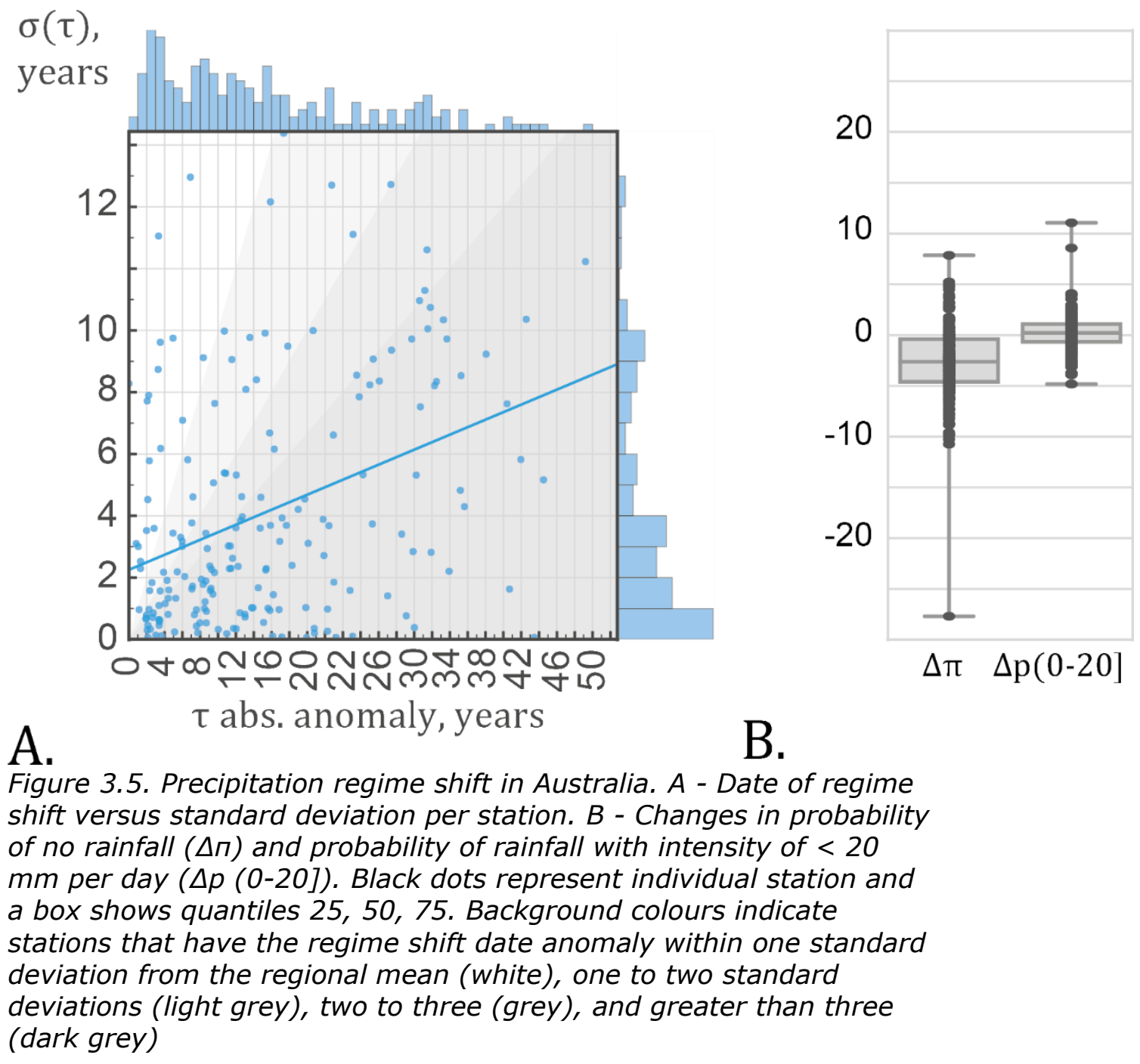




\subsection{Conclusions}

In this study, we used a Bayesian approach to quantify changes in precipitation regimes in four regions in South-East Asia. The precipitation changes in South-East Asia is a subject of debate in literature, the presence of regime shift in Northern Hemisphere regions can explain the difficulty in detecting changes in precipitation regime in this region. Precipitation regime is stable for all but few years where regime shift occurs. High variability additionally masks the presence of a regime shift. Bayesian regime shift detection allows to uncover underlaying changes and create a clear picture of changes that occurred.

The results demonstrate a significant increase in the prevalence of dry conditions in Java and a moderate increase in the number of days with precipitation in Indochina and the Philippines. The regime shift in the mid-1970s can be clearly observed in daily precipitation records for Indochina and the Philippines. This agrees with the well-known change in the PDO phase in 1975/76. The physical connection between precipitation regime and PDO phase should be investigated further to predict future regime changes.

The presented Bayesian method for regime shift detection demonstrates good performance in detecting changes in daily precipitation records in South East Asia. While no change in the mean is present in many timeseries, the presented method is still capable of detecting a regime shift and can be used in a variety of applications. 


\title{
4. Precipitation regime shifts in CMIP6 model experiments
}

\begin{abstract}
This chapter presents a brief look into the CMIP6 models ability to reproduce the ENSO and PDO anomalies and their effects on precipitation and sea surface temperatures. Methodology for model intercomparison closely follows the analysis from the previous chapters. Precipitation in the Maritime Continent is not well reproduced by the models, while sea surface temperature parameters are somewhat predictable. Almost all of the analyzed models capture ENSO-associated anomalies, but only a few reproduce PDOassociated anomalies. Many models show similar climate shifts that we detect in the observation data. However, more work is required to understand how those shifts form in the models.
\end{abstract}

\subsection{Introduction}

The Maritime Continent is one of the most complex regions from the climate perspective. The Maritime Continent (MC) climate forms under the influence of several large-scale processes such as El-Niño, MJO, Monsoons, TCZ movements, and PDO. The Maritime Continent is located in the Indo-Pacific Warm Pool (IPWP), the region with sea surface temperatures permanently above $28^{\circ} \mathrm{C}$. IPWP is often referred to as the heat engine of the world; strong convection in the area can reach altitudes of $15 \mathrm{~km}$ generating enormous amounts of latent heat in the process. The IPWP lays along the path of the Great Conveyor Belt and connects the Indian Ocean to the Pacific through the straights across the Indonesian Archipelago, making the $\mathrm{MC}$ a critical element of the global climate. As explained in Section 1.4 (Elements of complexity), the combination of the factors makes the region difficult to model, with Earth System Models (ESMs) consistently showing worse results in the MC compared to the other areas (Chandrasa and Montenegro, 2020). The modeling of the precipitation regime in the Maritime Continent is extraordinarily complex. High spatial resolution is required to account for local processes, making it challenging for global models. In addition, the influence of several large-scale circulation processes complicates the task for regional models. 
Modern climate change impacted virtually every aspect of the climate system, but changes in the precipitation regime in MC are not easy to estimate. The traditional methods detect no statistically significant trends. The fifth IPCC reports conclude that high spatial and temporal variability and lack of data do not conclude the modern changes in precipitation regime (Hijioka et al., 2014). Our previous studies utilized the Bayesian statistic technique to uncover the precipitation regime shift associated with PDO phase change leading to an increased number of dry days and changes in the probability of weak and extreme precipitation.

In this study, we attempt to evaluate how well CMIP6 GCMs can reproduce the factors governing the changes in precipitation regime in the Maritime Continent, including the changes in temperature of the IPWP and the complex picture of ENSO-PDO interactions. We identify the models that reproduce the precipitation regime in $M C$ better than the average and provide a future projection of the precipitation regime in the MC.

\subsection{Data and Methods}

The state-of-the-art climate system modeling data is available through the Coupled Model Intercomparison Project sixth phase (CMIP6). Models participating in the CMIP6 perform strictly defined experiments with standard input data to make the results comparable with all other models. I this study, data from two experiments is used - historical experiment reproduces historical climate from 1850 to 2014 and is used to evaluate models skill versus observed values; the ssp585 experiment covers the 2015-2100 period and is used to estimate future climate change. Ssp585 is an aggressive climate change scenario approximately analog to $\boldsymbol{R C P 8 . 5}$ used in CMIP5. Three variables are used - daily precipitation (pr), monthly surface temperature (ts), and a land fraction (sft/f). Precipitation data is used to assess the model's skill in reproducing precipitation regimes in the Maritime Continent and its future changes. Surface temperature is used to calculate PDO and Nino3.4 indexes, and a land fraction is used to create a sea-land mask. We are using only a single model variant - "r1i1p1f1".

The observed parameters are calculated from NOAA ERSSTV5 for SST and CRU TS4 for precipitation. All precipitation parameters and PDO and Nino3.4 indexes are calculated using the same observation and model data procedure.

The classical PDO index is used in chapter 2, calculated as the first principle component of SST anomalies in the 20-60N, $170 \mathrm{E}-120 \mathrm{E}$ region after removing the annual cycle and global average anomaly. Typically the period $1901-2000$ is used to calculate the base climatology and EOF vector. Unfortunately, because of the nature of 
PC based index, the index is sensitive to the base period selection, and calculating the index based on the modeled values leads to incomparable results. For this work, we are using Tripole Index for the Interdecadal Pacific Oscillation (TPI) - an index that closely follows IPD and PDO values but is based on differences between SST anomalies in different regions and does not use the EOF. The TPI index is defined as

$$
T P I_{\text {raw }}=S S T_{\text {reg2 }}-\frac{S S T_{\text {reg1 }}+S S T_{\text {reg } 3}}{2}
$$

Where $\mathrm{SST}_{\text {regx }}$ is a mean SST anomaly for region $1(25-45 \mathrm{~N}, 140 \mathrm{E}-$ $145 \mathrm{~W}), 2$ (10S-10N, 170E-90W), 3 (50S-15S, 150E-160W), and $T P I_{\text {raw }}$ is an unfiltered TPI index. If a low-pass filter is applied to the unfiltered TPI index, the resulting filtered TPI is positively correlated with IPD and PDO. Here we only use the unfiltered version of the TPI. We use the Nino3.4 index calculated from NOAA ERSSTV5 for observed data and from ts data for CMIP6 models. We are using the standard definition of the Nino3.4 index as an SST anomaly in the Nino3.4 region (5S-5N, 170W-120W).

We use averaged SST and precipitation anomalies in the IPWP defined as the area between 20S-20N and 90-160E. Precipitation anomalies are calculated using only the terrestrial part of the region for comparability with CRU TS precipitation data.

The regime shift in the modeled precipitation is investigated using the Bayesian regime shift detection method introduced in Chapter 3. A detailed introduction to the Bayesian regime shift detection is given in Chapter 3. Unfortunately, running the exact version described in Chapter 3 using CMIP6 models precipitation data is not feasible computationally. To dramatically reduce the computational cost, we run regime shift detection on regionally averaged monthly anomalies instead of daily precipitation used in the original method. Few modifications were made to the previously used method to adjust to the different data. First, the Zero Inflated Gamma distribution that was initially used to describe daily precipitation distribution is not suitable for describing monthly anomalies and is replaced by Normal distribution. Second, the Normal distribution has only two parameters - mean and standard deviations in contrast to three parameters for Zero Inflated Gamma. The following equations describe the resulting model for regime shift detection used in this chapter

$R_{a} \sim N(\mu, \sigma)$

Where $R_{a}$ is monthly precipitation anomaly, $N$ is a normal distribution, and $\mu, \sigma$ are mean and standard deviations 
$\mu, \sigma= \begin{cases}\mu_{1}, \sigma_{1} & \text { if } t<\tau, \\ \mu_{2}, \sigma_{2} & \text { if } t \geq \tau\end{cases}$

Where $t$ is time, and $\tau$ is a regime shift position. The prior parameters $\mu_{1}, \sigma_{1}, \mu_{2}, \sigma_{2}$ are described using Normal distribution, and prior values are defined from input data. The prior values for regime shift position $\tau$ are uniformly distributed except for the first and last five years. Using monthly anomalies instead of daily precipitation values limits the method's effectiveness and makes it unable to detect changes on a daily scale. For example, one of the significant conclusions from Chapter 3 was that precipitation regime shift manifests in the changes in the number of dry days; such change is impossible to detect using the monthly anomalies. On the positive side, trading reduced robustness of the method for computational effectiveness allows using algorithm recursively for detecting multiple regime shifts per time series. If the regime shift is detected, the time series is split into parts before and after the regime shift, and regime shift detection is applied recursively to every segment until no additional shift points are detected or time-series length gets below 20 years.

\subsection{Mean Precipitation and SST in CMIP6 models}

We start by evaluating the CMIP6 model's accuracy in reproducing the temperature in the IPWP. Figure 4.1 shows the observed and modeled mean sea surface temperature anomalies and the precipitation anomalies in the IPWP.

The tested CMIP6 models can reproduce the SST anomalies in the IPWP well. Different models are in good agreement with each other, and observations mostly fall within the modeled range (Figure 4.2). For SST, models reproduce not only the anomalies but the baseline SST values as well. For example, the observed mean SST in the IPWP for $1901-2000$ is $27.9^{\circ} \mathrm{C}$, and modeled values fall within $\pm 3 \%$ of the observed mean (Figure 4.2). For precipitation on land in the IPWP region, the mean annual sum for $1901-2000$ is $2165 \mathrm{~mm}$, and models fall within the $\pm 40 \%$ range from the observed values (Figure 4.1 ). Several models give accurate estimates of both SST and precipitation - MIROC6, EC-Earth3, MRI-ESM2-0.

As we can see from Figure 4.1 and Figure 4.2, the spread of model estimates is much larger for precipitation than the SST. Similarly, for the SST, the models can reproduce the historical anomalies in the 20th century and rapid temperature increase in the last two decades. The main difference between the observed and modeled data is that the observed values have large variability compared to modeled ones. In the extreme ssp585 scenario, models predict continuous 
rapid temperature increase through the 21st century, and the model uncertainty range is increasing approximately trifold towards the end of the prediction period. For precipitation anomalies, the observed data fall within the range of model uncertainty in the historical period. For the prediction period, in contrast to the SST predictions, the models show dramatically different scenarios from fast growth (INM CM4) to noticeable decline (ACCESS-ESM-1-5). 

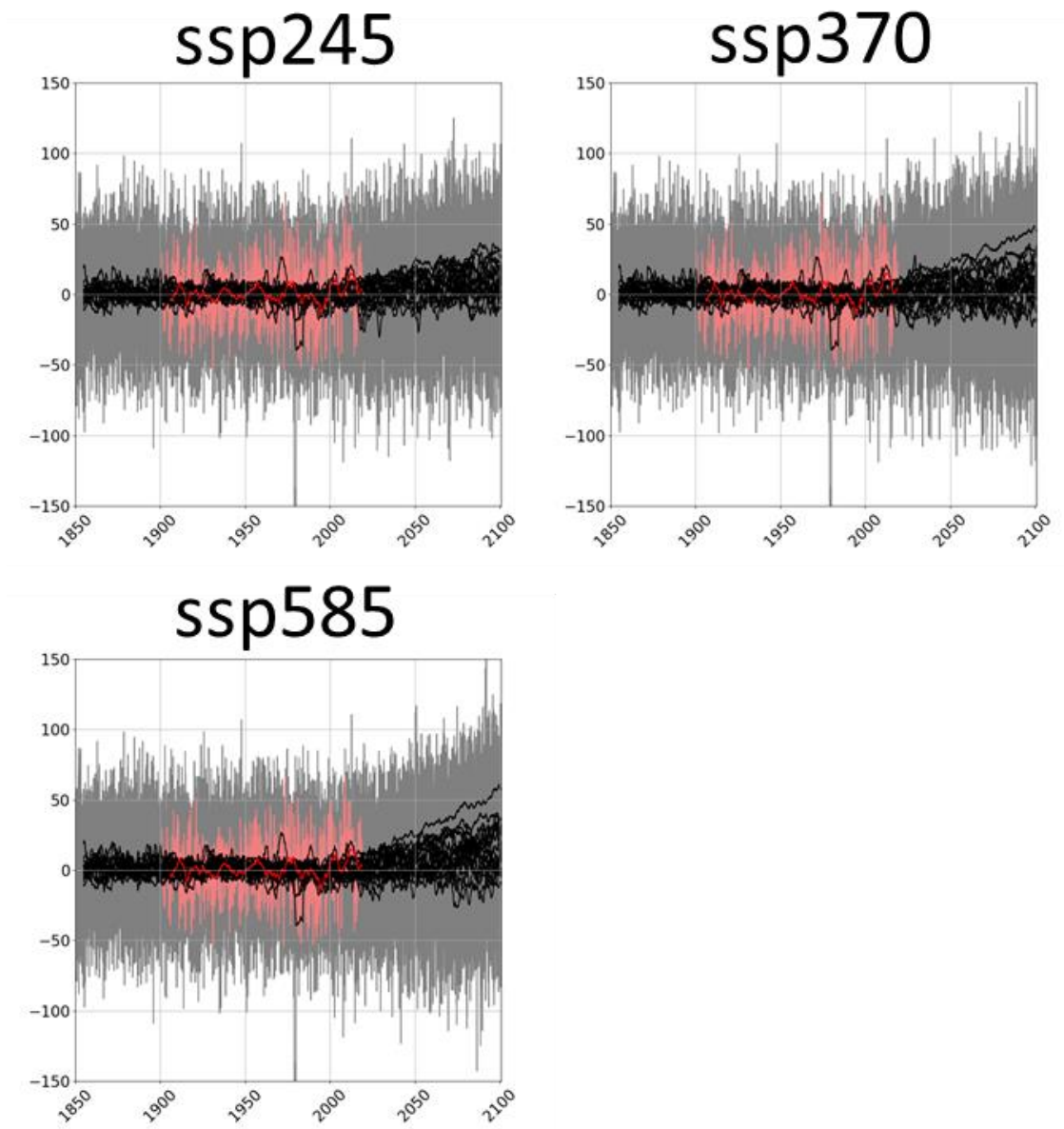

Figure 4.1. Precipitation anomalies in the IPWP (20S-20N, 90-160E). Observed (coral), 5-year running mean of observed data (red), CMIP6 models data from historical and future experiments (grey), and 5-year running mean for model data (black). 


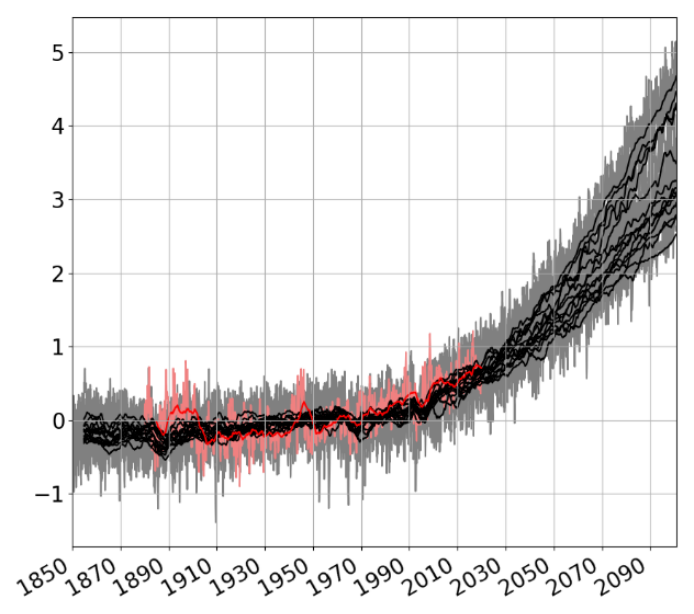

Figure 4.2 Monthly mean sea surface temperature anomalies in the IPWP (-20-20N, 90-160E). Observed (coral), 5-year running mean of observed data (red), CMIP6 models data from historical and ssp585 experiments (grey), and 5-year running mean for model data (black). 


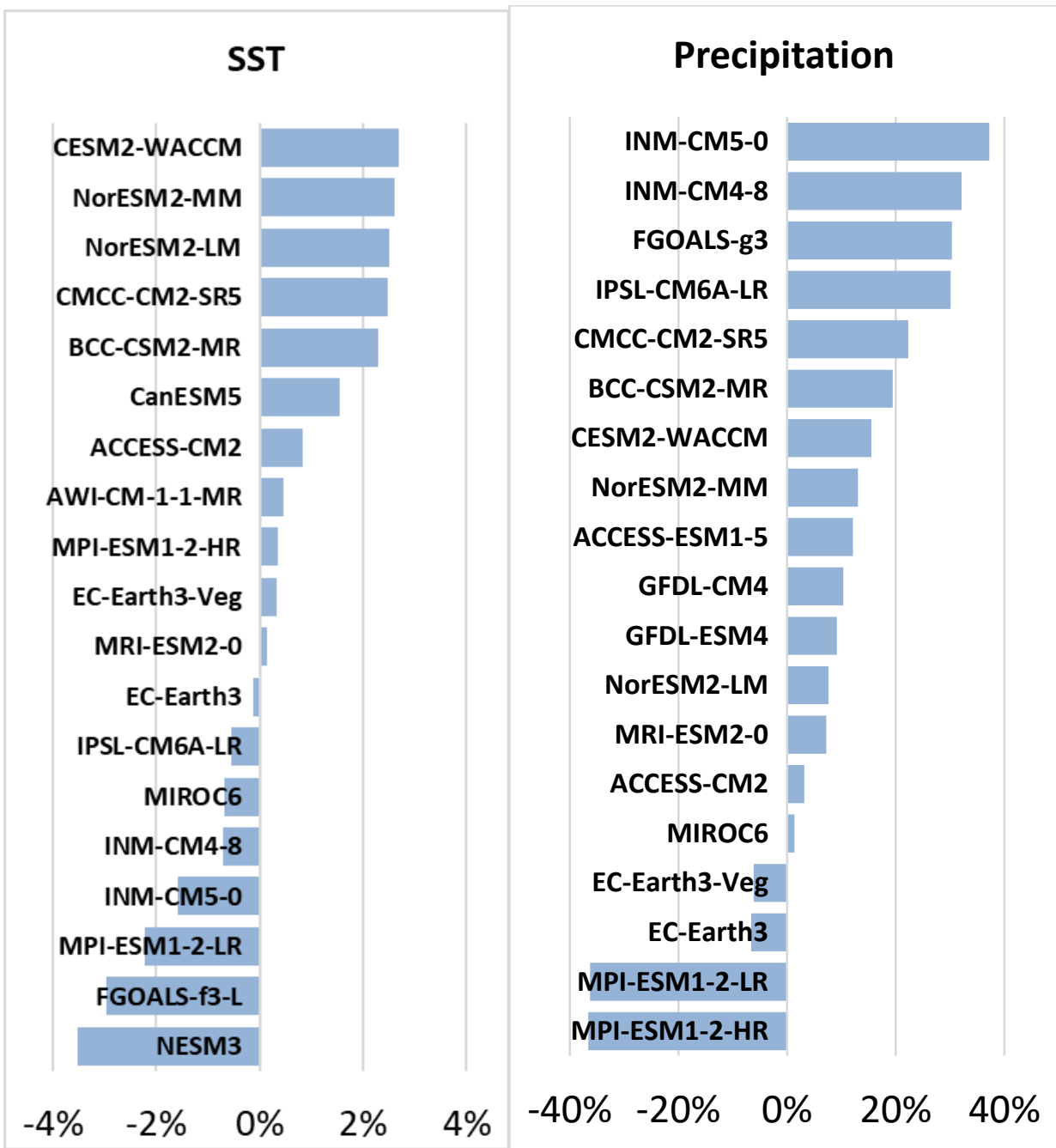

Figure 4.3. Mean annual precipitation on land and SST in the IPWP region, 1901-2000. CMIP6 model minus observations, the difference expressed as a percentage of the observed value. 


\section{Influence of El Nino and TPI on precipitation in the IPWP}

Our previous research shows that interactions between the Pacific Decadal cycle and ENSO play a critical role in forming precipitation regimes in the Maritime Continent. To predict future changes in precipitation regime, GCMs should reproduce the effects of ENSO and PDO cycles on the precipitation in the Maritime Continent. We use the TPI index to represent the Pacific decadal cycle and Nino 3.4 to represent the ENSO. We evaluate the model performance in reproducing historical changes in TPI and Nino3.4 and the interaction between precipitation regime and TPI and Nino3.4 cycles. Figure 4.4 shows the Taylor diagrams and Nino34 indexes, SST, and precipitation anomalies in IPWP. The Taylor diagram shows the correlation coefficient, the root-mean-square error, and the standard deviation between the modeled and observed data. The figure shows little correlation between the modeled and observed Nino3.4 or precipitation anomalies in the IPWP, but the standard deviation is close to the observed one. The mean SST anomaly in the IPWP is the only parameter that shows a high correlation between observed and modeled data. The high correlation coefficient for IPWP SST is explained by the fact that the IPWP time series contains a global warming trend reproduced by the models. Calculating the correlation coefficient for time-series with a common trend results in inflated correlation values. TPI index, on the other hand, is calculated by subtracting the global warming signal from SST anomalies and thus shows a much lower correlation coefficient. The mechanism of common trend inflating the correlation numbers is apparent when analyzing the model's skill in reproducing the TPI. Modeled SST in the individual TPI regions has a higher correlation with the observations compared to the resulting TPI index. The higher correlation is due to the individual regions contain a global warming signal. However, after subtracting region averages from each other, the common trend disappears, and the correlation score drops. Additionally, IPWP has a much larger area than the Nino3.4 region or individual TPI regions, so the average SST anomalies should be easier to reproduce. 
Nino 3.4

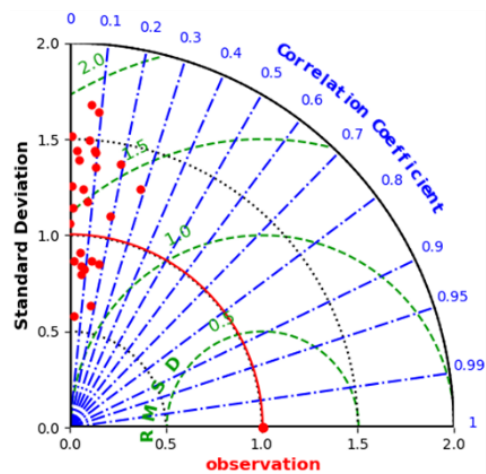

IPWP SST

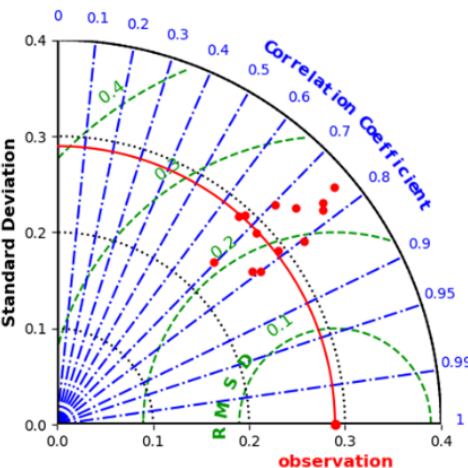

IPWP prec.

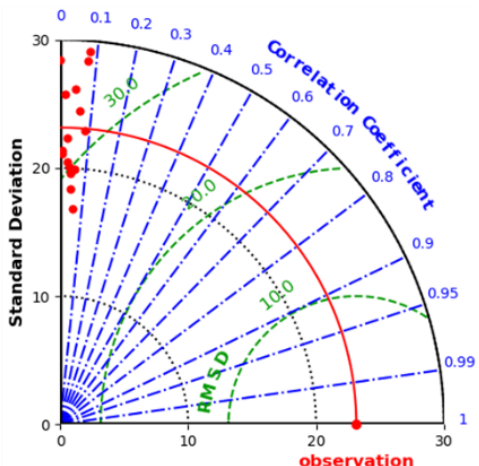

Figure 4.4 Taylor diagram showing CMIP6 models skill in reproducing historical changes in TPI, IPWP SST, IPWP precipitation.

Moreover, een the perfect climate model is not expected to reproduce the ENSO cycles in sync with the historical data, which makes comparing the correlations between the observed and modeled Nino 3.4 meaningless. However, we can expect the GCMs to reproduce statistical parameters of TPI and Nino3.4 and their effects on the precipitation regime. So to assess the model ability to reproduce process related to the observed regime shift we designed a few metrics that are not requiring the syncronisity between modeled and observed cycles.

First, we are looking at the frequency of occurrences for different phases of Nino3.4 and TPI, their combinations, and effects on the precipitation anomalies. Modeled Nino3.4 has a much higher number of positive events compared to negative events. This bias is illustrated by calculating the ratio between the number of months with positive Nino3.4 values and months with negative Nino3.4 values ( $\mathrm{P} / \mathrm{N}$ ratio in Table 4.1). For the observed data, this ratio is 1.07 , but half of the models show a ratio between 2 and 8 . For TPI, the ratio between positive and negative events is 0.6 from observations. The models show a ratio between 0.2 and 2.3, with half of the models within 0.2 from observed values.

Second, we compare the impact of Nino3.4 and TPI on precipitation regimes in modeled and observed climates. Table 4.1 shows the mean daily precipitation anomaly for different TPI and Nino3.4 phases and Kolmogorov-Smirnov (KS) statistic showing the statistical significance of the difference between precipitation anomalies during the positive and the negative phases. For both Nino3.4 and TPI, we delineate the positive, negative, and neutral phases. The threshold separating the positive and negative phases from the neutral is defined as an anomaly with an absolute value above two standard deviations. That is the definition that was used in Chapter 2 . The 
definition based on standard deviation rather than fixed values is beneficial because different GCMs show different amplitudes of TPI and Nino3.4. The results show that almost all models correctly reproduce the difference in precipitation anomalies between Nino3.4 positive and negative phases. The negative phase is associated with higher precipitation anomalies, and the difference is statistically significant on a 0.01 level based on the KS test. Only one tested model (IPSL-CM6A-LR) shows a lower anomaly for the Nino3.4 negative phase. For the TPI phases, the situation is similar. In observations, TPI negative phase is associated with positive precipitation anomaly and TPI positive phase with negative precipitation anomaly. The difference between the two regimes is statistically significant in observations. The tested CMIP6 models, except for INM models, show a statistically significant difference in precipitation anomalies between TPI phases. From those models, one (IPSL-CM6A-LR) has the difference of the opposite sign compared to the observations. Three models from 15 tested demonstrated that TPI negative phase is associated with a larger precipitation anomaly that corresponds to the TPI positive phase.

There is no clear consensus between tested CMIP6 models of the predicted TPI. Individual models show an increase or decrease in the TPI, with the majority not showing significant changes. The range of model predictions is increased in the second half of the 21st century, and some individual models also show an increase in the TPI amplitude.

Overall, the analysis shows that at least some models can reproduce the impact of Nino3.4 and TPI of the precipitation in the Maritime Continent. Furthermore, suppose the precipitation regime shift in the Maritime Continent is governed by the long cycle in TPI or PDO. In that case, as our previous analysis (Chapters 2, 3) suggests, we can expect models are reproducing precipitation regime shifts as well. 
Table 4.1. Mean precipitation anomalies ( $\mathrm{mm} / \mathrm{month}$ ) in the IPWP during positive and negative phases for PDO and Nino34, differences between phases (diff), Kolmogorov-Smirnov statistic (KS) testing the statistical significance of differences between phases, a ratio of number of positive events to the number of negatives $(P / N)$

\begin{tabular}{|l|l|l|l|l|l|l|l|l|l|}
\hline & $\begin{array}{l}\text { PDO- } \\
\text { Median } \\
\text { Anomaly }\end{array}$ & $\begin{array}{l}\text { PDO+ } \\
\text { Median } \\
\text { Anomaly }\end{array}$ & $\begin{array}{l}\text { PDO } \\
\text { KS- } \\
\text { stat. } \\
\text { - } \\
\text { value }\end{array}$ & $\begin{array}{l}\text { PDO } \\
\text { Standard } \\
\text { Deviation }\end{array}$ & $\begin{array}{l}\text { Nino34- } \\
\text { Median } \\
\text { Anomaly }\end{array}$ & $\begin{array}{l}\text { Nino34+ } \\
\text { Median } \\
\text { Anomaly }\end{array}$ & $\begin{array}{l}\text { Nino34 } \\
\text { KS- } \\
\text { stat. } \\
\text { p-value }\end{array}$ & $\begin{array}{l}\text { Nino34 } \\
\text { Standard } \\
\text { Deviation }\end{array}$ & $\begin{array}{l}\text { Nino } \\
\text { P/N } \\
\text { Ratio }\end{array}$ \\
\hline Observations & 5.33 & -3.86 & 0.00 & 0.68 & 1.75 & -9.39 & 0.00 & 0.53 & 1.07 \\
\hline $\begin{array}{l}\text { ACCESS- } \\
\text { CM2 }\end{array}$ & -5.90 & -1.62 & 0.16 & 1.25 & -0.51 & -11.32 & 0.00 & 0.63 & 2.31 \\
\hline $\begin{array}{l}\text { AWI-ESM-1- } \\
\text { 1-LR }\end{array}$ & -4.03 & -9.96 & 0.01 & 1.43 & -3.26 & -9.91 & 0.00 & 0.52 & 3.09 \\
\hline BCC-ESM1 & 2.07 & -6.57 & 0.03 & 0.65 & 0.59 & -18.58 & 0.00 & 0.53 & 0.66 \\
\hline $\begin{array}{l}\text { CMCC-CM2- } \\
\text { SR5 }\end{array}$ & -6.05 & 11.09 & 0.00 & 1.88 & 5.68 & -13.28 & 0.00 & 1.02 & 8.11 \\
\hline EC-Earth3 & 6.64 & 0.23 & 0.00 & 3.29 & 5.84 & 0.21 & 0.00 & 0.91 & 4.51 \\
\hline $\begin{array}{l}\text { EC-Earth3- } \\
\text { Veg }\end{array}$ & 5.59 & -1.63 & 0.00 & 3.03 & 4.35 & -1.36 & 0.00 & 1.21 & 106.2 \\
\hline $\begin{array}{l}\text { EC-Earth3- } \\
\text { Veg-LR }\end{array}$ & -1.60 & 11.98 & 0.00 & 1.90 & 4.84 & -2.45 & 0.00 & 0.63 & 4.84 \\
\hline INM-CM4-8 & -3.33 & -4.08 & 0.67 & 1.59 & -2.11 & -4.42 & 0.00 & 0.38 & 2.24 \\
\hline INM-CM5-0 & -0.28 & 0.50 & 0.80 & 1.57 & -0.97 & -5.51 & 0.00 & 0.40 & 1.83 \\
\hline $\begin{array}{l}\text { IPSL-CM6A- } \\
\text { LR }\end{array}$ & -0.83 & 1.19 & 0.91 & 1.28 & -1.11 & 0.16 & 0.19 & 0.71 & 1.99 \\
\hline $\begin{array}{l}\text { MPI-ESM-1- } \\
\text { 2-HAM }\end{array}$ & -3.75 & 1.86 & 0.26 & 1.49 & 1.03 & -12.64 & 0.00 & 0.53 & 0.67 \\
\hline $\begin{array}{l}\text { MPI-ESM1-2- } \\
\text { LR }\end{array}$ & -2.49 & -4.32 & 0.67 & 1.35 & -2.12 & -8.76 & 0.00 & 0.50 & 0.95 \\
\hline NorESM2-LM & 1.84 & -2.36 & 0.08 & 0.76 & 1.69 & -16.20 & 0.00 & 0.84 & 0.98 \\
\hline $\begin{array}{l}\text { NorESM2- } \\
\text { MM }\end{array}$ & -15.35 & 12.32 & 0.00 & 2.00 & 0.95 & -15.99 & 0.00 & 1.12 & 8.94 \\
\hline TaiESM1 & -2.04 & 8.48 & 0.00 & 2.00 & 7.04 & -15.54 & 0.00 & 0.95 & 4.11 \\
\hline
\end{tabular}

\subsection{Precipitation Regime Shift in CMIP6 models}

For every CMIP6 GCM, we calculate monthly anomaly precipitation averaged over the terrestrial part of the Maritime Continent. Figure 4.5 shows the precipitation anomaly in the IPWP for each model individually. Timeseries combining historical and ssp585 experiments from 1850 to 2100 are analyzed using the Bayesian regime shift detection algorithm adapted from Chapter 3. Vertical lines show points where precipitation regime shift is most probable. The majority of models show increased annual precipitation and the end of the 
21st century, some of the models show a stable regime, and few show a decrease in annual precipitation. Multiple models demonstrate non-linear changes in annual precipitation with fast transitions between stable regimes or stable regime-changing to linear increase after some stress is accumulated. Such regime shifts mirror our previous findings showing that the precipitation regime in the Maritime Continent changes non-linearly driven by changes in the PDO cycle.

Some models (for example-ACCESS-CM2, EC-Earth3-Veg, GFDLCM4) have a regime shift detected around 2014, which most likely highlights the split between the historical and ssp585 experiments. In some cases, the regime shift line was located precisely in 2014, and sometimes there are two lines in close proximity of 2014. Two or three precipitation regime shifts points are often detected close to each other with much more extended periods with no regime shift points on both sides of the period with regime shifts. Such positioning of change points can be interpreted as a transition period between two stable regimes with two regime shift points marking the beginning and the end of transition periods. However, when the transition period is more extended, or the beginning/end is less defined, a third regime shift point might be detected. Thus, the single standalone regime shift detection line indicates a more defined regime shift or trend change.

Some models (ACCESS-CM2, GFDL-ESM4) do not have regime change shifts in precipitation in the MC. Some models show regime shift around 1975 (for example, MPI models and NorESM2-LM) Few models (ACESS-ESM1-5, NorESM2-MM) show a shift to the regime with lower average precipitation and higher standard deviation in the second half of the 21st century.

Most models (IPSL-CM6A-LR, MPI-ESM1-2-HR, MPI-ESM1-2-LR, ECEarth3-Veg, GFDL-CM4, CMCC-CM2-SR5) show transition to the regime with more precipitation and higher standard deviation in the second half of the 21st century. Furthermore, some model results (INM-CM4-8, INM-CM5-0, EC-Earth3) can be interpreted either as a continuous linear trend towards higher precipitation or a very long transition to the higher stable regime. 

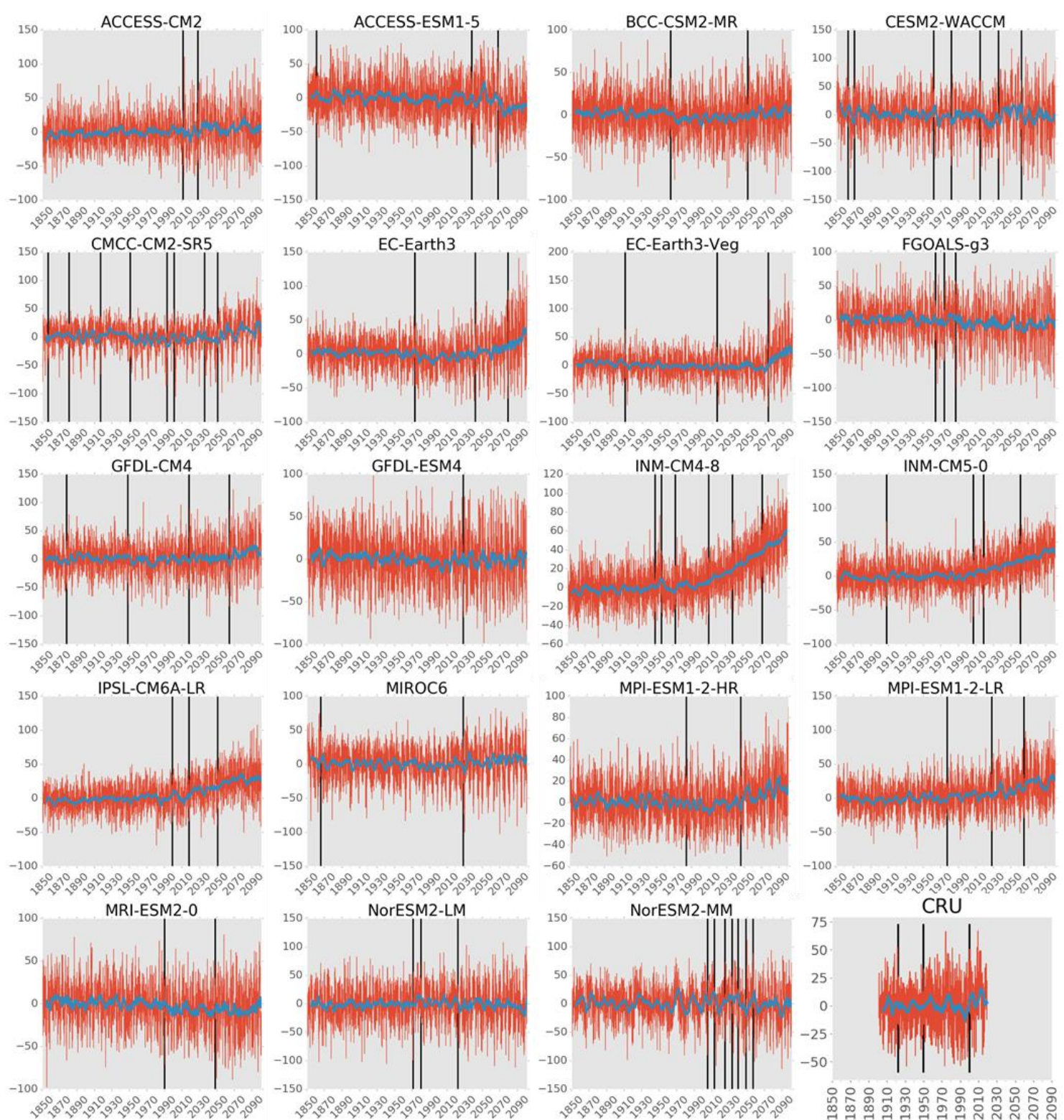

Figure 4.5. Monthly precipitation anomalies averaged in the Maritime Continent for individual models according to ssp585 scenario (red), five years running mean of those anomalies (blue), and most probable positions of precipitation regime shifts (black vertical lines). 


\subsection{Conclusions}

Previous studies have shown that ENSO is reproduced in state-of-theart GCMs and that the MC is a notoriously tricky region to model. The results show that GCMs can reproduce the impact of ENSO on the precipitation regime in the MC. Almost all models can reproduce the sign of typical ENSO anomalies, and few models get realistic amplitudes of the anomalies. However, the GCMs underestimate the number of ENSO negative events.

The GCMs do not reproduce PDO and IPO and their influence on precipitation. While here we quantify ENSO using the Nino3.4 index, an SST anomaly in one region, the TPI used to quantify the IPO is a relationship between SST anomalies in three different regions.

Further research is needed to investigate if GCMs have some PDO-like process that manifests differently into SST patterns or GCMs lack some of the elements necessary to reproduce the PDO.

Many models show rapid shifts between stable regimes or a sharp change from a stable regime to an upward/downward trend. The model data supports the idea of observed non-linear change in precipitation regime in the IPWP.

We can expect a significant increase in the total amount of precipitation in the IPWP, but the change might be non-linear. While some models predict a decrease in the total amount of precipitation, the models that demonstrate better results in the test overwhelmingly show an increase in total precipitation. 


\title{
5. Machine Learning Prediction of the Madden-Julian Oscillation index value ${ }^{3}$
}

\begin{abstract}
We present two machine learning models for predicting large-scale hydrometeorological circulations using the example of Madden-Julian circulation prediction. Models based on Convolution Neural Networks and Temporal Convolution Networks are presented. Both models demonstrate high performance in the chosen task. Presented models can be used in a wide array of problems in hydrometeorology and earth sciences.

Presented models demonstrate two contrasting approaches to predicting circulation processes. The model based on convolution neural networks uses extensive information of the system's current state and predicts the future state of the system at $\mathrm{N}$ time steps ahead. In contrast, the model based on temporal convolution networks focuses on the information from previous steps and makes a prediction one time step at a time. Despite wildly different approaches, both models demonstrate almost identical performance in the chosen task.

The article discusses machine learning models' performance in contrast to traditional numerical models and the practical applicability of the presented methods. Presented models can provide a functional prediction of the Madden-Julian Oscillation when the computational resources needed for numerical predictions not available. In other tasks, models have the potential to match or even overperform the traditional methods.
\end{abstract}

\subsection{Introduction}

Recent studies used machine learning (ML) to predict different aspects of weather and climate system dynamics. From increasing prediction time for Nino 3.4 index (Ham et al., 2019) to Google's new precipitation nowcasting system (Agrawal et al., 2019), machine learning demonstrates the ability to outperform traditional methods.

\footnotetext{
3 this chapter has been published as - KOKOREV, V., A.MUSTAFIN, ETTEMA, J., SIEGMUND, P. 2021. Machine Learning Based Prediction of the Madden-Julian Oscillation Index. Earth Science Informatics, (submitted).
} 
In this study, we investigate the ability of ML methods in predicting the Madden-Julian Oscillation index.

The Madden-Julian Oscillation (MJO) (Madden and Julian, 1971) is the dominant mode of the interseasonal (30-90 days) variability in the tropical atmosphere-ocean system (Zhang, 2005). The MJO is characterized by slowly eastward propagating cyclonic and anticyclonic systems that enhance and suppress rainfall, respectively (Madden and Julian, 1972, Tian and Waliser, 2014). The MJO has both direct and indirect effects on global weather and climate. A direct effect is enhanced and suppressed convective precipitation along its propagation pathway in the Indian and Pacific Oceans. Indirect effects influence or trigger the ENSO cycles by propagating atmospheric and oceanic waves generated by the MJO (Zhang, 2015). The MJO influences tropical cyclone activity, frequency of extreme rainfall, and cold surges. The active phase increases the probability of extreme rainfall by $40 \%$ in regions under $\mathrm{MJO}$ influence (Jones et al., 2004).

Extreme weather events such as hurricanes and flooding associated with MJO result in billions of damages annually. The ability to predict the periods with an increased probability of extreme events caused by MJO is critical. The current forecast horizon of the MJO for stateof-the-art numerical weather prediction (NWP) methods is $16-35$ days, with little practical significance after 10-14 days. However, in India and South-East Asia, where MJO is the dominant mode of the interseasonal (30-90 days) variability, the lead time of a weather forecast can be increased up to several weeks. State-of-the-art NWP models demonstrate skillful prediction of MJO index value up to 5 weeks (Kim et al., 2018). In this study, we explore the ability of ML methods to predict the MJO index and compare the results with existing methods

To the best of our knowledge, only very few studies apply ML methods for predicting the MJO index. The previous studies that involve $\mathrm{MJO}$ in combination with $\mathrm{ML}$ and statistical methods primarily focused on the classification of MJO phases. Notably, a study by (Toms et al., 2019) shows that convolution neural networks (CNN) can accurately classify MJO phases based on Outgoing Longwave Radiation (OLR) data. Another study uses a K-mean unsupervised learning algorithm to label MJO phases. It then uses CNN to predict one of the four phases 1-5 days in advance with an accuracy of 9376\% (Chattopadhyay et al., 2020). Earlier work by the same author (Chattopadhyay et al., 2013) uses Self-Organizing Maps to identify horizontal and vertical structures of the MJO through its life cycle. However, it does not aim to make a prediction.

Unlike the previous studies, this chapter presents two different MLbased approaches to predicting MJO index values. The first approach 
is based on spatial pattern recognition in meteorological fields using a $\mathrm{CNN}$ model. The second approach is based on the novel Temporal Convolutional Network (TCN) architecture that utilizes temporal patterns to predict the MJO index values. The primary purpose of using two different models is to introduce the ML methods that could have broad use in Earth Science applications. Two models are briefly introduced in the methods section, along with the prediction target. The Data section described data used, and transformations applied. After the data description, the model's architecture is introduced in dedicated sections. Results and Discussion conclude this chapter.

\subsection{Methods}

This study investigates the performance of two different ML models Convolutional Neural Network (CNN) and Temporal Convolutional Network (TCN). Those two architectures were chosen because both, in recent studies, demonstrated excellent performance in predicting the Nino 3.4 index (Yan et al., 2020, Ham et al., 2019) outperforming traditional models. The two models use vastly different approaches to predicting the MJO index. The CNN model used in this study utilizes extensive information about the current state of the atmosphere and the ocean but has no information about the previous states. The model takes as global input fields of atmospheric and ocean variables in coarse resolution to predict RMM1 and RMM2 directly at N steps ahead without going through intermediate steps. In contrast, the TCN uses relatively few general indexes describing the current state of the system and considers past states. Another difference is how the prediction is generated: the CNN is trained to make a prediction directly for several days ahead, while the TCN is predicting all of the input variables one day ahead and then takes predicted data as a new input to generate longer predictions.

The previous ML-based studies focused on predicting the MJO phase and used the accuracy of phase prediction to evaluate the model (Chattopadhyay et al., 2013, Toms et al., 2019, Chattopadhyay et al., 2020). This article follows the lead of best available models and predicts the MJO index value and not the MJO phase. From the literature, the most common way to evaluate the accuracy of NWPbased $\mathrm{MJO}$ prediction is the bivariate correlation of predicted and observed real-time multivariate MJO (RMM) index (Kim et al., 2018). The RMM index consists of the first two normalized principal components (RMM1 and RMM2) of combined daily anomalies of outgoing longwave radiation (OLR) and zonal winds at 850 (U850) and $200 \mathrm{hPa}$ (U200) (Liu et al., 2015). The RMM index has often been criticized for the usage of OLR that has little influence on the resulting index. Several suggestions were made to improve the RMM index by 
scaling OLR anomalies to enhance their influence (Liu et al., 2015) or replace OLR with meridionally averaged $200-\mathrm{hPa}$ velocity potential (Ventrice et al., 2013). Alternatively, (Kiladis et al., 2014) developed a separate OLR-based MJO index (OMI) that also uses principal component analysis applied to the OLR field. In this study, we calculate RMM without such alterations as this is most commonly used and, therefore, simplifies our results with previous studies. However, we also investigate the Velocity Potential MJO (VPM) index's predictability (Ventrice et al., 2013) compared to the more commonly used RMM index.

Both models are trained to predict values of the RMM1 and RMM2 simultaneously. Predictions are evaluated using the bivariate correlation of RMM1 and RMM2 between the observed and predicted indexes. The evaluation metric is chosen because it evaluates traditional forecasts and therefore allows easy comparison of previous results. Predicted values of RMM1 and RMM2 are denormalized before calculating bivariate correlation. Bivariate correlation is calculated using the following formula (Kim et al., 2018):

$$
\text { corr }=\frac{\sum\left(R M M 1_{t} * R M M 1_{p}+R M M 2_{t} * R M M 2_{p}\right)}{\sqrt{\sum R M M 1_{t}^{2}+R M M 2_{t}^{2}} * \sqrt{\sum R M M 1_{p}^{2}+R M M 2_{p}^{2}}}
$$

The forecast is considered skillful if the value of the bivariate correlation of RMM1 and RMM2 is above 0.5 (Kim et al., 2018). Stateof-the-art numerical weather prediction (NWP) demonstrates a 0.8 correlation for 14 days forecast and 0.5 for periods around 20-30 days (Li et al., 2019, Vitart, 2017, Kim et al., 2018). In addition to predicting daily RMM, we test the ability of both CNN and TCN models to predict weekly averaged RMM values. In those experiments, both input and predictand data are smoothed using a seven-day running mean to reduce random noise bring up the signal. Seven days mean values are assigned to the last day of the moving window, so no future information is leaked.

We tested six model variations: two CNN models and four TCN models (see Table 5.2). The two CNN models differentiate by using either standard daily input or smoothed with seven days moving window as described above. The model variation that uses 7-days smoothed input is trained to predict RMM indexes similarly smoothed with a seven-day rolling window. TCN models have two versions that use different input. The first version (TCNi) inputs the global circulation indexes such as RMM, MJO, Nino, VPM. The second version (TCNpc) inputs principal components of meteorological. Each version has the variation that uses data smoothed with seven days rolling window (TCNi_7d, TCNpc_7d) and a variation the does not use smoothing (TCNi, TCNpc). A detailed description of the data used is given in the next section. The exact input and output for each of the model variations are described in Table 5.2. 


\subsection{Data}

The values of the RMM indexes from 1981 to 2019 are obtained from the KNMI Climate Explorer (https://climexp.knmi.nl/). The RMM1 and RMM2 value are normalized using Min-Max Feature scaling, following the formula -

$$
X^{\prime}=\frac{X-X_{\min }}{X_{\max }-X_{\min }}
$$

Both models use to input information about surface pressure, sea surface temperature, zonal wind, and outgoing longwave radiation. However, depending on the model, we use one of the two categories of data, namely gridded geospatial data and global indices data. The first category is daily fields of five variables - Sea Surface Temperature (SST), Atmospheric pressure at the surface (SP), Uwind at $850 \mathrm{hPa}$ surface (U850), U-wind at $200 \mathrm{hPa}$ surface (U200), and Outgoing Longwave Radiation (OLR). The geospatial data come from two sources: SP, U850, and U200 come from ERA5, SST, and OLR from NOAA reanalysis. The detailed information and citation are listed in Table 1. All datasets have a global spatial coverage but have different temporal coverage and different spatial resolution. We only use data from the period common to all input datasets and RMM indexes - from September 1981 to August 2019.

The following three-step procedure is used to standardize the input from different datasets. First, we standardize temporal coverage and resolution. Hourly data from ERA5 are averaged to daily mean values. Second, we standardize the temporal resolution - the original data is regrided to Gaussian N16 grid (32×64), which is approximately $5 \times 5$ degrees. Two southmost data rows covering Antarctica are not used since they have no data for SST, resulting in a 30x64 final grid. Third, the data input is normalized with Min-Max Feature scaling. Every cell was processed independently, meaning that 0 and 1 represent minimum and maximum in the cell rather than global. The importance of each variable will be tested utilizing the CNN model by using only the information from one variable at a time. The second data category is global indices that include the information on large-scale processes influencing MJO and information on the state of the MJO itself. We use indexes that describe climate modes that MJO can potentially interact with - El-Niño Southern Oscillation (ENSO), Indian Ocean Dipole (IOD), North Atlantic Oscillation (NAO), and Pacific North American pattern (PNA). To describe the MJO itself, we use Realtime Multivariate MJO suggested by (Wheeler and Hendon, 2004), MJO 1-10 indexes, and the Velocity Potential MJO index (VPM). In addition, we calculate the first and second principal components (PC) of all the five geospatial variables described above (SST, SP, OLR, U200, U850). The indices that are 
not already between 0 and 1 are normalized using Min-Max feature scaling similarly to all the other data.

Train-Test data split is done similarly for both models, with the last five years allocated to test set and 3 years before the validation set. That leaves approximately 30 years for the training dataset. The validation set is used for adjusting the model's meta-parameters and ensemble parameters. The test set is used for the final evaluation, of which the results are presented in this article.

\subsection{Convolution Neural Network}

Figure 1 shows the schematics of the model architecture. The model consists of three blocks of Convolution layers followed by MaxPool layers and dropout with three fully connected layers in the end. Five input channels are used, one for every input variable; each channel is a map with the $30 \times 64$ shape (latitude, longitude). The first convolution layer has a $4 \times 8$ kernel on a Gaussian N16 grid that translates approximately to a region size of $20^{\circ}$ latitude to $40^{\circ}$ longitude. The model is forecasting normalized values of the RMM1 and RMM2 indexes. The default number of filters per layer is 256, 128,64 , and our tests show that further increasing the size of the network does not improve the performance.

The model is trained for 15 epochs, and further training does not significantly increase model performance. A dropout rate of $30 \%$ is used on each of the three dropout layers. The high dropout rate is necessary to prevent overfitting, and our testing shows that lower dropout rates result in less stable performance and overfitting with more comprehensive training.

\section{Input}
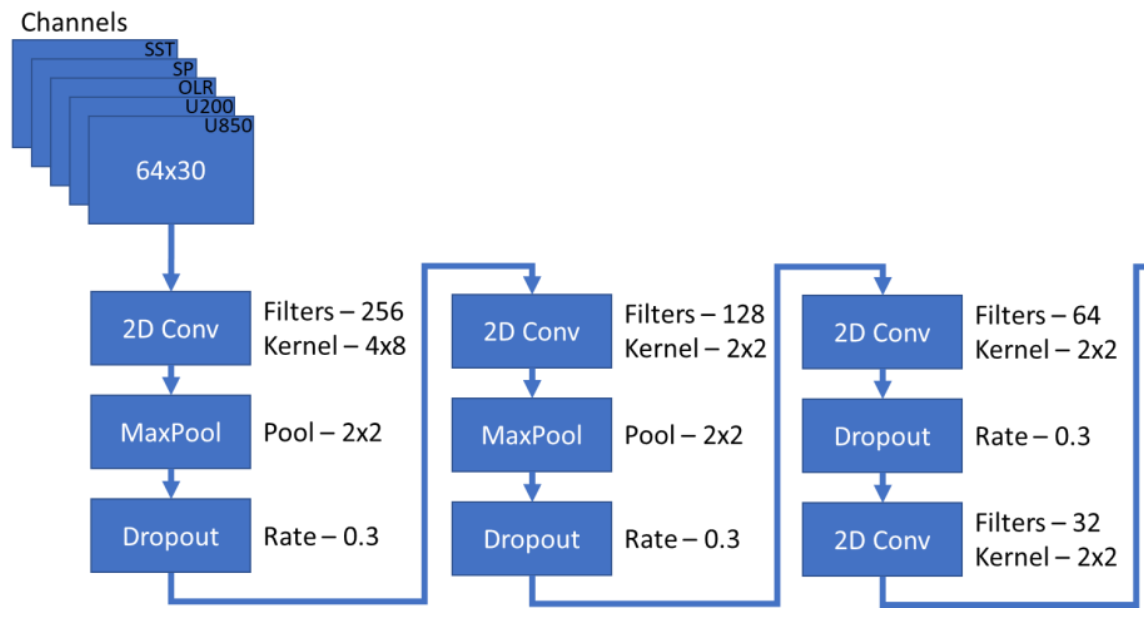

\section{Output} RMM1, RMM2

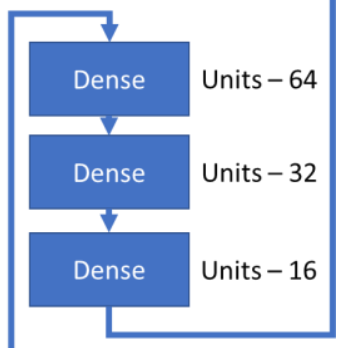


Figure 5.1. The architecture of the Convolution Neural Network (CNN) Model.

\subsection{Temporal Convolution Network}

Temporal convolutional networks are a novel architecture for sequence modeling that hierarchically captures relationships at different time scales (Lea et al., 2016). The TCN-based models are not yet widely used in Earth science applications, with one notable exception. In a recent study, a TCN model combined with an ensemble empirical mode decomposition (EEMD) was used to predict Niño 3.4 index and Southern Oscillation Index with an accuracy above that achieved with NWP models (Yan et al., 2020). TCN consistently outperformed other sequence modeling methods such as LSTM and ARIMA in a variety of applications.

Ensemble empirical mode decomposition (EEMD) was successfully used to enhance the TCN-based ENSO prediction in previous studies (Yan et al., 2020). The same technique is challenging to apply for RMM prediction since the RMM index is already a first and second principal component. The attempts to deconstruct RMM further require hundreds of components and do not make much sense from a methodological perspective. The TCN PCs model presented in this article employs a somewhat similar idea of using signal decomposition combined with TCN. Since it is not feasible to use EEMD or other signal decomposition techniques with RMM signal directly, we use PC decomposition techniques on spatial-temporal fields of meteorological variables composing the RMM signal. We can expect that using multivariate EMD instead of PC to decompose spatial-temporal fields of meteorological variables might yield better results. PC-based decomposition has well-known limitations when applied to systems in which dynamical modes are not normal to each other (Chattopadhyay et al., 2020), for example, mid-latitude circulations (Palmer, 1998, Farrell and Ioannou, 1996) The TCN model used in this study consist of three convolutional layers, each followed by Rectified Linear Unit and completed by three fully connected (dense) layers. The three convolution layers use 32, 64 , and 64 filters, respectively, with kernel size 4 . The dense layers sizes are 64, 64, and 32 .

TCN model inputs different data than CNN. It uses data from the second category - daily time series of global circulation indexes, as described in the data section.

The model is trained in two phases; it is trained normally for 100 epochs in the first phase. In the second stage, which also lasts 100 epochs, the model is randomly given either data for this step or data from the next step with a fifty-fifty chance. The model is trained to 
predict all the input parameters one step (day) ahead. The multiple steps model uses predicted values as a new input to generate the predicted trajectory step by step. After the training, the 42 days ahead trajectories are generated from every day of the test dataset, and the model skill for a range of prediction lengths is assessed.

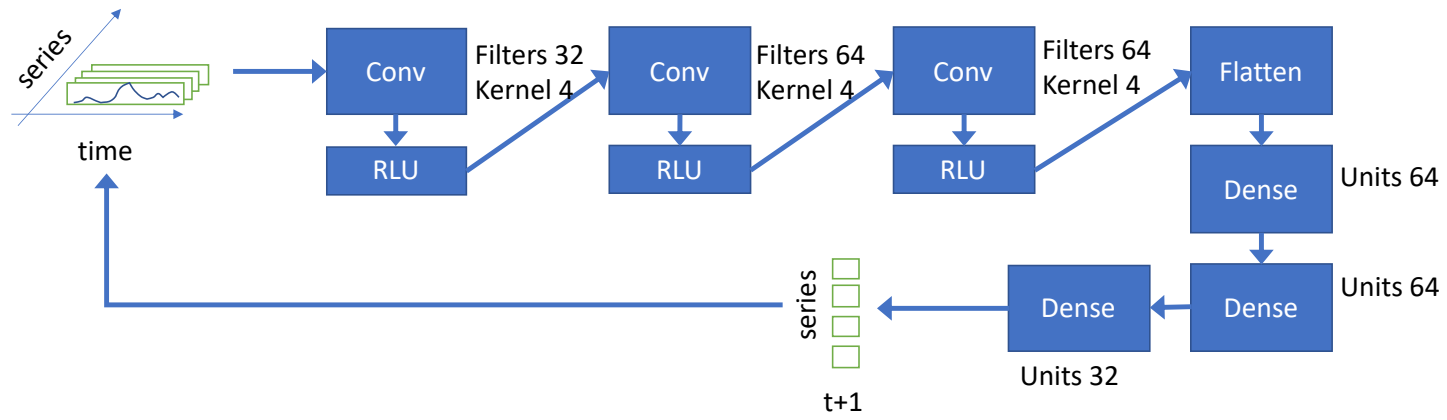

Figure 5.2. The architecture of the Temporal Convolution Model (TCN)

\subsection{Results}

All model variations demonstrate remarkably similar performance independent of lead time. Figures 3 and 4 demonstrate the value of bivariate correlation for different lead times for CNN and TCN models, respectively. For TCN, results are calculated for every day up to 42 days lead time. For the CNN model, results were only measured for 1 , $7,14,21$ days because the model must be trained for a specific lead time. Skillful prediction is maintained for up to 14 days for both CNN and TCN PCs models. Predictions of 7-day averaged values are skillful up to 16 days for CNN and 18 days for TCN PCs.

There is a difference in performance between the different versions of CNN models, as shown in Figure 5.3, and different TCN models in Figure 5.4. As expected, the versions of both CNN and TCN that use seven days smoothing are overperforming the respected versions that use raw input. However, the smoothed prediction offers a lower value, and the mild increase in prediction probably not compensates for the use of smoothed values. Here we will focus on comparing the versions of the models not using smoothed data.

To understand which variable provides the most information for the CNN model, we can compare the importance of five different variables (SST, SP, OLR, U850, and U200) of the first data category by training the CNN model using only the information from one variable at the time. Comparing the bivariate correlation for 14 days lead for individual fields, we observe that the best prediction is achieved using SP with 0.34 correlation followed by ORL, U850, and $\mathrm{U} 200(0.29,0.27$, and 0.23 respectively). SST is the least valuable predictor that can achieve only 0.17 correlation on its own. 
All three models (CNN, TCNi, TCNpc) show similar performance in the first week of the prediction, demonstrating the 0.7 correlation at the seven-day lead time. In the second week, the performance differences are starting to show. In the third week, TCNpc demonstrates much lower rate of performance decline compare to CNN, at the 21 days lead time TCNpc have bivariate correlation with the observations of $0.4, \mathrm{CNN}-0.3, \mathrm{TCNi}-0.25$. The skillful prediction horizon for TCNi is only 13 days. It is overperformed by both TCNpc and CNN that provide a skillful forecast for $\sim 15$ days. We additional tested a version of the TCN model that uses the inputs from both TCNi and TCNpc but have not demonstrated a significant performance increase compared to TCNpc.

There is a noticeable difference in the amplitude of the predicted and the observed RMM. The amplitude, calculated as the difference between $90^{\text {th }}$ and $10^{\text {th }}$ quantile, is 2.6 for observed RMM 1.9-2.0 for modeled RMM. For weekly averaged RMM, the observed amplitude is 2.4, and the modeled amplitude is 1.5-1.7 depending on the specific model.

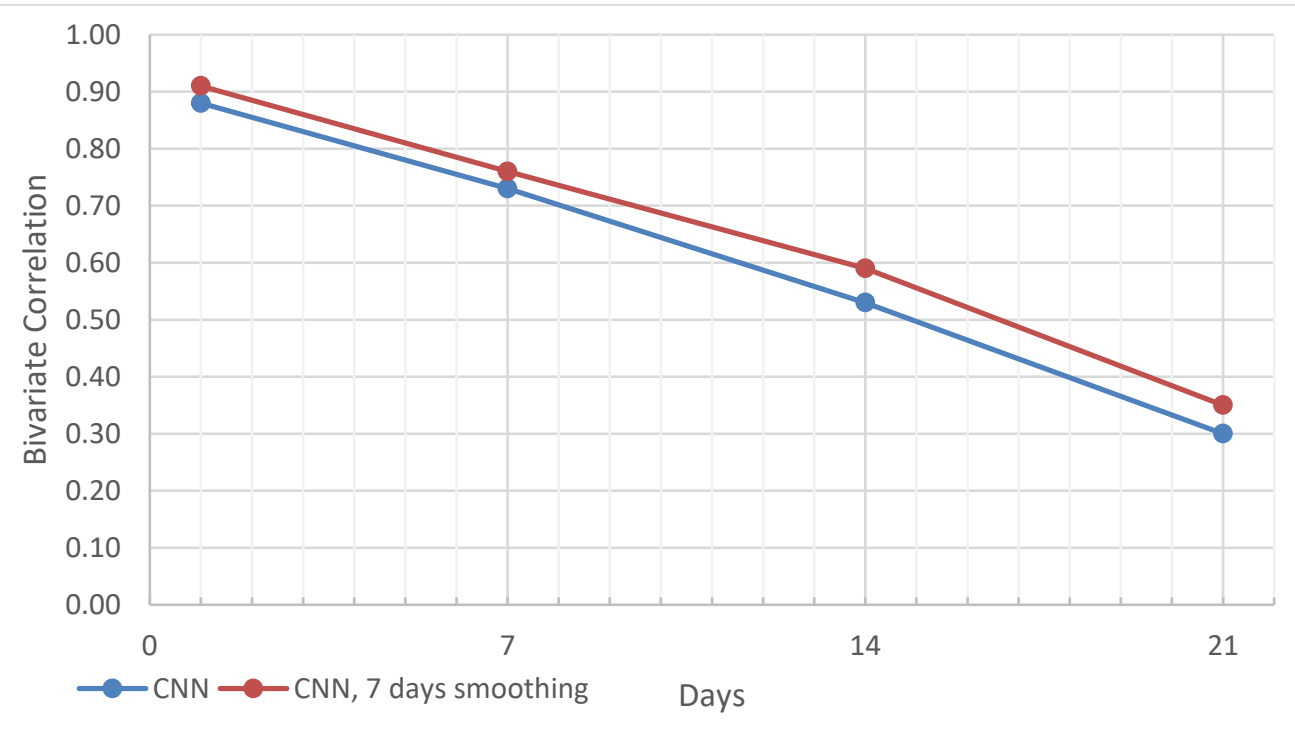

Figure 5.3. Bivariate correlation of predicted and observed RMM index value depending on a lead time for versions of the CNN model 


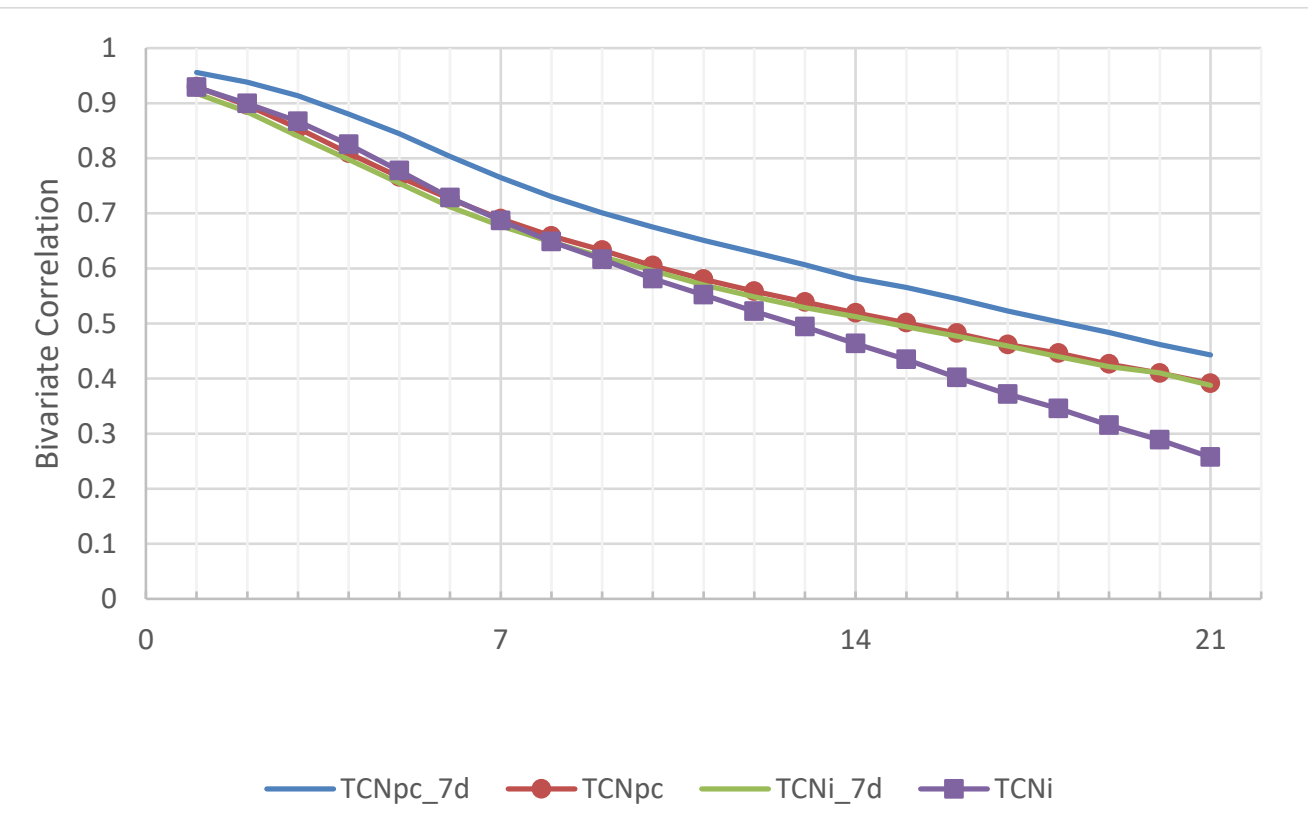

Figure 5.4. Bivariate correlation of predicted and observed RMM index value depending on a lead time for versions of the TCN model

Here we briefly examine how the best performing version of the TCN (TCNpc) predicts the Nino3.4 index. The TCN model produces predictions one step ahead for all the input variables, which allows us to evaluate its ability to predict the MJO index value and other circulation indexes. Looking at the Nino3.4 index predictions is particularly interesting since the previous studies indicate that Nino3.4 can be predicted well by models similar to those used in this study. For Nino 3.4 prediction, the model maintains an above 0.9 correlation between predicted and observed Nino3.4 index for the first 21 days and stays above 0.85 for the 42 days period that we tested. The much higher predictability for Nino3.4 compared to MJO can be explained by the slower evolution of ENSO compares to MJO. For both TCN and CNN models, it is possible to improve the prediction by using the ensabmle of models traineed with different random seeds. The model performance varies between different training attempts, and averaging out the training results might yield a performance improvement. For CNN, the variation between the training attempts is negligible. The prediction horizon varies by less than a day. Averaging the results with such slight variations does not improve the prediction horizon. For TCN, the results vary significantly from training to training (See Figure 5.7). By averaging the results of an ensemble of models trained with different random seeds, we can stabilize and improve the performance and push the horizon of skillful 
prediction from 14 days to 17 days (Figure 5.7). We use the first three years of the test period to evaluate the performance of individual candidates for the ensemble and use the last five years for a final evaluation of the resulting ensemble. However, this method is probably not practical as it increases the risks of overfitting to the specific test period, has increased computational expenses, and only moderately increases the prediction accuracy.

RMM1
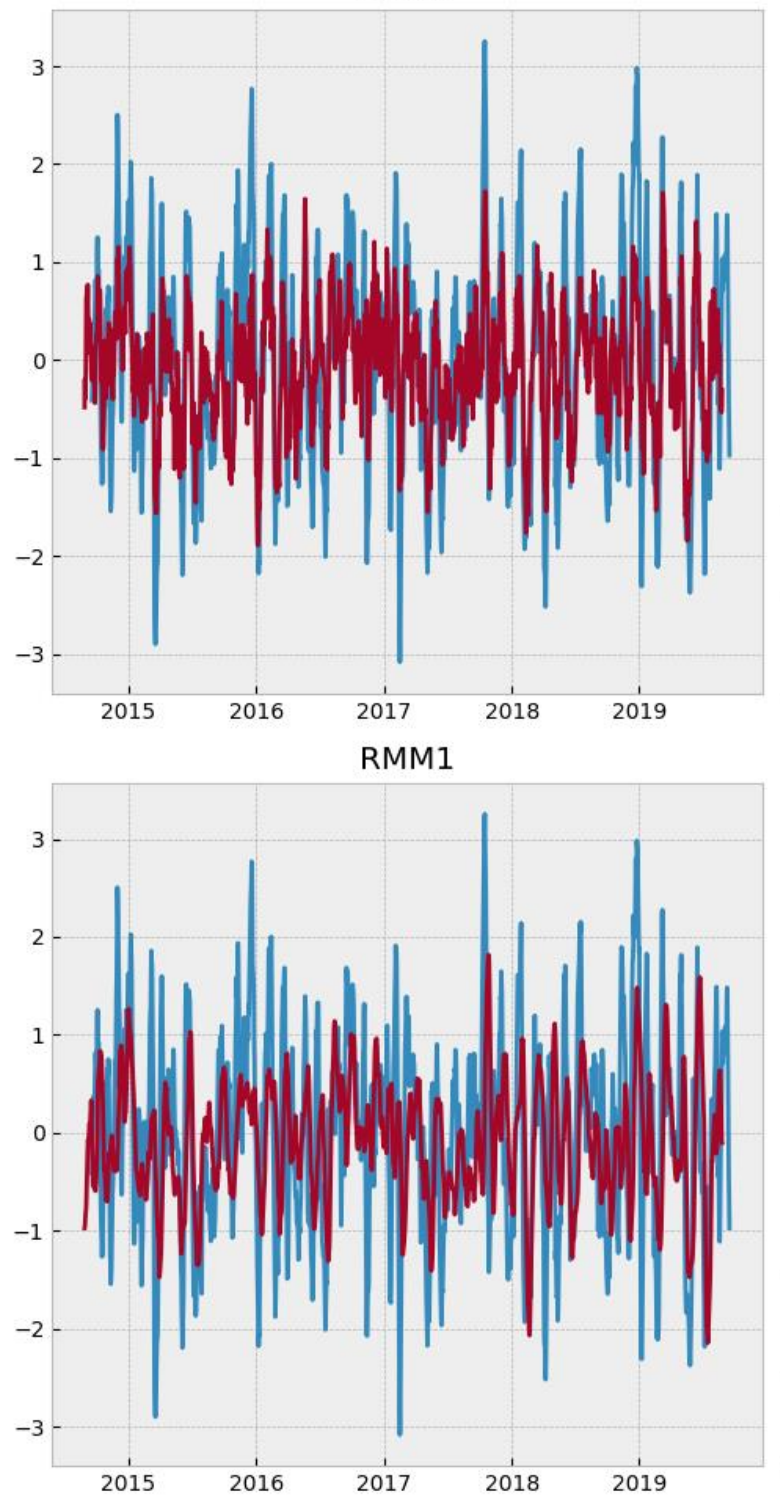

RMM2
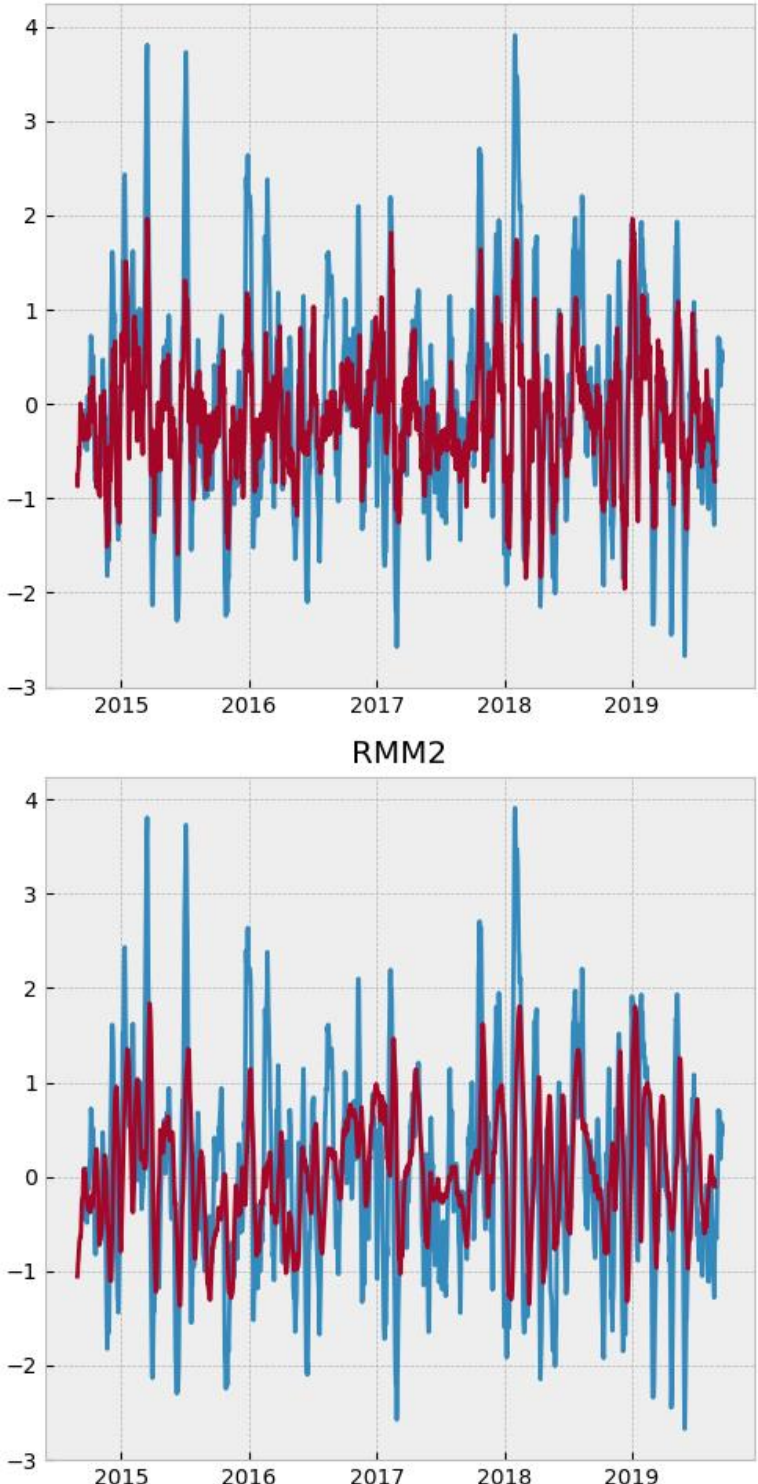
Figure 5.5. CNN model predictions - observed (Blue) and seven days lead time prediction (red) for RMM1 (left) and RMM2 (right) for regular input (top row) and 7-day smoothed data (bottom row).
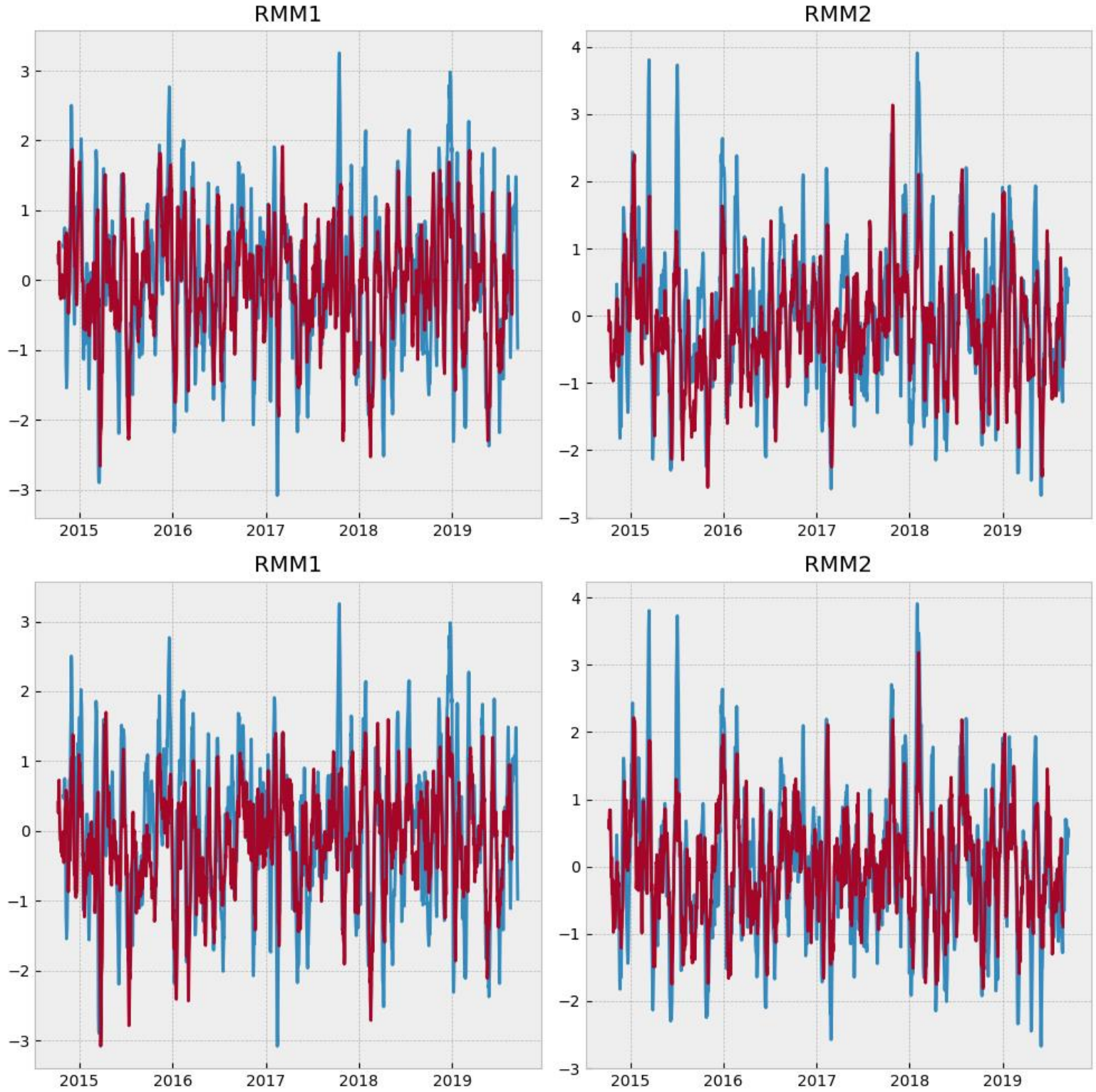

Figure 5.6. TCN model predictions - observed (Blue) and seven days lead time prediction (red) for RMM1 (left) and RMM2 (right) for 7-day smoothed indexes data (top row) and 7-day smoothed principal components (bottom row). 


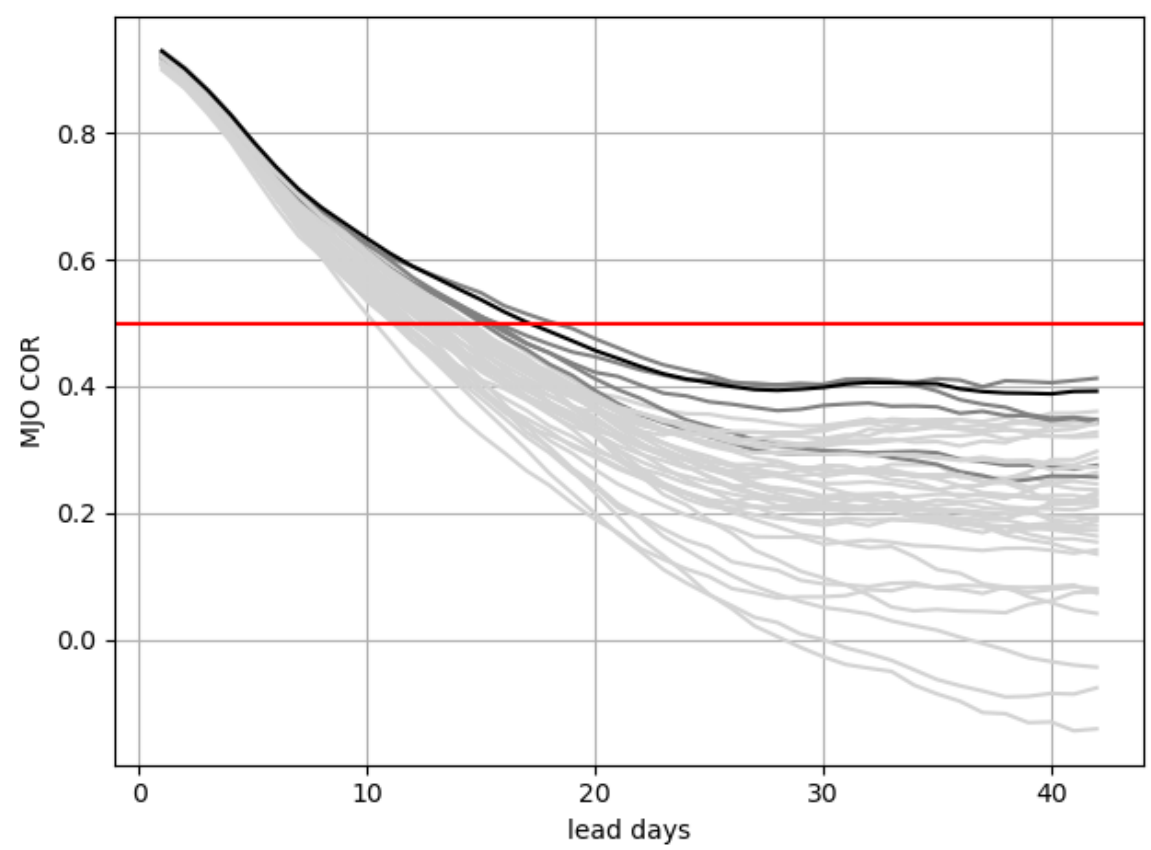

Figure 5.7. Individual models (light grey), selected ensemble members (grey) and ensemble mean (black). RMM bivariate correlation decline with increasing lead time for an ensemble of TCN models.

\subsection{Discussion and Conclusions}

This article presents a first attempt to predict MJO index values using two ML methods, CNN and TCN. Both presented models demonstrate similar performance maintaining skillful prediction for over two weeks, especially for 7-day smoothed data. This mirrors results from recent high-profile studies that demonstrated similar performance with CNN (Ham et al., 2019) and EEMD-TCN (Yan et al., 2020) in the predicted Nino 3.4 index, with both previous studies showing $\sim 0.6$ correlation for a 12-month leading time. The models in this study achieved the exact 0.6 correlation for $11-14$ days lead time, which is much lower than NWP. The difference in the prediction horizon relative to the NWP might be explained by the timescales of ENSO and MJO. ENSO cycles take place on characteristic timescales of a few years far beyond traditional NWP models' capabilities. The characteristic timescale of $\mathrm{MJO}$ is dramatically shorter and well in range on traditional NWP forecasts. Additionally, MJO is an arguably 
better understood physical process, further increasing the skill of traditional models.

Using the 7-day smoothing for the input and target data improves performance for both TCN and CNN models. The difference in bivariate correlation for 7-day smoothed models and non-smoothed ones are under 0.1 . The slight increase in bivariate correlation probably does not compensate for the reduced value in predicting a 7-day smoother RMM instead of the regular one.

In both TCN and CNN models, the effect of ensemble averaging on prediction horizon was tested. For CNN, the stabilizing effect is insignificant. It can be achieved by increasing the size of the neural network, although ensembles still have slightly better performance compared to the individual models. For TCN, ensembles show much better performance compared to individual models.

Out of all six model variations, TCN PCs shown the best result with the bivariate correlation of 0.52 for 14 days lead time for TCNpc and 0.58 for TCNpc_7d. CNN models give similar results with 0.53 and 0.59 bivariate correlation for non-smoothed and 7-day smoothed versions, respectively. While the difference in skill between CNN and TCN PCs is slight, the TCN PCs model uses much fewer input data (just several global indexes as an input versus global grids of several variables) and, because of that, requires less computational resources.

Another notable difference with previous studies is that the presented CNN model only uses information from current timesteps to make a prediction. Our experiments with adding information from previous timesteps to the CNN model input do not improve the prediction. It is astonishing considering that a similar model for Niño 3.4 index prediction (Ham et al., 2019) and our own reproducing of this study (https://github.com/kokorev/Nino_CNN) uses information from three previous timesteps and demonstrates decreased performance when using only one current timestep. The reasons behind this difference between $\mathrm{MJO}$ and Nino3.4 predictions in utilizing the information from previous timestamps require further investigations.

Both CNN and TCN demonstrate excellent performance in predicting Earth system processes outperforming previous ML-based attempts in MJO index value prediction. The big advantage of the presented models is their applicability in a wide array of earth science applications with minimal changes to the model architecture. Presented CNN model inputs NetCDF files in standard Gaussian N16 grid and can be easily modified to work with higher resolutions if necessary. Any global gridded data can be easily used as a predictor and model for regression and modification classification tasks. The TCN model is also connected very well with basic concepts in the Earth sciences. TCN model inputs time series, which can be either 
observed time series or decomposed data of higher dimensionality. TCN models show an enormous potential in time series predictions, a task that is among the most common in the Earth sciences.

The code for both models available on the GitHub (github.com/kokorev). 
Table 5.1. Meta information about the data used in this study. For variable short name used through the text, long name, dataset name, spatial resolution, and citation provided.

\begin{tabular}{|c|c|c|c|c|}
\hline $\begin{array}{l}\text { Short } \\
\text { Name }\end{array}$ & Long Name & $\begin{array}{l}\text { Temporal } \\
\text { and Spatial } \\
\text { Resolution }\end{array}$ & $\begin{array}{l}\text { Dataset and } \\
\text { Organization }\end{array}$ & reference \\
\hline SST & $\begin{array}{l}\text { Sea surface } \\
\text { temperature } \\
\text { anomaly }\end{array}$ & $\begin{array}{l}2^{\circ} \times 2^{\circ} \\
\text { daily }\end{array}$ & $\begin{array}{l}\text { NOAA OISST } \\
\text { v.2 }\end{array}$ & $\begin{array}{l}\text { (Banzon et } \\
\text { al., 2020) }\end{array}$ \\
\hline SP & $\begin{array}{l}\text { Surface } \\
\text { Pressure }\end{array}$ & $\begin{array}{l}30 \mathrm{~km} \times \\
30 \mathrm{~km}, \\
\text { hourly }\end{array}$ & $\begin{array}{l}\text { ERA5, } \\
\text { ECMWF }\end{array}$ & $\begin{array}{l}\text { (Hersbach } \\
\text { et al., 2020) }\end{array}$ \\
\hline U850 & $\begin{array}{l}\text { U-wind at } \\
850 \mathrm{mba} \\
\text { surface }\end{array}$ & $\begin{array}{l}30 \mathrm{~km} x \\
30 \mathrm{~km}, \\
\text { hourly }\end{array}$ & $\begin{array}{l}\text { ERA5, } \\
\text { ECMWF }\end{array}$ & $\begin{array}{l}\text { (Hersbach } \\
\text { et al., 2020) }\end{array}$ \\
\hline U200 & $\begin{array}{l}\text { U-wind at } \\
850 \mathrm{mba} \\
\text { surface }\end{array}$ & $\begin{array}{l}30 \mathrm{~km} \mathrm{x} \\
30 \mathrm{~km}, \\
\text { hourly }\end{array}$ & $\begin{array}{l}\text { ERA5, } \\
\text { ECMWF }\end{array}$ & $\begin{array}{l}\text { (Hersbach } \\
\text { et al., 2020) }\end{array}$ \\
\hline OLR & $\begin{array}{l}\text { Outgoing } \\
\text { Longwave } \\
\text { Radiation }\end{array}$ & $\begin{array}{l}2^{\circ} \times 2^{\circ} \\
\text { daily }\end{array}$ & $\begin{array}{l}\text { NOAA } \\
\text { Interpolated } \\
\text { OLR }\end{array}$ & $\begin{array}{l}\text { (Hai-Tien } \\
\text { Lee and } \\
\text { Program, } \\
\text { 2011) }\end{array}$ \\
\hline $\begin{array}{l}\text { RMM1, } \\
\text { RMM2 }\end{array}$ & $\begin{array}{l}\text { Realtime } \\
\text { Multivariate } \\
\text { MJO }\end{array}$ & $\begin{array}{l}\text { Global } \\
\text { daily index }\end{array}$ & $\begin{array}{l}\text { KNMI climate } \\
\text { explorer }\end{array}$ & $\begin{array}{l}\text { (van } \\
\text { Oldenborgh } \\
\text { et al., 2008) }\end{array}$ \\
\hline $\begin{array}{l}\mathrm{MJO} \\
1-10\end{array}$ & $\begin{array}{l}\text { Madden-Julian } \\
\text { Oscillation } \\
\text { Index }\end{array}$ & $\begin{array}{l}\text { Global } \\
\text { daily index }\end{array}$ & $\begin{array}{l}\text { KNMI climate } \\
\text { explorer }\end{array}$ & $\begin{array}{l}\text { (van } \\
\text { Oldenborgh } \\
\text { et al., 2008) }\end{array}$ \\
\hline $\begin{array}{l}\text { Nino } \\
1+2, \\
3.4,4\end{array}$ & $\begin{array}{l}\text { Nino SST } \\
\text { indices }\end{array}$ & $\begin{array}{l}\text { Global } \\
\text { daily index }\end{array}$ & $\begin{array}{l}\text { KNMI climate } \\
\text { explorer }\end{array}$ & $\begin{array}{l}\text { (van } \\
\text { Oldenborgh } \\
\text { et al., 2008) }\end{array}$ \\
\hline SOI & $\begin{array}{l}\text { Southern } \\
\text { Osculation } \\
\text { Index }\end{array}$ & $\begin{array}{l}\text { Global } \\
\text { daily index }\end{array}$ & $\begin{array}{l}\text { KNMI climate } \\
\text { explorer }\end{array}$ & $\begin{array}{l}\text { (van } \\
\text { Oldenborgh } \\
\text { et al., 2008) }\end{array}$ \\
\hline $\begin{array}{l}\text { VPM } \\
\text { pc1, } \\
\text { pc2 }\end{array}$ & $\begin{array}{l}\text { The Velocity } \\
\text { Potential MJO } \\
\text { index }\end{array}$ & $\begin{array}{l}\text { Global } \\
\text { daily index }\end{array}$ & $\begin{array}{l}\text { KNMI climate } \\
\text { explorer }\end{array}$ & $\begin{array}{l}\text { (van } \\
\text { Oldenborgh } \\
\text { et al., 2008) }\end{array}$ \\
\hline $\begin{array}{l}\text { SST } \\
\text { PC1, } \\
\text { PC2 }\end{array}$ & $\begin{array}{l}\text { Principle } \\
\text { components of } \\
\text { Sea Surface } \\
\text { temperature }\end{array}$ & $\begin{array}{l}\text { Global } \\
\text { daily index }\end{array}$ & $\begin{array}{l}\text { Calculated } \\
\text { from SST } \\
\text { using CDO }\end{array}$ & $\begin{array}{l}\text { (van } \\
\text { Oldenborgh } \\
\text { et al., 2008) }\end{array}$ \\
\hline $\begin{array}{l}\text { SP } \\
\text { PC1, } \\
\text { PC2 }\end{array}$ & $\begin{array}{l}\text { Principle } \\
\text { components of } \\
\text { Surface } \\
\text { Pressure } \\
\end{array}$ & $\begin{array}{l}\text { Global } \\
\text { daily index }\end{array}$ & $\begin{array}{l}\text { Calculated } \\
\text { from SP } \\
\text { using CDO }\end{array}$ & $\begin{array}{l}\text { Calculated } \\
\text { for this } \\
\text { study }\end{array}$ \\
\hline
\end{tabular}




\begin{tabular}{|l|l|l|l|l|}
\hline $\begin{array}{l}\text { U850 } \\
\text { PC1, } \\
\text { PC2 }\end{array}$ & $\begin{array}{l}\text { Principle } \\
\text { components of } \\
\text { U-wind at } \\
850 m b a \\
\text { surface }\end{array}$ & $\begin{array}{l}\text { Global } \\
\text { daily index }\end{array}$ & $\begin{array}{l}\text { Calculated } \\
\text { from U850 } \\
\text { using CDO }\end{array}$ & $\begin{array}{l}\text { Calculated } \\
\text { for this } \\
\text { study }\end{array}$ \\
\hline $\begin{array}{l}\text { U200 } \\
\text { PC1, }\end{array}$ & $\begin{array}{l}\text { Principle } \\
\text { components of } \\
\text { U-wind at } \\
\text { PC2 } \\
\text { surface }\end{array}$ & $\begin{array}{l}\text { Global } \\
\text { daily index }\end{array}$ & $\begin{array}{l}\text { Calculated } \\
\text { from U200 } \\
\text { using CDO }\end{array}$ & $\begin{array}{l}\text { Calculated } \\
\text { for this } \\
\text { study }\end{array}$ \\
\hline $\begin{array}{l}\text { OLR } \\
\text { PC1, } \\
\text { PC2 }\end{array}$ & $\begin{array}{l}\text { Principle } \\
\text { components of }\end{array}$ & $\begin{array}{l}\text { Global } \\
\text { daily index }\end{array}$ & $\begin{array}{l}\text { Calculated } \\
\text { from OLR } \\
\text { using CDO }\end{array}$ & $\begin{array}{l}\text { Calculated } \\
\text { for this } \\
\text { study }\end{array}$ \\
\hline
\end{tabular}

Table 5.2. List of model variations for CNN and TCN methods, with input and output listed

\begin{tabular}{|l|l|l|}
\hline Model & Input & Output \\
\hline CNN & SST, SP, U850, U200, OLR & $\begin{array}{l}\text { RMM1, RMM2 for the } \\
\text { Nth prediction step }\end{array}$ \\
\hline $\begin{array}{l}\text { CNN, 7days } \\
\text { smoothed } \\
\text { (CNN_7d) }\end{array}$ & SST, SP, U850, U200, OLR & $\begin{array}{l}\text { Smoothed RMM1, } \\
\text { RMM2 for the Nth } \\
\text { day ahead }\end{array}$ \\
\hline $\begin{array}{l}\text { TCN Index } \\
\text { (TCNi) }\end{array}$ & $\begin{array}{l}\text { RMM 1-2; MJO 1-10; Nino } \\
1+2,3.4,4 ; \text { VPM pc1-2, } \\
\text { VPM amplitude, }\end{array}$ & $\begin{array}{l}\text { Same as input, for } \\
\text { every prediction } \\
\text { step }\end{array}$ \\
\hline $\begin{array}{l}\text { TCN Index, } \\
\text { seven days } \\
\text { smoothed } \\
\text { (TCNi_7d) }\end{array}$ & $\begin{array}{l}\text { Same as TCN smoothed with } \\
\text { seven days rolling window }\end{array}$ & $\begin{array}{l}\text { Same as input, for } \\
\text { every prediction } \\
\text { step }\end{array}$ \\
\hline $\begin{array}{l}\text { TCN PCs } \\
\text { (TCNpc) }\end{array}$ & $\begin{array}{l}\text { RMM 1-2; SST PC1-2; SP } \\
\text { PC1-2; U850 PC1-2; U200 } \\
\text { PC1-2; OLR PC1-2; Nino }\end{array}$ & $\begin{array}{l}\text { Same as input, for } \\
\text { every prediction } \\
\text { step }\end{array}$ \\
$\begin{array}{l}\text { TC2, 3.4, 4; } \\
\text { SCN PCs, } \\
\text { smoothed } \\
\text { (TCNpc_7d) }\end{array}$ & $\begin{array}{l}\text { Same as TCN PCs smoothed } \\
\text { with seven days rolling }\end{array}$ & $\begin{array}{l}\text { Same as input, for } \\
\text { every prediction } \\
\text { step }\end{array}$ \\
\hline
\end{tabular}




\section{Conclusions}

This thesis investigated precipitation regime changes in the Maritime Continent (MC) and concluded that distinctly different precipitation regimes had been observed. The rapid change between different precipitation regimes named precipitation regime shift associated with Pacific Decadal Oscillation (PDO) causes a rapid change in the MC's precipitation spatial and temporal distribution. Therefore, we can expect the future change in precipitation regime to come as a rapid precipitation regime shift rather than a gradual, linear transition. Three independent lines of evidence for the regime shift in the MC were presented - evidence from physical understanding of the process, evidence from statistical analysis of observed precipitation data, and evidence from GCMs experiments. The thesis also explores the predictability of global circulation processes using the modern Machine Learning (ML) approach. These conclusions summarize the presented lines of evidence and the results of the ML study, explore the potential for future work and societal impact of this study. Below, each line of evidence is summarized in a separate subsection.

\subsection{Physical evidence}

Some evidence of the PDO cycle's influence on global climate and the $\mathrm{MC}$ were available in the existing literature and were summarized in the introduction (Chapter 1). For example, studies on PDO modulating monsoon and on PDO impacting global temperature were previously available or came up during the work on this thesis. One of the novel elements in this study is the influence of PDO on the precipitation regime in the MC. To be more specific, the focus of this thesis was the influence of PDO on ENSO-associated precipitation anomalies in the MC. The influence of PDO on the ENSO-induced anomalies is called the PDO-ENSO modulation effect. The ENSO is the most substantial factor of long-period precipitation variability in the MC, making the PDO-ENSO modulation effect especially noticeable. Chapter 2 concludes that the PDO cycle modulates the impacts of ENSO on precipitation regimes in the MC. The PDO cold and hot phases are associated with statistically distinct spatial and temporal distributions of ENSO-associated precipitation and SST anomalies in the MC. Opposite PDO phases create different precipitation regimes by altering ENSO and Monsoon impacts on precipitation. Based on his mechanism, it can be expected that transitions between opposite PDO phases in 1946, 1976, and 1999 lead to changes in the precipitation regime. The estimation of expected changes in precipitation regime between opposite PDO phases is provided in Chapter 2. Given the 
suggested PDO-ENSO modulation mechanism, the MC's precipitation regime shifts should be observed in 1946, 1976/77, and 1999.

\subsection{Statistical evidence}

Chapter 3 presents statistical evidence that the precipitation regime shift of 1976/77 can be observed in the data. The novel Bayesian method for time-series regime shift detection is presented in Chapter 3 . The Bayesian regime shift detection allows detecting changes in distribution parameters of daily precipitation and not only changes in long period mean values. The presented method does not make any assumptions of the regime shift existence or position. It also provides a measure of uncertainty for regime shift position. In chapter 3 , the presented method is applied to daily observed weather station data from the SACA\&D archive. The statistical evidence of the precipitation regime shift of $1976 / 77$ is presented. The regime shift of 1976/77 was detected in the Northern Hemispheric part of the MC. The Southern Hemispheric part of the MC experienced more gradual, linear changes in the precipitation regime than the Northern Hemispheric part. The quantitative change in precipitation distribution estimated from this method is consistent with the ones suggested by the analysis of PDO-ENSO interactions in Chapter 2.

The regime shift of 1999 was often detected as the second most likely regime shift position on selected stations. However, we could not confirm this regime shift for the whole dataset due to the computational cost of running the recursive regime shift detection method. Running the Bayesian regime shift detection on a gridded version of the SACA dataset (1981-2018) also shows regime shift in 1999. However, it coincides with a dramatic change in the number of weather stations providing data for the gridded archive. Therefore, it is difficult to prove that the detected regime shift is caused by the physical process rather than changes in the input data. Due to these reasons, results relating to the 1999 regime shift were not included in Chapter 3.

In chapter 5 , the modified, recursive version of the regime shift detection method is introduced, as described in the next section. The results of running the modified algorithm on the time-series of mean monthly precipitation anomalies in the $\mathrm{MC}$ are presented in Chapter 5 . The results show that the modified algorithm can detect the regime shift in 1999, the second regime shift in the early 1950-x, several years after the expected date. The regime shift of 1976 is missed due to the modified method's low sensitivity and limitations of using spatial and temporal aggregated data. 


\subsection{GCMs-based evidence}

Chapter 5 presents the evidence of precipitation regime shifts existing in the CMIP6 model simulations. The methodology used in chapter 2 is reused to test the model's ability to reproduce the PDO-ENSO modulation effect. Most models reproduce ENSO impacts on precipitation, and a smaller subset of models also reproduces PDOENSO modulation effects. The range of uncertainty for predicted precipitation values is high across all the Shared Socioeconomic Pathways (SSP) experiments. The individual models predict both increase and a decline in the total precipitation amount in the MC. However, models that reproduce PDO-ENSO interaction effects well overwhelmingly predict an increase in the precipitation amount. Additional evidence can be provided using the Bayesian regime shift detection method on CMIP6 Historical and SSP experiments. Using the Bayesian detection algorithm presented in chapter 3 on the CMIP6 data encounters two problems. First, the modeled daily precipitation data is low quality, and monthly precipitation sums are preferable. Secondly, and more importantly, it is computationally not feasible to run the Bayesian detection algorithm presented in chapter 3 on the whole mass on modeled data. The modified version of the algorithm is introduced to circumvent both issues. The modified version inputs monthly mean precipitation anomalies averaged for the $\mathrm{MC}$ and used normal distribution to describe them. Much of the algorithm's sensitivity is lost because of the switch from locally observed daily precipitation to spatially averaged monthly aggregated precipitation anomalies. On the upside, with the simplified algorithm, it becomes feasible to run the algorithm recursively to detect multiple regime shifts per time series.

The results of applying the modified algorithm to the CMIP6 climate simulations data show that GCMs simulations have precipitation regime shifts in both historical and predictive model experiments. The results increase the evidence that the detected precipitation regime shift is a fundamental feature of the climate system.

\subsection{Machine learning for predicting precipitation regime shift}

Forecasting precipitation regimes and regime shifts on a seasonal scale and beyond are challenging using traditional methods. Recent studies show that for specific applications, the ML-based forecast can outperform traditional predictions. The potential for ML-driven prediction of impacts of extreme precipitation should be explored. Chapter 4 explores the possibility of using Machine Learning (ML) for predicting global circulation indexes. The example of MJO prediction is used to test the performance of CNN and TCN models. 
The CNN and TCN models introduced in chapter 4 use a very different approach to predicting time series. CNN model uses much spatial information but does not consider previous timesteps. The TCN model, on the other side, uses much temporal information about circulation indexes but does not consider spatial patterns beyond the information encoded in the indexes. Both models demonstrate similar performance with the ability to predict the MJO for a bit over two weeks. The used models demonstrate promising performance but fall short of overperforming traditional approaches.

The version of the CNN model used in Chapter 4 shows excellent performance in predicting Nino3.4, maintaining skillful prediction for up to 12 months ahead. The results fall outside of the scope of this thesis but shown in the dedicated GitHub repository (https://github.com/kokorev/Nino_CNN)

\subsection{Future work}

\subsubsection{Bayesian regime shift detection performance.}

The presented Bayesian regime shift detection method proved invaluable for this study and demonstrated potential for other applications. The main downsides of the methods are their computational cost and rarely fails to converge. The Bayesian regime shift detection method's improvements should be made to investigate further the influence of the PDO cycle of the precipitation regime and global climate. Both versions of the Bayesian regime shift detection method used in this thesis suffer from high computational cost and slow performance. The computational cost should be reduced to facilitate future research. Optimizing MCMC performance can yield moderate improvement, but achieving a significant speedup MCMC should be replaced with a different numerical method for Bayesian Inference. The best alternative to MCMC in this context is Integrated Nested Laplace Approximation (INLA). Fundamental limitations of the INLA do not allow for realizing regime shift detection based on Gamma distribution (presented in Chapter 3). However, the realization of the method based on Normal distribution is possible. The straightforward realization of the same method using the R-INLA package has a similar performance to the original. However, with some optimization, R-INLA realization should have at least an order of magnitude faster than the original, MCMC-based realization. Developing a more efficient realization of the Bayesian regime shift detection method will allow a detailed exploration of the observed precipitation regime shift's spatial structure. It will also enable a global study of the PDO-driven regime shifts. As an added benefit, 
the switch to using INLA will eliminate the issues with convergence since it does not rely on numerical approximations.

Additionally, a version of the method for early detection of regime shifts should be developed. The early detection algorithm should estimate the probability of recent regime shift occurrence in real-time as new data comes in. Such early detection systems are developed in other disciplines that deal with mathematically similar problems, for example, borehole drilling or stock trading. Those methods could, with some effort, be adopted to the detection of climatic regime shifts. For the MC's precipitation regime, the natural variability is exceptionally high, making early detection of the regime shift challenging based on precipitation observations alone. The physical connection to other climatic variables such as SST could be exploited to improve the method's reliability.

\subsubsection{Studying the impacts of historical precipitation regime shifts}

The impact of PDO phase change on the marine environment and fishing industry has been studied extensively. The environmental and economic impact of the precipitation regime shift in the MC should be studied similarly. Precipitation regime shift expected to impact agriculture, water management, frequencies of flash floods, and landslides. Understanding these impacts is essential for planning adaptation measures and planning the response to a new regime shift.

The precipitation regime shift model described in this thesis presents a valuable framework for understanding the impacts of precipitation changes on the natural and anthropogenic systems. Additional work is needed to translate the the changes in the precipitation distribution that we estimated to the metrics that are more understandable and comparable with the other studies. A good way forward will be to look into changes in standard climatic indecies associated with detected regime changes. While there are studies that focuses on changes in selected indecies in a specific regions, for example (Orange et al., 2018, Klein Tank et al., 2006, Suman and Maity, 2020), the big picture behind the local changes often remains hidden. The method demonstrated in this thesis can be used as a unifying framework to study rapid changes in the regime shifts globally. Some of the precipitation indiecies could be estimated directly from the precipitation distribution, and studied within presented Bayesian regime shift detection method, while others requarie to make some adjustment to the method. Studying the changes in the climate indecies could bridge the gap between academic nature of presented 
results and economic impacts that rapid changes in climate regimes are causing.

The other way to bring the presented results to practical usefulness will be to look for evidence of the climate impacts in the economic data. One can find the evidence of climate regime shift having an impact on economic activity, for example, the period of positive PDO from 1977-1999 corresponds to higher rice yields in Indonesia. However, this approach requaries long term economic data and specific knowledge of economic process to persue seriously.

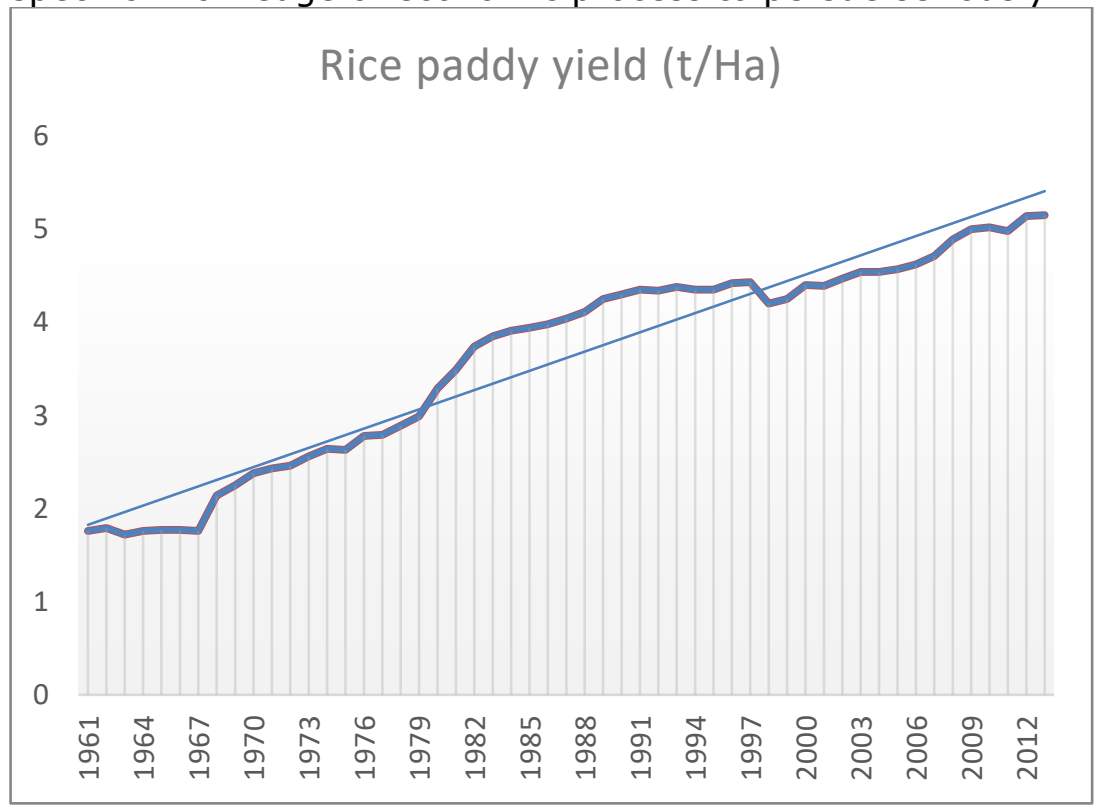

Figure 6.1. Annual Rice Yield per Hectare in Indonesia 1961-2013. data from [http://ricepedia.org/indonesia]

\subsection{Societal context}

The results presented in this thesis are increasing the evidence of the occurrence of non-linear, non-gradual changes in the climate system in historical time. The precipitation regime shift presented here is one of many similar effects. Some of them were listed in the introduction, and some are perhaps yet to be discovered. Nevertheless, the existence of such events should be considered when estimating the rate of climate change and planning adaptation measures.

\subsubsection{Perceived rate of climate change}

There is convincing evidence of long-period ocean oscillations such as the PDO governing trend of global temperature. During negative PDO, 
ocean heat content increases while global air temperature stays stable; during positive PDO, the global air temperature trend is strongly positive, but ocean heat content remains stable (see Chapter 1 , figure 3 ). The alterations between periods of ocean warming and atmospheric warming explain the cold period of 1946-1976 and apparent climate "hiatus" in 1998-2014. The choice of the period for trend estimation is an important methodological question. The period's choice can under or overestimate the rate of change depending on the position of tipping points in the chosen period. Knowing the position of regime shift points presents a guide for choosing a period for estimating a rate of change. This question is discussed in the author's previous publication (Anisimov et al., 2013). Despite an increasing body of evidence, those tipping points in the global temperature series are only discussed in a few specialized publications and almost non-existent in public discourse. Bringing the understanding of the stepwise nature of climate change to the public discourse is essential. The existence of periods with no atmospheric warming is a common argument of climate change deniers, most famously US Senator Ted Cruz (R) announcing in 2016 that there has been "no significant warming whatsoever for the last 18 years" (Mooney, 2016). At that time, the rebuttals to this argument focused on cherry-picking and using a hot El-Niño year (1997) to start the trend. However, such rebuttals do not address why such a long period with zero trends exists. While most reasonable people would agree that picking only 18.9 years with no warming is not the correct thing to do, the additional explanation can strengthen the scientific community's argument. The model of alternating periods of atmospheric and oceanic warming can be a better explanation since it provides the reason for the "hiatus" in global temperatures rather than dismissing the argument purely on the grounds of methodology.

\subsubsection{The impact of fast changes}

As highlighted in the fifth IPCC report, the rate of change is often more critical than the magnitude of change when discussing the impacts of climate change. For example, the PDO phase change of 1976 led to a devastating impact on the North Pacific environment and the collapse of salmon fishing in Alaska. However, the phase change of 1999 had a much smaller impact on the environment. The difference between the two events is the speed of change - the phase change of 1976 happened in less than a year, while phase change in 1999 occurred gradually over several years, given the ecosystems time to adjust to changing conditions. The rapid change from one level to the other has a different impact than a gradual change between the same levels. 
Understanding and being able to predict the timing and the speed of PDO phase change is crucial. Future changes of precipitation regime in the $\mathrm{MC}$ are likely to come in short periods of fast change after a stable regime. The potential of fast change in precipitation regime should be considered during adaptation planning. Adapting to the new precipitation regime may require changing a crop calendar, water use guidelines, and other measures that could not be implemented instantly. Planning and early detection can dramatically reduce the impact of the precipitation regime shift.

The fast precipitation regime shift described in this thesis is expected to have a higher impact than a gradual change of the same magnitude. Long periods of stability reduce the perceived need for adaptation planning, causing the following fast changes to have a massive impact due to lack of adaptation. The impact of rapid change compounding with the lack of adaptation can lead to dramatic consequences. Further study of the precipitation regime shift and its impacts is necessary. 


\section{Bibliography:}

AGRAWAL, S., BARRINGTON, L., BROMBERG, C., BURGE, J. R., GAZEN, C. \& HICKEY, J. 2019. Machine Learning for Precipitation Nowcasting from Radar Images. ArXiv, abs/1912.12132.

ALDRIAN, E. \& DWI SUSANTO, R. 2003. Identification of three dominant rainfall regions within Indonesia and their relationship to sea surface temperature. International Journal of Climatology, 23, 1435-1452.

ALEXANDERSSON, H. 1986. A homogeneity test applied to precipitation data. Journal of Climatology, 6, 661-675.

AMIEN, I., REJEKININGRUM, P., PRAMUDIA, A. \& SUSANTI, E. 1996. Effects of interannual climate variability and climate change on rice yield in Java, Indonesia. Water, Air, and Soil Pollution, 92, 29-39.

ANDREOLI, R. V. \& KAYANO, M. T. 2005. ENSO-related rainfall anomalies in South America and associated circulation features during warm and cold Pacific decadal oscillation regimes. International Journal of Climatology, 25, 2017-2030.

ANISIMOV, O., KOKOREV, V. \& ZHIL'TSOVA, Y. 2013. Temporal and spatial patterns of modern climatic warming: case study of Northern Eurasia. Climatic Change, 118, 871-883.

BANZON, V., SMITH, T. M., CHIN, T. M., LIU, C. \& HANKINS, W. 2016. A long-term record of blended satellite and in situ seasurface temperature for climate monitoring, modeling and environmental studies. Earth Syst. Sci. Data, 8, 165-176.

BANZON, V., SMITH, T. M., STEELE, M., HUANG, B. \& ZHANG, H.-M. 2020. Improved Estimation of Proxy Sea Surface Temperature in the Arctic. Journal of Atmospheric and Oceanic Technology, 37, 341-349.

BARLOW, M., NIGAM, S. \& BERBERY, E. H. 2001. ENSO, Pacific Decadal Variability, and U.S. Summertime Precipitation, Drought, and Stream Flow. Journal of Climate, 14, 2105-2128.

BUISHAND, T. A. 1982. Some methods for testing the homogeneity of rainfall records. Journal of Hydrology, 58, 11-27.

BULYGINA, O. N., RAZUVAEV, V. N., KORSHUNOVA, N. N. \& GROISMAN, P. Y. 2007. Climate variations and changes in extreme climate events in Russia. Environmental Research Letters, 2, 045020.

CHANDRASA, G. T. \& MONTENEGRO, A. 2020. Evaluation of regional climate model simulated rainfall over Indonesia and its application for downscaling future climate projections. International Journal of Climatology, 40, 2026-2047. 
CHATTOPADHYAY, A., HASSANZADEH, P. \& PASHA, S. 2020. Predicting clustered weather patterns: A test case for applications of convolutional neural networks to spatiotemporal climate data. Scientific Reports, 10, 1317.

CHATTOPADHYAY, R., VINTZILEOS, A. \& ZHANG, C. 2013. A Description of the Madden-Julian Oscillation Based on a SelfOrganizing Map. Journal of Climate, 26, 1716-1732.

CHAVEZ, F. P., RYAN, J., LLUCH-COTA, S. E. \& ÑIQUEN C., M. 2003. From Anchovies to Sardines and Back: Multidecadal Change in the Pacific Ocean. Science, 299, 217-221.

CHU, P.-S. \& ZHAO, X. 2004. Bayesian Change-Point Analysis of Tropical Cyclone Activity: The Central North Pacific Case. Journal of Climate, 17, 4893-4901.

COOK, B. I., SMERDON, J. E., SEAGER, R. \& COOK, E. R. 2014. PanContinental Droughts in North America over the Last Millennium*. Journal of Climate, 27, 383-397.

DAVIDSON-PILON, C. 2015. Bayesian Methods for Hackers: Probabilistic Programming and Bayesian Inference Using Python and PyMC, Addison-Wesley Professional.

DESER, C., PHILLIPS, A. S. \& HURRELL, J. W. 2004. Pacific Interdecadal Climate Variability: Linkages between the Tropics and the North Pacific during Boreal Winter since 1900. Journal of Climate, 17, 3109-3124.

DRIJFHOUT, S. 2018. The relation between natural variations in ocean heat uptake and global mean surface temperature anomalies in CMIP5. Scientific Reports, 8, 7402.

EASTERBROOK, D. J. 2016. Chapter 21 - Using Patterns of Recurring Climate Cycles to Predict Future Climate Changes. In: EASTERBROOK, D. J. (ed.) Evidence-Based Climate Science (Second Edition). Elsevier.

EBBESMEYER, C. C., CAYAN, D. R., MCLAIN, D. R., NICHOLS, F. H., PETERSON, D. H. \& REDMOND, K. T. 1991. 1976 step in the Pacific climate: forty environmental changes between 19681975 and 1977-1984. Seventh Annual Pacific Climate (PACLIM) Workshop. Asilomar Conference Center, Pacific Grove, CA.

FAJAR JANURIYADI, N., KAZAMA, S., RIYANDO MOE, I. \& KURE, S. 2018. Evaluation of future flood risk in Asian megacities: a case study of Jakarta. Hydrological Research Letters, 12, 1422.

FARRELL, B. F. \& IOANNOU, P. J. 1996. Generalized Stability Theory. Part I: Autonomous Operators. Journal of the Atmospheric Sciences, 53, 2025-2040. 
GROISMAN, P. Y., KNIGHT, R. W. \& KARL, T. R. 2012. Changes in Intense Precipitation over the Central United States. Journal of Hydrometeorology, 13, 47-66.

HAI-TIEN LEE \& PROGRAM, N. C. 2011. NOAA Climate Data Record (CDR) of Daily Outgoing Longwave Radiation (OLR). In: CENTER, N. N. C. D. (ed.).

HAM, Y.-G., KIM, J.-H. \& LUO, J.-J. 2019. Deep learning for multiyear ENSO forecasts. Nature, 573, 568-572.

HARE, S. R. \& MANTUA, N. J. 2000. Empirical evidence for North Pacific regime shifts in 1977 and 1989. Progress in Oceanography, 47, 103-145.

HARRIS, I., OSBORN, T. J., JONES, P. \& LISTER, D. 2020. Version 4 of the CRU TS monthly high-resolution gridded multivariate climate dataset. Scientific Data, 7, 109.

HARRIS, I. C. \& JONES, P. D. 2017. CRU TS4.01: Climatic Research Unit (CRU) Time-Series (TS) version 4.01 of high-resolution gridded data of month-by-month variation in climate (Jan. 1901- Dec. 2016). In: UNIT, U. O. E. A. C. R. (ed.). Centre for Environmental Data Analysis.

HARTMANN, B. \& WENDLER, G. 2005. The Significance of the 1976 Pacific Climate Shift in the Climatology of Alaska. Journal of Climate, 18, 4824-4839.

HENDON, H. H. 2003. Indonesian Rainfall Variability: Impacts of ENSO and Local Air-Sea Interaction. Journal of Climate, 16, 1775-1790.

HENDON, H. H., WHEELER, M. C. \& ZHANG, C. 2007. Seasonal Dependence of the MJO-ENSO Relationship. Journal of Climate, 20, 531-543.

HERSBACH, H., BELL, B., BERRISFORD, P., HIRAHARA, S., HORÁNYI, A., MUÑOZ-SABATER, J., NICOLAS, J., PEUBEY, C., RADU, R., SCHEPERS, D., SIMMONS, A., SOCI, C., ABDALLA, S., ABELLAN, X., BALSAMO, G., BECHTOLD, P., BIAVATI, G., BIDLOT, J., BONAVITA, M., DE CHIARA, G., DAHLGREN, P., DEE, D., DIAMANTAKIS, M., DRAGANI, R., FLEMMING, J., FORBES, R., FUENTES, M., GEER, A., HAIMBERGER, L., HEALY, S., HOGAN, R. J., HÓLM, E., JANISKOVÁ, M., KEELEY, S., LALOYAUX, P., LOPEZ, P., LUPU, C., RADNOTI, G., DE ROSNAY, P., ROZUM, I., VAMBORG, F., VILLAUME, S. \& THÉPAUT, J.-N. 2020. The ERA5 global reanalysis. Quarterly Journal of the Royal Meteorological Society, 146, 1999-2049.

HIJIOKA, Y., LIN, E., PEREIRA, J. J., CORLETT, R. T., CUI, X., INSAROV, G. E., LASCO, R. D., LINDGREN, E. \& SURJAN, A. 2014. Asia. In: BARROS, V. R., FIELD, C. B., DOKKEN, D. J., MASTRANDREA, M. D., MACH, K. J., BILIR, T. E., CHATTERJEE, M., EBI, K. L., ESTRADA, Y. O., GENOVA, R. C., GIRMA, B., 
KISSEL, E. S., LEVY, A. N., MACCRACKEN, S., MASTRANDREA, P. R. \& WHITE, L. L. (eds.) Climate Change 2014: Impacts, Adaptation, and Vulnerability. Part B: Regional Aspects. Contribution of Working Group II to the Fifth Assessment Report of the Intergovernmental Panel of Climate Change. Cambridge, United Kingdom and New York, NY, USA: Cambridge University Press.

HOEGH-GULDBERG, O., CAI, R., POLOCZANSKA, E. S., BREWER, P. G., SUNDBY, S., HILMI, K., FABRY, V. J. \& JUNG, S. 2014. The Ocean. In: BARROS, V. R., FIELD, C. B., DOKKEN, D. J., MASTRANDREA, M. D., MACH, K. J., BILIR, T. E., CHATTERJEE, M., EBI, K. L., ESTRADA, Y. O., GENOVA, R. C., GIRMA, B., KISSEL, E. S., LEVY, A. N., MACCRACKEN, S., MASTRANDREA, P. R. \& WHITE, L. L. (eds.) Climate Change 2014: Impacts, Adaptation, and Vulnerability. Part B: Regional Aspects. Contribution of Working Group II to the Fifth Assessment Report of the Intergovernmental Panel of Climate Change. Cambridge, United Kingdom and New York, NY, USA: Cambridge University Press.

HU, P., ZHANG, Q., SHI, P., CHEN, B. \& FANG, J. 2018. Flood-induced mortality across the globe: Spatiotemporal pattern and influencing factors. Science of The Total Environment, 643, 171-182.

HU, Z.-Z. \& HUANG, B. 2009. Interferential Impact of ENSO and PDO on Dry and Wet Conditions in the U.S. Great Plains. Journal of Climate, 22, 6047-6065.

HUANG, B., BANZON, V. F., FREEMAN, E., LAWRIMORE, J., LIU, W., PETERSON, T. C., SMITH, T. M., THORNE, P. W., WOODRUFF, S. D. \& ZHANG, H.-M. 2017. Extended Reconstructed Sea Surface Temperature (ERSST), Version 5. In: INFORMATION, N. N. C. F. E. (ed.).

JIAO, Y. 2009. Regime shift in marine ecosystems and implications for fisheries management, a review. Reviews in Fish Biology and Fisheries, 19, 177-191.

JONES, C., WALISER, D. E., LAU, K. M. \& STERN, W. 2004. Global Occurrences of Extreme Precipitation and the Madden-Julian Oscillation: Observations and Predictability. Journal of Climate, $17,4575-4589$.

KEFI, M., MISHRA, B. K., MASAGO, Y. \& FUKUSHI, K. 2020. Analysis of flood damage and influencing factors in urban catchments: case studies in Manila, Philippines, and Jakarta, Indonesia. Natural Hazards.

KILADIS, G. N., DIAS, J., STRAUB, K. H., WHEELER, M. C., TULICH, S. N., KIKUCHI, K., WEICKMANN, K. M. \& VENTRICE, M. J. 
2014. A Comparison of OLR and Circulation-Based Indices for Tracking the MJO. Monthly Weather Review, 142, 1697-1715. KIM, H., VITART, F. \& WALISER, D. E. 2018. Prediction of the Madden-Julian Oscillation: A Review. Journal of Climate, 31, 9425-9443.

KIM, J.-W., YEH, S.-W. \& CHANG, E.-C. 2013. Combined effect of El Niño-Southern Oscillation and Pacific Decadal Oscillation on the East Asian winter monsoon. Climate Dynamics, 42, 957971.

KING, A. D., KAROLY, D. J. \& VAN OLDENBORGH, G. J. 2017. Climate Change and El Niño Increase Likelihood of Indonesian Heat and Drought. Bulletin of the American Meteorological Society, 97, S113-S117.

KLEIN TANK, A. M. G., PETERSON, T. C., QUADIR, D. A., DORJI, S., ZOU, X., TANG, H., SANTHOSH, K., JOSHI, U. R., JASWAL, A. K., KOLLI, R. K., SIKDER, A. B., DESHPANDE, N. R., REVADEKAR, J. V., YELEUOVA, K., VANDASHEVA, S., FALEYEVA, M., GOMBOLUUDEV, P., BUDHATHOKI, K. P., HUSSAIN, A., AFZAAL, M., CHANDRAPALA, L., ANVAR, H., AMANMURAD, D., ASANOVA, V. S., JONES, P. D., NEW, M. G. \& SPEKTORMAN, T. 2006. Changes in daily temperature and precipitation extremes in central and south Asia. Journal of Geophysical Research, 111.

KOKOREV, V., ETTEMA, J. \& SIEGMUND, P. 2020. Analysis of PDOENSO modulation effect on precipitation anomalies in the Maritime Continent. International Journal of Climatology.

KUSUMA, W. D., MURDIMANTO, A., Y ADEN, L., SUKRESNO, B., JATISWORO, D. \& HANINTYO, R. 2017. Sea Surface Temperature Dynamics in Indonesia.

LEA, C., VIDAL, R., REITER, A. \& HAGER, G. D. 2016. Temporal convolutional networks: A unified approach to action segmentation. European Conference on Computer Vision. Springer.

LESTARI, S., KING, A., VINCENT, C., KAROLY, D. \& PROTAT, A. 2019. Seasonal dependence of rainfall extremes in and around Jakarta, Indonesia. Weather and Climate Extremes, 24, 100202.

LI, W., ZHU, Y., ZHOU, X., HOU, D., SINSKY, E., MELHAUSER, C., PEÑA, M., GUAN, H. \& WOBUS, R. 2019. Evaluating the MJO prediction skill from different configurations of NCEP GEFS extended forecast. Climate Dynamics, 52, 4923-4936.

LIU, C. \& ZIPSER, E. 2014. Differences between the Surface Precipitation Estimates from the TRMM Precipitation Radar and Passive Microwave Radiometer Version 7 Products. Journal of Hydrometeorology, 15, 2157-2175. 
LIU, P., ZHANG, Q., ZHANG, C., ZHU, Y., KHAIROUTDINOV, M., KIM, H.-M., SCHUMACHER, C. \& ZHANG, M. 2015. A Revised RealTime Multivariate MJO Index. Monthly Weather Review, 144, 627-642.

LYON, B. \& BARNSTON, A. G. 2005. ENSO and the Spatial Extent of Interannual Precipitation Extremes in Tropical Land Areas. Journal of Climate, 18, 5095-5109.

MADDEN, R. A. \& JULIAN, P. R. 1971. Detection of a 40-50 Day Oscillation in the Zonal Wind in the Tropical Pacific. Journal of the Atmospheric Sciences, 28, 702-708.

MADDEN, R. A. \& JULIAN, P. R. 1972. Description of Global-Scale Circulation Cells in the Tropics with a 40-50 Day Period. Journal of the Atmospheric Sciences, 29, 1109-1123.

MANTUA, N. J. \& HARE, S. R. 2002. The Pacific Decadal Oscillation. Journal of Oceanography, 58, 35-44.

MANTUA, N. J., HARE, S. R., ZHANG, Y., WALLACE, J. M. \& FRANCIS, R. C. 1997. A Pacific Interdecadal Climate Oscillation with Impacts on Salmon Production**. Bulletin of the American Meteorological Society, 78, 1069-1080.

MARJUKI, SCHRIER, G. V. D., TANK, A. M. G. K., BESSELAAR, E. J. M. V. D., NURHAYATI \& SWARINOTO, Y. S. 2016. Observed Trends and Variability in Climate Indices Relevant for Crop Yields in Southeast Asia. Journal of Climate, 29, 2651-2669.

MCAFEE, S. A. 2014. Consistency and the Lack Thereof in Pacific Decadal Oscillation Impacts on North American Winter Climate. Journal of Climate, 27, 7410-7431.

MCGOWAN, J. A., BOGRAD, S. J., LYNN, R. J. \& MILLER, A. J. 2003. The biological response to the 1977 regime shift in the California Current. Deep Sea Research Part II: Topical Studies in Oceanography, 50, 2567-2582.

MINISTRY OF FOREIGN AFFAIRS OF THE NETHERLANDS 2018. Climate Change Profile: Indonesia. The Hague.

MOONEY, C. 2016. Ted Cruz keeps saying that satellites don't show global warming. Here's the problem. The Washington Post.

NEWMAN, M., ALEXANDER, M. A., AULT, T. R., COBB, K. M., DESER, C., DI LORENZO, E., MANTUA, N. J., MILLER, A. J., MINOBE, S., NAKAMURA, H., SCHNEIDER, N., VIMONT, D. J., PHILLIPS, A. S., SCOTT, J. D. \& SMITH, C. A. 2016. The Pacific Decadal Oscillation, Revisited. Journal of Climate, 29, 4399-4427.

NUR'UTAMI, M. N. \& HIDAYAT, R. 2016. Influences of IOD and ENSO to Indonesian Rainfall Variability: Role of Atmosphere-ocean Interaction in the Indo-pacific Sector. Procedia Environmental Sciences, 33, 196-203. 
Ó RUANAIDH, J. J. K. \& FITZGERALD, W. J. 1996. Retrospective Changepoint Detection. Numerical Bayesian Methods Applied to Signal Processing. New York, NY: Springer New York.

O'GORMAN, P. A. 2012. Sensitivity of tropical precipitation extremes to climate change. Nature Geoscience, 5, 697-700.

ORANGE, N. B., CHESNY, D. L., PRIMACK, A. G., GENDRE, B., MAINA, S. N., GIBLIN, T. W. \& MORRIS, D. C. 2018. An extreme climate transition in the Caribbean's Virgin Islands. I. Evidence of teleconnection with the 1976/1977 Pacific climate shift. International Journal of Climatology, 38, 2730-2742.

ORTLIEB, L. 2000. The Documented Historical Record of El Niño Events in Peru: An Update of the Quinn Record (Sixteenth through Nineteenth Centuries). In: DIAZ, H. F. \& MARKGRAF, V. (eds.) El Niño and the Southern Oscillation: Multiscale Variability and Global and Regional Impacts. Cambridge: Cambridge University Press.

PALMER, T. N. 1998. Nonlinear Dynamics and Climate Change: Rossby's Legacy. Bulletin of the American Meteorological Society, 79, 1411-1423.

PETERSON, W. T. \& SCHWING, F. B. 2003. A new climate regime in northeast pacific ecosystems. Geophysical Research Letters, 30.

PETTITT, A. N. 1979. A Non-Parametric Approach to the Change-Point Problem. Journal of the Royal Statistical Society. Series $C$ (Applied Statistics), 28, 126-135.

POWELL, A. M. \& XU, J. 2012. The 1977 Global Regime Shift: A Discussion of Its Dynamics and Impacts in the Eastern Pacific Ecosystem. Atmosphere-Ocean, 50, 421-436.

POWER, S., CASEY, T., FOLLAND, C., COLMAN, A. \& MEHTA, V. 1999. Inter-decadal modulation of the impact of ENSO on Australia. Climate Dynamics, 15, 319-324.

POWER, S., HAYLOCK, M., COLMAN, R. \& WANG, X. 2006. The Predictability of Interdecadal Changes in ENSO Activity and ENSO Teleconnections. Journal of Climate, 19, 4755-4771.

QIAN, J.-H., ROBERTSON, A. W. \& MORON, V. 2010. Interactions among ENSO, the Monsoon, and Diurnal Cycle in Rainfall Variability over Java, Indonesia. Journal of the Atmospheric Sciences, 67, 3509-3524.

QIAN, J.-H., ROBERTSON, A. W. \& MORON, V. 2013. Diurnal Cycle in Different Weather Regimes and Rainfall Variability over Borneo Associated with ENSO. Journal of Climate, 26, 1772-1790.

QUINN, W. H., ZOPF, D. O., SHORT, K. S. \& YANG, R. T. W. K. 1978. Historical trends and statistics of the Southern Oscillation, El Nino, and Indonesian droughts ( Peru). FISHERY BULLETIN, 76. 
RELIFWEB 2016. Indonesia. Food Security Monitoring Bulletin.

REYNOLDS, R. W., SMITH, T. M., LIU, C., CHELTON, D. B., CASEY, K. S. \& SCHLAX, M. G. 2007. Daily High-Resolution-Blended Analyses for Sea Surface Temperature. Journal of Climate, 20, 5473-5496.

RODYSILL, J. R., RUSSELL, J. M., VUILLE, M., DEE, S., LUNGHINO, B. \& BIJAKSANA, S. 2019. La Niña-driven flooding in the IndoPacific warm pool during the past millennium. Quaternary Science Reviews, 225, 106020.

ROXY, M. K., DASGUPTA, P., MCPHADEN, M. J., SUEMATSU, T., ZHANG, C. \& KIM, D. 2019. Twofold expansion of the IndoPacific warm pool warps the MJO life cycle. Nature, 575, 647651.

RUGGIERI, E. 2013. A Bayesian approach to detecting change points in climatic records. International Journal of Climatology, 33, 520-528.

RUPPERT, J. H. \& JOHNSON, R. H. 2016. On the cumulus diurnal cycle over the tropical warm pool. Journal of Advances in Modeling Earth Systems, 8, 669-690.

SALINGER, M. J., RENWICK, J. A. \& MULLAN, A. B. 2001. Interdecadal Pacific Oscillation and South Pacific climate. International Journal of Climatology, 21, 1705-1721.

SEKARANOM, A. B., NURJANI, E., HADI, M. P. \& MARFAI, M. A. 2018. Comparsion of TRMM Precipitation Satellite Data over Central Java Region - Indonesia. Quaestiones Geographicae, 37, 97.

SUMAN, M. \& MAITY, R. 2020. Southward shift of precipitation extremes over south Asia: Evidences from CORDEX data. Scientific Reports, 10, 6452.

SUPARI, TANGANG, F., JUNENG, L. \& ALDRIAN, E. 2017. Observed changes in extreme temperature and precipitation over Indonesia. International Journal of Climatology, 37, 19791997.

SUPARI, TANGANG, F., SALIMUN, E., ALDRIAN, E., SOPAHELUWAKAN, A. \& JUNENG, L. 2018. ENSO modulation of seasonal rainfall and extremes in Indonesia. Climate Dynamics, 51, 2559-2580.

SURMAINI, E., HADI, T. W., SUBAGYONO, K. \& PUSPITO, N. T. 2014. Early detection of drought impact on rice paddies in Indonesia by means of Niño 3.4 index. Theoretical and Applied Climatology, 121, 669-684.

SUSANTO, R. D., FFIELD, A., GORDON, A. L. \& ADI, T. R. 2012. Variability of Indonesian throughflow within Makassar Strait, 2004-2009. Journal of Geophysical Research: Oceans, 117, n/a-n/a. 
TANG, Y. \& YU, B. 2008. MJO and its relationship to ENSO. Journal of Geophysical Research: Atmospheres, 113.

TIAN, B. \& WALISER, D. 2014. Madden-Julian Oscillation (MJO). In: NJOKU, E. G. (ed.) Encyclopedia of Remote Sensing. New York, NY: Springer New York.

TIAN, B., WALISER, D. E. \& FETZER, E. J. 2006. Modulation of the diurnal cycle of tropical deep convective clouds by the MJO. Geophysical Research Letters, 33.

TILLINGER, D. \& GORDON, A. L. 2010. Transport weighted temperature and internal energy transport of the Indonesian throughflow. Dynamics of Atmospheres and Oceans, 50, 224232.

TOMS, B. A., KASHINATH, K., PRABHAT \& YANG, D. 2019. Deep Learning for Scientific Inference from Geophysical Data: The Madden-Julian Oscillation as a Test Case. arXiv: Atmospheric and Oceanic Physics.

TRENBERTH, K. E. \& FASULLO, J. T. 2013. An apparent hiatus in global warming? Earth's Future, 1, 19-32.

VAN DEN BESSELAAR, E. J. M., VAN DER SCHRIER, G., CORNES, R. C., IQBAL, A. S. \& KLEIN TANK, A. M. G. 2017. SA-OBS: A Daily Gridded Surface Temperature and Precipitation Dataset for Southeast Asia. Journal of Climate, 30, 5151-5165.

VAN OLDENBORGH, G., COELHO, C. \& DOBLAS-REYES, F. 2008. Exploratory analysis and verification of seasonal forecasts with the KNMI Climate Explorer. ECMWF Newsletter, 4-5.

VAN OLDENBORGH, G. J., DOBLAS-REYES, F. J., WOUTERS, B. \& HAZELEGER, W. 2012. Decadal prediction skill in a multimodel ensemble. Climate Dynamics, 38, 1263-1280.

VENTRICE, M. J., WHEELER, M. C., HENDON, H. H., III, C. J. S., THORNCROFT, C. D. \& KILADIS, G. N. 2013. A Modified Multivariate Madden-Julian Oscillation Index Using Velocity Potential. Monthly Weather Review, 141, 4197-4210.

VICENTE-SERRANO, S. M., LÓPEZ-MORENO, J. I., GIMENO, L., NIETO, R., MORÁN-TEJEDA, E., LORENZO-LACRUZ, J., BEGUERÍA, S. \& AZORIN-MOLINA, C. 2011. A multiscalar global evaluation of the impact of ENSO on droughts. Journal of Geophysical Research, 116.

VILLAFUERTE II, M. Q., MATSUMOTO, J. \& KUBOTA, H. 2015. Changes in extreme rainfall in the Philippines (1911-2010) linked to global mean temperature and ENSO. International Journal of Climatology, 35, 2033-2044.

VITART, F. 2017. Madden-Julian Oscillation prediction and teleconnections in the S2S database. Quarterly Journal of the Royal Meteorological Society, 143, 2210-2220. 
VON NEUMANN, J. 1941. Distribution of the Ratio of the Mean Square Successive Difference to the Variance. Ann. Math. Statist., 12, 367-395.

WANG, L., CHEN, W. \& HUANG, R. 2008. Interdecadal modulation of PDO on the impact of ENSO on the east Asian winter monsoon. Geophysical Research Letters, 35.

WANG, S., HUANG, J., HE, Y. \& GUAN, Y. 2014a. Combined effects of the Pacific Decadal Oscillation and El Nino-Southern Oscillation on global land dry-wet changes. Sci Rep, 4, 6651.

WANG, S., HUANG, J., HE, Y. \& GUAN, Y. 2014b. Combined effects of the Pacific Decadal Oscillation and El Niño-Southern Oscillation on Global Land Dry-Wet Changes. Scientific Reports, 4, 6651.

WANG, X. \& LIU, H. 2016a. PDO modulation of ENSO effect on tropical cyclone rapid intensification in the western North Pacific. Climate Dynamics, 46, 15-28.

WANG, X. \& LIU, H. 2016b. PDO modulation of ENSO effect on tropical cyclone rapid intensification in the western North Pacific. J Climate Dynamics, 46, 15-28.

WELCH, B. L. 1947. The Generalization Of 'Student's' Problem When Several Different Population Variances Are Involved. Biometrika, 34, 28-35.

WELLER, E., MIN, S.-K., CAI, W., ZWIERS, F. W., KIM, Y.-H. \& LEE, D. 2016. Human-caused Indo-Pacific warm pool expansion. Science Advances, 2, e1501719.

WESTERN, B. \& KLEYKAMP, M. 2017. A Bayesian Change Point Model for Historical Time Series Analysis. Political Analysis, 12, 354374.

WFP INDONESIA 2016. The Impact of Drought on Households in Four Provinces in Eastern Indonesia. World Food Programme.

WHEELER, M. C. \& HENDON, H. H. 2004. An All-Season Real-Time Multivariate MJO Index: Development of an Index for Monitoring and Prediction. Monthly Weather Review, 132, 1917-1932.

WHITFIELD, P. H., MOORE, R. D., FLEMING, S. W. \& ZAWADZKI, A. 2010. Pacific Decadal Oscillation and the Hydroclimatology of Western Canada-Review and Prospects. Canadian Water Resources Journal / Revue canadienne des ressources hydriques, 35, 1-28.

WIJNGAARD, J. B., KLEIN TANK, A. M. G. \& KÖNNEN, G. P. 2003. Homogeneity of 20th century European daily temperature and precipitation series. International Journal of Climatology, 23, 679-692.

WMO 2017. WMO Guidelines on the Calculation of Climate Normals. WMO. 
WOOSTER, W. S. \& ZHANG, C. I. 2004. Regime shifts in the North Pacific: early indications of the 1976-1977 event. Progress in Oceanography, 60, 183-200.

WORLD BANK 2019. World Bank national accounts data, and OECD National Accounts data files.

YAMANAKA, M. D. 2016. Physical climatology of Indonesian maritime continent: An outline to comprehend observational studies. Atmospheric Research, 178-179, 231-259.

YAMANAKA, M. D., OGINO, S.-Y., WU, P.-M., JUN-ICHI, H., MORI, S., MATSUMOTO, J., SYAMSUDIN, F. J. P. I. E. \& SCIENCE, P. 2018. Maritime continent coastlines controlling Earth's climate. $5,21$.

YAN, J., MU, L., WANG, L., RANJAN, R. \& ZOMAYA, A. Y. 2020. Temporal Convolutional Networks for the Advance Prediction of ENSO. Scientific Reports, 10, 8055.

YANG, L. \& FU, Z. 2017. Out-phased decadal precipitation regime shift in China and the United States. Theoretical and Applied Climatology, 130, 535-544.

YASUNAKA, S. \& HANAWA, K. 2002. Regime Shifts Found in the Northern Hemisphere SST Field. Journal of the Meteorological Society of Japan, 80, 119-135.

YATAGAI, A., KAMIGUCHI, K., ARAKAWA, O., HAMADA, A., YASUTOMI, N. \& KITOH, A. 2012. APHRODITE: Constructing a Long-Term Daily Gridded Precipitation Dataset for Asia Based on a Dense Network of Rain Gauges. Bulletin of the American Meteorological Society, 93, 1401-1415.

ZHANG, C. 2005. Madden-Julian Oscillation. Reviews of Geophysics, 43.

ZHANG, C. 2015. CLIMATE AND CLIMATE CHANGE | Global Impacts of the Madden-Julian Oscillation. In: NORTH, G. R., PYLE, J. \& ZHANG, F. (eds.) Encyclopedia of Atmospheric Sciences (Second Edition). Oxford: Academic Press.

ZHANG, X., WANG, J., ZWIERS, F. W. \& GROISMAN, P. Y. 2010. The Influence of Large-Scale Climate Variability on Winter Maximum Daily Precipitation over North America. Journal of Climate, 23, 2902-2915. 


\section{Summary}

This thesis focuses on changes in the precipitation regime in the Maritime Continent. The Maritime Continent is the region between the Indian and Pacific oceans consisting of the Indonesian and Philippine archipelagos and countless other smaller islands. The Maritime Continent connects the Indian and Pacific oceans and plays a crucial role in the world's climate. Land-sea interactions dominate precipitation in the Maritime Continent. The precipitation is heavily influenced by seasonal monsoons and oceanic oscillations such as the El Niño Southern Oscillation (ENSO) and Pacific Decadal Oscillation (PDO). Climate change influences many aspects of the climate in South-East Asia. While changes in air and sea temperatures are well documented, the Maritime Continent precipitation changes are understudied. Lack of data and high temporal and spatial variability, among other factors, lead to difficulties in forming a conceptual model of historical and future change in precipitation regime in the Maritime Continent. This study contributes to filling this gap.

This study applies the precipitation regime shift - a rapid change from one stable regime to another, to explain historical variations in precipitation in the Maritime Continent. The study suggests that the interaction between the PDO and ENSO creates alternating precipitation regimes in the Maritime Continent and Indochina peninsula. The precipitation regime changes manifest differently in different parts of the Maritime Continent but can be observed almost everywhere in this region.

\section{LINEAR CHANGE}

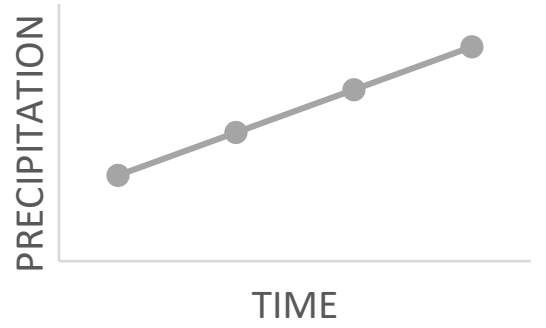

REGIME SHIFT

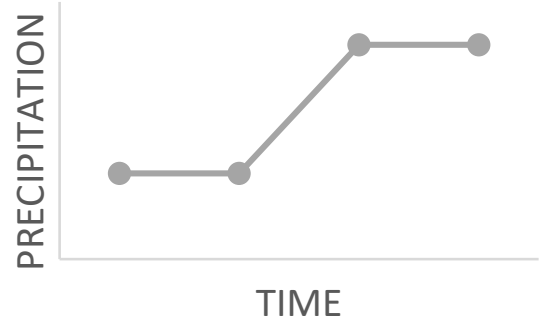

Figure 1. Schematic illustration of the difference between gradual (linear) change and regime shift

This thesis presents three separate lines of evidence for the regime shift's existence and its connection to the PDO. Chapters 1 and 2 present evidence of the regime shift in historical datasets. Chapter 3 
looks for evidence of the regime shift in historical and future climate model simulations. Chapter 4 investigates the use of machine learning to predict long-term oscillations in the atmospheric and the ocean that lead to a precipitation regime shift.

Chapters 1 and 2 present statistical evidence for the regime shift in different datasets and using different methods. Chapter 1 uses longperiod monthly data for precipitation, sea surface temperature, Pacific Decadal Oscillation, and EI Niño Southern Oscillation. By separating precipitation and sea surface temperature data by different combinations of PDO and ENSO phases, the results demonstrate that statistically different regimes are formed. This part of the study also shows how changes in the PDO phase can cause rapid precipitation regime changes in the Maritime Continent.

A key piece of evidence for existence of the regime shift comes from Chapter 2, where a novel Bayesian method for detecting precipitation regime shifts is presented. The Bayesian regime detection method demonstrates that precipitation regime shift models explain historical changes better than linear change models. Moreover, the algorithm, using only precipitation data as input, can detect a regime shift at the precise time we expect it to occur - coinciding with the PDO phase change. The regime shift detection method requires a large amount of data. Hereto we used the state-of-the-art precipitation dataset of the South Asian Climate Assessment and Dataset (SACA\&D). SACA\&D is a daily observational dataset developed at KNMI in collaboration with Indonesian National Meteorological Service BMKG and other national meteorological services. SACA\&D offers the most extensive collection of precipitation observations in the Maritime Continent available today.

Chapter 3 presents a separate line of evidence for precipitation regime shifts based on the model simulations. This study uses a simplified version of Bayesian regime shift detection to analyse precipitation regimes in the Maritime Continent simulated by CMIP6 climate models. The results show that the models that better reproduce the historical precipitation regime also show regime shifts occurring in the future simulations.

The final Chapter 4 investigates the use of machine learning in predicting long-period oscillations in the ocean and the atmosphere that govern the precipitation regime changes in the Maritime Continent. Different neural network architectures are tested in predicting Madden-Julian Oscillation and results are compared to traditional approaches. Both models trained to base prediction on spatial patters and models that use temporal patters demonstrate decent performance. The results demonstrate how modern machine learning models can improve seasonal prediction, including predicting the potential shift in precipitation regimes. 
In conclusion, this study presents a coherent and compelling conceptual model of historical changes in the Maritime Continent precipitation regime. The Maritime Continent's precipitation regime is governed by the Pacific Decadal Oscillation and goes through alternating drier and wetter regimes following the PDO cycle. The presence of the regime shift is demonstrated in several independent datasets and using different methods. While natural variability still plays a large role in determining day-to-day weather, the current precipitation regime shifts the precipitation probability distribution towards wetter or drier conditions.

The rapid changes in precipitation regime have far-reaching consequences for adaptation planning and understanding climate change processes in general. The rate of change often plays a more prominent role in determining impacts than the magnitude of change. The regime shift creates a period with a high rate of change followed by perceived stability. Long stable periods create the illusion of a lack of climate changes in precipitation. The periods of fast changes can lead to overestimations of the real rate of change over a more extended period. It is critical to understand the mechanism of precipitation regime shifts in the Maritime Continent and its effect on society to develop an effective adaptation strategy for future regime shifts. This study contributes to a growing body of evidence of nonlinear changes in the climate system and opens a discussion about our perception of climate change in general. 


\section{Samenvatting}

Dit proefschrift richt zich op veranderingen in het neerslagregime op het Maritieme Continent. Het Maritieme Continent is het gebied tussen de Indische en de Stille Oceaan, bestaande uit de Indonesische en Filipijnse archipels en talloze andere kleinere eilanden. Het Maritieme Continent verbindt de Indische en Stille Oceaan en speelt een cruciale rol in het wereldklimaat. De interacties tussen land en zee domineren de neerslag op het Maritieme Continent. De neerslag wordt sterk beïnvloed door seizoensgebonden moessons en oceanische oscillaties zoals de El Niño Southern Oscillation (ENSO) en de Pacific Decadal Oscillation (PDO). Klimaatverandering beïnvloedt veel aspecten van het klimaat in Zuidoost-Azië. Hoewel veranderingen in lucht- en zeetemperaturen goed gedocumenteerd zijn, zijn de neerslagveranderingen op het Maritieme Continent onvoldoende bestudeerd. Gebrek aan gegevens en hoge temporele en ruimtelijke variabiliteit, naast andere factoren, leiden tot problemen bij het vormen van een conceptueel model van historische en toekomstige veranderingen in het neerslagregime op het Maritieme Continent. Dit onderzoek draagt bij aan het opvullen van deze lacune.

Deze studie past de neerslagregimeverschuiving toe - een snelle verandering van het ene stabiele regime naar het andere, om historische variaties in neerslag op het Maritieme Continent te verklaren. De studie suggereert dat de wisselwerking tussen de PDO en ENSO zorgt voor afwisselende neerslagregimes op het Maritieme Continent en het schiereiland Indochina. De veranderingen in het neerslagregime manifesteren zich verschillend in verschillende delen van het Maritieme Continent, maar kunnen bijna overal in deze regio worden vastgesteld. 


\section{LINEAR CHANGE}

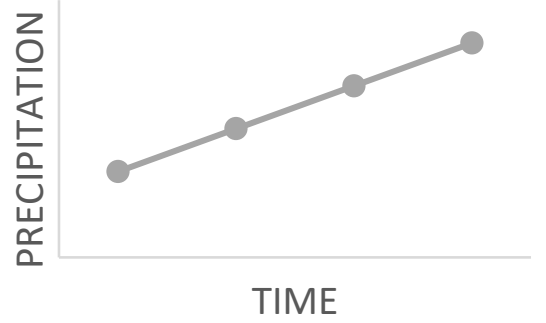

\section{REGIME SHIFT}

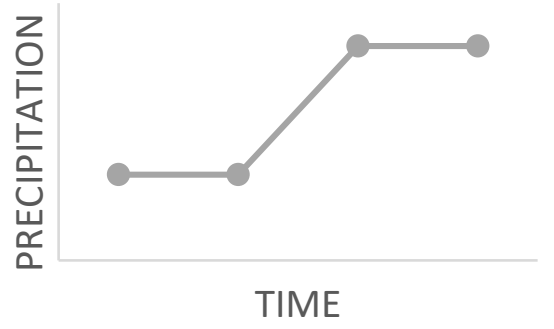

Figuur 1. Schematische weergave van het verschil tussen geleidelijke (lineaire) verandering en regimeshift.

Dit proefschrift presenteert drie afzonderlijke bewijslijnen voor het bestaan van de regimewisseling en het verband met de PDO. Hoofdstukken 1 en 2 presenteren bewijs van de regime-shift in historische datasets. Hoofdstuk 3 zoekt naar bewijs voor de regimeshift in historische en toekomstige simulaties van klimaatmodellen. Hoofdstuk 4 onderzoekt het gebruik van machine learning om lange termijn oscillaties in de atmosfeer en de oceaan te voorspellen die leiden tot een verschuiving van het neerslagregime.

Hoofdstukken 1 en 2 presenteren statistisch bewijs voor de regimeshift in verschillende datasets en met behulp van verschillende methoden. Hoofdstuk 1 gebruikt maandelijkse gegevens over een lange periode voor neerslag, temperatuur van het zeeoppervlak, Pacific Decadal Oscillation en El Niño Southern Oscillation. Door de gegevens over de neerslag en de temperatuur van het zeeoppervlak te bepalen voor verschillende combinaties van PDO- en ENSO-fasen, tonen de resultaten het bestaan van statistisch verschillende regimes. Dit deel van de studie laat ook zien hoe veranderingen in de PDOfase snelle veranderingen in het neerslagregime op het Maritieme Continent kunnen veroorzaken.

Een belangrijk bewijs voor het bestaan van de regime-shift geeft hoofdstuk 2, waar een nieuwe Bayesiaanse methode voor het detecteren van neerslagregime-shifts wordt gepresenteerd. De Bayesiaanse regime-detectiemethode laat zien dat modellen voor neerslagregimeverschuiving historische veranderingen beter verklaren dan lineaire modellen. Bovendien kan het algoritme, dat alleen neerslaggegevens als invoer gebruikt, een regimeverschuiving 
detecteren op het precieze moment dat we verwachten dat het zal plaatsvinden - samenvallend met de PDO-faseverandering. De regime shift-detectiemethode vereist een grote hoeveelheid waarnemingen. Hiervoor gebruiken we de state-of-the-art neerslagdataset van de South Asian Climate Assessment and Dataset (SACA\&D). SACA\&D is een dagelijkse waarnemingsdataset die bij het KNMI is ontwikkeld in samenwerking met de Indonesische Nationale Meteorologische Dienst BMKG en andere nationale meteorologische diensten. SACA\&D biedt de meest uitgebreide verzameling neerslagwaarnemingen op het Maritieme Continent die momenteel beschikbaar is.

Hoofdstuk 3 presenteert een aparte bewijslijn voor verschuivingen in het neerslagregime op basis van de modelsimulaties. Deze studie gebruikt een vereenvoudigde versie van Bayesiaanse regimeverschuivingsdetectie om neerslagregimes in het Maritieme Continent te analyseren, gesimuleerd door CMIP6-klimaatmodellen. De resultaten laten zien dat de modellen die het historische neerslagregime beter reproduceren, ook regimeverschuivingen laten zien die optreden in de toekomstige simulaties.

Het laatste hoofdstuk 4 onderzoekt het gebruik van machine learning bij het voorspellen van oscillaties op lange termijn in de oceaan en de atmosfeer die de veranderingen in het neerslagregime op het Maritieme Continent bepalen. Verschillende neurale netwerkmethoden worden getest bij het voorspellen van de Madden-Julian Oscillatie en de resultaten worden vergeleken met traditionele benaderingen. Beide modellen die zijn getraind om voorspellingen te baseren op ruimtelijke patronen en modellen die temporele patronen gebruiken, laten goede resultaten zien. De resultaten laten zien hoe moderne machine learning-modellen de seizoensvoorspelling kunnen verbeteren, inclusief het voorspellen van een mogelijke verschuiving in neerslagregimes.

Tot besluit presenteert deze studie een coherent en aansprekend conceptueel model van historische veranderingen in het neerslagregime op het Maritieme Continent. Het neerslagregime van het Maritieme Continent wordt vooral bepaald door de Pacific Decadal Oscillation en gaat door afwisselende drogere en nattere regimes volgens de PDO-cyclus. De aanwezigheid van de regime-shift wordt aangetoond in verschillende onafhankelijke datasets en met verschillende methoden. Hoewel voor het dagelijkse weer natuurlijke variabiliteit nog steeds van groot belang is, verschuift het huidige neerslagregime de kansverdeling van neerslag naar nattere of drogere omstandigheden. 
De snelle veranderingen in het neerslagregime hebben verstrekkende gevolgen voor de adaptatieplanning en het begrip van

klimaatverandering in het algemeen. De snelheid van verandering speelt vaak een meer prominente rol bij het bepalen van effecten dan de omvang van de verandering. De regimewisseling geeft een periode met een hoge mate van verandering, gevolgd door stabiliteit. Lange stabiele perioden geven de illusie dat het klimaat niet verandert, en tijdelijke snelle veranderingen kunnen een overschatting geven van de werkelijke snelheid van verandering over een langere periode. Het is van groot belang om het mechanisme van

neerslagregimeverschuivingen op het Maritieme Continent en het effect ervan op de samenleving te begrijpen om een effectieve aanpassingsstrategie voor toekomstige regimewisselingen te ontwikkelen. Deze studie maakt het bestaan van niet-lineaire veranderingen in het klimaatsysteem verder aannemelijk en draagt bij aan de discussie over onze perceptie van klimaatverandering in het algemeen. 